\title{
The NHS Long Term Plan and COVID-19
}

Assessing progress and the pandemic's impact Ruth Thorlby, Tim Gardner, Grace Everest, Lucinda Allen, Nihar Shembavnekar, Rebecca Fisher, Phoebe Dunn,

Finlay Turner-Berry, Caroline Fraser, Adam Briggs, Hugh Alderwick

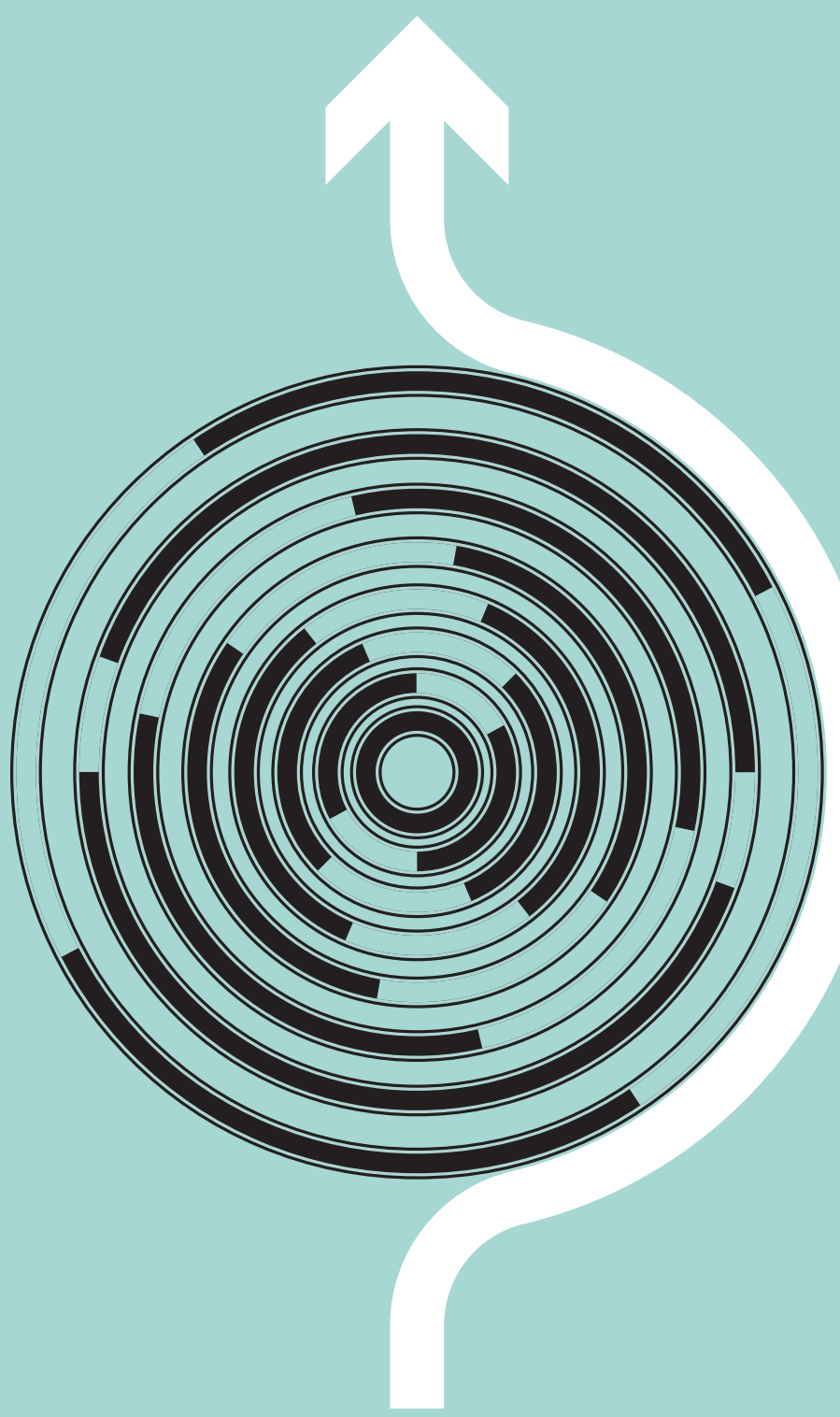




\section{Acknowledgements}

We would like to thank Siva Anandaciva, Jennifer Dixon and Sarah Scobie for their comments on earlier drafts of the paper. Errors or omissions remain the responsibility of the authors alone.

When referencing this publication please use the following URL: https://doi.org/10.37829/HF-2021-P08 


\section{Contents}

$\begin{array}{ll}\text { Key points } & 2\end{array}$

Introduction $\quad 4$

$\begin{array}{ll}\text { Approach and methods } & 6\end{array}$

What was promised in the plan?

Implementation timetable and key events (2019-2021) 8

$\begin{array}{ll}\text { Progress against the plan } & 12\end{array}$

1. 'A new service model for the 21st century' 12

2. 'More action on prevention and reducing inequalities' 19

3. 'Further progress on care quality, access and outcomes' 27

4. 'NHS staff will get the backing they need' 43

5. 'Digitally-enabled care will go mainstream across the NHS' 47

6. 'Taxpayers' investment will be used to maximum effect' 50

Discussion $\quad 53$

Waiting times 53

Prevention and inequalities $\quad 55$

Innovation $\quad 56$

Delivering improvements $\quad 57$

Wider spending and reform $\quad 58$

$\begin{array}{ll}\text { Conclusion and recommendations } & 60\end{array}$

$\begin{array}{ll}\text { References } & 61\end{array}$

$\begin{array}{ll}\text { Annex A } & 72\end{array}$ 


\section{Key points}

- COVID-19 has been the biggest shock in the NHS's history and its impacts on people's health and the health service will be felt for many years. This report assesses progress on the main pledges in the NHS Long Term Plan and the impact of COVID-19 on their delivery.

- In 2019, the NHS Long Term Plan set out a 10-year strategy for improving and reforming the NHS in England. The plan aimed to expand primary and community services, strengthen action on prevention and health inequalities, and improve quality of care for people with major diseases. Collaboration between local services was to help drive this progress.

- No part of the NHS's plan has been unaffected by the pandemic. Unsurprisingly, the overall picture is one of major delay, disruption, and increased demands on services. There have been delays to developing planned new services in primary and community care, and widespread disruption to elective care, cancer screening and treatment, mental health care, and other services, with serious consequences for people's health and wellbeing.

- The plan committed to maintaining and improving performance in hospital waiting times, but performance was declining even before COVID-19 hit. The pandemic had a major impact on hospital services, particularly in the first half of 2020. Although many non-COVID-19 services remained open and many others have been restored to pre-pandemic levels, there is a large backlog of unmet health care needs. Waiting lists for hospital care are the worst on record, at over 5.45 million at the end of June 2021, while only two-thirds of community services are reported to have been fully restored.

- The pandemic has also created new demands for NHS services beyond immediate COVID-19 care, including additional mental health needs and chronic side effects of COVID-19. Previous national targets - such as for expanding access to mental health services for adults and children - will need to be revisited to account for greater need.

- $\quad$ Some long term plan commitments have been accelerated by the COVID-19 response, such as improving access to remote consultations in primary care and outpatients. But these changes will need careful monitoring and evaluation to ensure that they meet their intended aims and do not exacerbate inequalities.

- COVID-19 has exposed and widened existing inequalities in health and care in England. The long term plan lacked detail on how inequalities would be reduced - and local plans to tackle inequalities were delayed before the pandemic. A more 
detailed framework of priorities, interventions, and measures for NHS agencies on tackling inequalities is now needed to ensure greater awareness of inequalities is translated into tangible action to reduce them.

- New partnership structures have been developed to help local agencies improve care, including integrated care systems (ICSs) and primary care networks (PCNs). PCNs have been vital to delivering the COVID-19 vaccination programme. But COVID-19 has held back the broader process of redesigning care to improve health and reduce inequalities, which is at the core of the NHS Long Term Plan.

- The Health and Care Bill 2021-22 will introduce changes to NHS structures in England - including formalising local partnerships. But the health system needs an updated strategy for improvement and reform that accounts for the massive disruption caused by COVID-19. This must confront hard trade-offs. Action to address the backlog in elective care must not come at the expense of interventions to prevent disease and reduce inequalities in health and care.

- Making progress depends on government decisions about investment and reform. Before the pandemic, government failed to provide the NHS with the long-term investment needed to expand the workforce and improve NHS infrastructure. Without enough staff and adequate buildings and equipment, the NHS will not be able to recover services after the pandemic.

- $\quad$ Significant additional investment has been promised, but major unknowns around the future course of the pandemic mean there is considerable uncertainty over whether this will be sufficient. Projections suggest the NHS England budget needs to increase by at least $£ 7.1 \mathrm{bn}$ in $2022 / 23$, not including the substantial additional funding that may be needed to cover any immediate costs of dealing with COVID-19 and the virus having an ongoing impact on the NHS's ability to deliver care. This is the minimum required to put the NHS on course to tackle the growing backlog of treatment by $2024 / 25$, cover increases in underlying pressures, the costs of implementing existing long term plan commitments, and meet increased demand for mental health services.

- After repeated delays, plans for a cap on social care costs were eventually announced in September 2021. While a bold and positive step forward that will start protecting people from incurring catastrophic costs, this falls well short of what is needed to stabilise the current system and deliver the comprehensive reform needed to fully deliver the Prime Minister's promise to fix social care once and for all.

- Wider reform is also needed to improve population health and reduce inequalities. Government currently has no national strategy for reducing health inequalities in England and public health budgets were 24\% smaller per capita in 2021/22 than $2015 / 16$. Increased investment in the NHS must go alongside investment in the wider services that shape health. 


\section{Introduction}

If the pandemic had not struck in early 2020, the NHS in England would have been into the third year of its 10-year programme of reform and improvements to services set out in the NHS Long Term Plan.

The long term plan was drawn up in response to a 5-year funding commitment made by Prime Minister Theresa May in 2018, on the 70th anniversary of the NHS. In a speech delivered at the Royal Free Hospital in London, May said that past funding increases had been 'inconsistent and short-term', and that the NHS needed to be able to 'plan for the future with ambition and confidence." May committed to increase the NHS budget by $3.4 \%$ in real terms between $2019 / 20$ and $2023 / 24$, and in return asked the NHS to develop a 10-year plan for reform.

Those plans were developed and consulted on by NHS England over the next 6 months, with the NHS Long Term Plan published in January 2019. The plan sets out a vision for better care in the community, improved treatment for major conditions such as cancer and mental illness, improved waiting times, more action to prevent ill health and reduce inequalities, and better use of technology. This was to be achieved through a mix of policy approaches - including stronger partnerships between the NHS and local government to lead local service changes, and new collaborations of general practices to provide more integrated care.

\section{Overtaken by events}

The proposals in the long term plan were built on May's 5-year funding pledge, and on the expectation that multi-year funding settlements for the Department of Health and Social Care would be set later in 2019 - covering public health, education and capital. The plan also anticipated the reform and investment promised by government for adult social care in England.

But events since the plan published have been turbulent. On 24 July 2019, Boris Johnson was appointed Prime Minister, and in October a general election was called. The Conservative manifesto recommitted the government to the existing NHS funding increases but added more priorities for the NHS, including new hospitals and additional GP appointments. The day after his victory at the polls on 12 December, the re-elected Prime Minister declared the NHS to be 'this one nation Conservative government's top priority.'

Less than 3 months later, the UK recorded its first death from COVID-19. By June 2021, COVID-19 had claimed over 150,000 lives in the UK, hospitalised over 460,000 people, ${ }^{3}$ and left a million reporting persistent symptoms after infection. ${ }^{4}$ Even though the government released billions of pounds to protect people's lives and livelihoods, the effects of policies to control the virus, including lockdowns and social distancing, have damaged 
the economy. Employment began to rise as the economy reopened in 2021, but by May 2021 there was still an estimated employment gap of 4.5 million people compared with the pre-pandemic period. ${ }^{5}$ The negative impact on people's finances and wellbeing has been felt most acutely by the most socioeconomically disadvantaged, younger people, and the self-employed.

The disruption to health and care staff and services has been severe. At the peaks of the pandemic, many NHS staff were redeployed to care for COVID-19 patients. Infections among staff have caused illness and death, and exacerbated staff shortages. Infection control measures have required wholesale changes to how services are delivered (and to whom) across the health and care system. The result has been delays to routine care and a rapidly growing backlog of unmet need. In social care, staff have also experienced high mortality and illness from COVID-19, and, like NHS staff, have experienced high levels of stress.

In response to the crisis, the government has spent heavily. The National Audit Office estimates that $£ 172 \mathrm{bn}$ has already been spent out of $£ 372 \mathrm{bn}$ that government expects to spend (as at May 2021). ${ }^{8}$ This includes support for businesses, individuals, and health and care services. Although the government has committed to protect the 5-year NHS spending plans, it is facing additional costs likely to run into billions of pounds over several years to meet new demand arising from the pandemic and to reduce the backlog of care. ${ }^{9}$ Economic uncertainty has meant short-term, 1-year funding commitments for public health, capital and education, and similar short-term funding for social care and local government.

The long term plan remains the blueprint for the NHS's evolution, but the pandemic has dealt a huge blow to both the NHS and social care. In what follows, we assess the overall progress of the main pledges in the NHS Long Term Plan and the impact of COVID-19 on their delivery. We provide a narrative of what was achieved before the pandemic, assemble the evidence of how the pandemic has affected progress against the different components of the plan, and identify implications for the future as the NHS and government plans its recovery from the pandemic. 


\section{Approach and methods}

In this report, we provide a narrative overview of the main developments following the publication of the NHS Long Term Plan in 2019 to June 2021. We then offer an assessment of the progress made against the main commitments in the plan.

The plan contains a large number of pledges and promises in its 136 pages (estimated to contain more than 100 commitments and 500 general ambitions). ${ }^{10}$ To assess progress, we focus on the indicators specified in NHS England's implementation framework, published in June $2019^{11}$ (shown in full at Annex A), and which also feature on NHS England's website as 'Long Term Plan Headline Metrics'. ${ }^{12}$

Finally, we offer some analysis of what this means for the timing and ordering of what the NHS aimed to do in the long term plan, over 2 very different years ago.

\section{Methods}

Our analysis is based on publicly available data and documents. For the narrative of events, we used our COVID-19 policy tracker,${ }^{13}$ covering events in 2020, supplemented by searches of government and other websites for developments since. We used a mix of data to assess progress. Where there are specific datasets referred to in the long term plan, we used these to assess how far national commitments had been delivered. Where new measures were promised but are yet to be developed, we used other national datasets on the same topic (for example, findings from the NHS staff survey on wellbeing in lieu of a new wellbeing metric).

Where data were missing, we accessed NHS England press releases, board papers, annual or other reports, and submissions to parliamentary committees or questions. For additional context, we also looked at reports produced by professional organisations and patient charities, in addition to relevant publications by official bodies, including the National Audit Office, Healthwatch and the Care Quality Commission.

Our assessment only provides a limited picture. We focus on the 'headline metrics' in the plan, which do not include commitments and general ambitions to improve care for major conditions including stroke, cardiovascular and respiratory disease, and other areas. Gaps in data make it difficult to assess progress in some of the priority areas. And new data on progress against different aspects of the long term plan are always emerging; the main analyses were based on data collected between February and May 2021, and as a result may have omitted more recent data. Nonetheless, the report attempts to give a comprehensive overview of COVID-19's impact on the long term plan so far. 


\section{What was promised in the plan?}

The long term plan built on existing goals from the NHS's previous national plan - the Five year forward view (published in 2014) - and existing national strategies for cancer and mental health. It was structured around the following six themes.

\section{1. 'A new service model for the 21 st century'}

The plan promised that outpatient services would be redesigned to reduce the volume of attendances by a third. Local general practices would come together to form primary care networks (PCNs) (each covering between 30,000 and 50,000 patients) and be funded to employ additional staff, intended to achieve a set of targets ranging from earlier cancer diagnosis to action on reducing health inequalities. Community services would receive additional funding to deliver quicker rehabilitation and crisis services. For acute hospitals, action would be taken to improve urgent care, shorten emergency stays, update waiting time targets (via a review of clinical standards) and improve hospital discharge in collaboration with local government.

\section{2. 'More NHS action on prevention and health inequalities'}

The plan committed new funding to expand NHS prevention programmes, including obesity, smoking cessation and to reduce alcohol-related hospital admissions. On inequalities, more accurate allocation of funding to local areas according to unmet need and inequalities was promised. Local 'systems' (now called integrated care systems (ICSs)) would be required to draw up plans to reduce inequalities in return for their funding allocations. There would be some national priorities for local systems to include in these plans, such as reducing inequalities experienced by people with learning disabilities, homeless people and those with severe mental illnesses.

\section{3. 'Further progress on care quality, access and outcomes'}

The plan set out actions to improve outcomes for specific diseases and provide better services for particular age groups. On diseases and conditions, the plan promised earlier diagnosis of cancers, expansion of mental health services underpinned by ringfenced increases in funding, and better treatment for cardiovascular and respiratory diseases. Pregnant women, children and people with learning disabilities were promised improved care and better outcomes, while action on behalf of everyone who need planned hospital treatment would reduce long waiting times.

\section{4. 'NHS staff will get the backing they need'}

A multi-year plan to increase the number of staff and boost access to training and development was promised, but not set out. The plan would be finalised once Health Education England had received its funding allocation from government for the following 
5 years, and would be consolidated into a comprehensive People Plan. Meantime, the long term plan committed funding for increasing clinical placements until 2021/22 and an international recruitment campaign. There would also be work to improve conditions for existing staff, ranging from increased access to continuing professional development to improvements in the culture within organisations.

\section{5. 'Digitally-enabled care will go mainstream across the NHS'}

The plan promised investment that would bring, over the next 10 years, widespread access to digital services for patients and more patients and clinicians being able to access and manage records online. Better data and analytic tools would be available to individual clinicians and those planning services within ICSs.

\section{6. 'Taxpayers' investment will be used to maximum effect'}

All the improvements and reforms set out in the long term plan were costed by national NHS agencies and estimated to be within the additional funding allocated to the NHS by government in 2018. Nevertheless, national NHS leaders assumed that productivity improvements of at least $1.1 \%$ a year would continue, administrative costs would be reduced and that all NHS organisations would return to financial balance.

\section{Implementation timetable and key events (2019-2021)}

The NHS Long Term Plan expected 2019/20 to be a 'transitional year'. Progress would be made on some commitments and the groundwork laid for the shift towards 'system' working, in which many of the existing sustainability and transformation partnerships (STPs) - geographically based groups of NHS providers, commissioners, and local government, responsible for leading local service changes - would begin their transition to ICSs (see section on Integrated care systems). Later in January 2019, local systems received their financial allocations for the 5-year period (2019/20 to 2023/24). In return, they were asked to develop local plans for delivering the long term plan commitments.

NHS England offered to help ICSs with this process, including 'intensive support for the most challenged systems'. The long term plan emphasised the need for organisations to collaborate to improve care and manage resources, not pursuing objectives to benefit their own organisations at the expense of others. The plan also described the need for legislative change to support progress on delivering its objectives, and set out a series of proposals (including rolling back NHS competition rules and establishing a firmer legal basis for local partnership working), which were put out for wider engagement the following month. ${ }^{14}$

In June 2019, NHS England published an implementation framework, ${ }^{11}$ containing detailed guidance for local areas about to draw up their 5-year plans. STPs and ICSs were instructed to complete these by November 2019, and the plans were to be incorporated into a national implementation plan by the 'end of the year'. This was intended to allow the national plans to '... properly take account of the government Spending Review decisions on workforce education and training budgets, social care, councils' public health service and NHS capital investment.' 
NHS England continued to draft proposals for the legal underpinning it argued was needed to deliver the long term plan. In September 2019, NHS England published recommendations to government for an NHS bill, ${ }^{15}$ based on the findings of an engagement process that had begun in February 2019. NHS England reported strong support for repealing legislation relating to NHS competition and procurement, and recommended statutory guidance for the creation of joint committees running ICSs.

At the end of January 2020, a year after the publication of the long term plan, the NHS Operational Planning Guidance was published. The guidance noted that 2020/21 was going to be a 'critical year' in creating new ways for the NHS to work as a system. The guidance set out a revised timetable for local plans, which had not been published at the end of 2019 as promised. These were now due by April 2020. ${ }^{16} \mathrm{~A}$ people plan was due in the coming months', after which a national implementation plan would follow.

\section{The arrival of COVID-19}

Less than 2 months later, COVID-19 had plunged the NHS into an unimaginably different world. By mid-March 2020, although confirmed COVID-19 cases were still under 1,000 in the UK, modelling was predicting a huge surge of illness and deaths: if no action was taken, health services would be overwhelmed. ${ }^{17}$ Even with a combination of suppression measures, such as population-wide social distancing, pressures on hospitals were expected to be severe.

On 17 March, the NHS took widespread action to free up staff and beds in anticipation of the coming surge. NHS England asked hospitals to postpone non-urgent operations for 3 months from mid-April at the latest and to urgently discharge all patients deemed 'medically fit' to leave. ${ }^{18}$ Community services were given responsibility for leading the care of discharged patients and funding was promised for any social care that might be needed. Hospitals were told to continue emergency admissions, urgent cancer care and other types of clinically urgent services. General practices were also asked to switch as much care as possible to remote forms, with face-to-face consultations only if absolutely necessary. Long term plan deadlines for ICS plans, the clinical standards review and the national implementation plan were dropped.

On 29 April, NHS England paid tribute to the 'fastest and most far-reaching repurposing of NHS services, staffing and capacity in our 72-year history', which had allowed the NHS to care for over 19,000 inpatients per day with COVID-19, and continue to deliver other essential services. ${ }^{19}$ The letter also noted that there had been steep falls in non-COVID-19 emergency admissions (as well as the expected drop in non-urgent activity) and called for local areas to 'step up' non-COVID-19 emergency care and start planning to restart routine elective care, while maintaining capacity in case of a COVID-19 resurgence.

Over the summer of 2020, cases, hospitalisations and deaths from COVID-19 continued to fall. On 19 June, the UK's COVID-19 alert level was dropped from 4 to 3, meaning that the virus was in general circulation but no longer rising or increasing exponentially. At the end of July, NHS England declared that a 'third phase' of NHS pandemic response should begin, with the aim of returning non-COVID-19 services to normal levels as 
soon as possible, while planning for winter pressures, including a possible COVID-19 resurgence. ${ }^{20}$ Some of the long term plan priorities were to be resumed for PCNs, community and mental health services, and services for people with learning disabilities.

During the summer lull in infections, the government announced a major reorganisation of Public Health England, which had led the response to COVID-19 and is also responsible for prevention and screening. On 18 August, the former Secretary of State for Health and Social Care announced the abolition of Public Health England and the creation of a new UK-wide organisation, the National Institute for Health Protection (subsequently renamed The Health Security Agency), to improve the response to COVID-19 and future threats to public health. ${ }^{21}$ The secretary of state promised to 'consult widely' on the future of Public Health England's 'incredibly important' role in health improvement and prevention.

\section{The second wave hits}

There was to be no 'fourth phase' letter. Instead, on 4 November, NHS England announced a return to an incident 'level 4' (the highest level) in the face of rising cases and hospitalisations. Shortly before Christmas, NHS trusts were advised by NHS England to mobilise all their available surge capacity, prioritise 'timely and safe' discharge, and make full use of the independent sector and other available capacity to continue to treat as many elective cases as possible, while maintaining urgent non-COVID-19 services. ${ }^{22}$ General practice was urged to maintain pre-pandemic appointment levels, at the same time as assisting with vaccinations, described as the 'highest priority task' for PCNs for the foreseeable future.

On 4 January, the chief medical officers of the UK warned that there was a 'material risk' of the NHS being overwhelmed within 21 days if no action was taken. ${ }^{23}$ The same day, the Prime Minister announced a third lockdown for England.

In its board meeting on 28 January, NHS England's performance update captured the enormity of the second wave of COVID-19: 33,000 patients with COVID-19 in hospital beds in England, and over 250,000 cared for since the pandemic began. ${ }^{24}$ Even though NHS organisations had tried to keep as many non-COVID services open during this peak as possible, the January board papers reported that 200,000 patients had waited more than a year for routine hospital treatment (this was over 330,000 by May 2021).

By early March 2021, cases and hospitalisations had begun to fall again. Government committed to a gradual relaxation of lockdown restrictions, extending the duration of emergency economic support to millions of employees and businesses. ${ }^{25}$ On 3 March, the Chancellor unveiled a Budget that added a further $£ 65 \mathrm{bn}$ to support the economy over the next 2 years on top of the $£ 270$ bn already committed..$^{26} 2$ weeks later, the Secretary of State for Health and Social Care announced that the NHS would be receiving an additional $£ 6.6 \mathrm{bn}$ for the first half of 2021 to meet COVID-19-related costs. ${ }^{27}$ But there was less generosity towards other sectors crucial to delivering the long term plan. The public health grant for local authorities (announced on 16 March) of $£ 3.3 \mathrm{bn}$ for 2021/22 represented only a small $(£ 45 \mathrm{~m})$ increase on the previous year, and a real-terms per capita reduction of $24 \%$ compared with $2015 / 16 .^{28}$ 
After analysing the public spending commitments in the Budget for departments not protected by previous funding arrangements (defence, the NHS and schools), the Institute for Fiscal Studies concluded that unprotected budgets faced real-terms cuts of around 3\% between 2021/22 and 2022/23. ${ }^{29}$ This includes local government, a key partner in many of the long term plan pledges on prevention and reducing health inequalities. The promise to reform adult social care was repeated in the Queen's Speech on 11 May, but was not linked to a potential bill. ${ }^{30}$

\section{Rising expectations}

On 16 March 2021, the government announced its expectations for the health service for the next year, via the 2021/22 'mandate' to NHS England. ${ }^{31}$ This included delivering the commitments made in the Conservative party's 2019 election manifesto, such as 50,000 more nurses, alongside continuing the response to COVID-19 and resuming work to implement the long term plan. Together with a new annex of 'headline commitments', the updated mandate added substantially to what the NHS was expected to deliverwith additional priorities effectively set through the inclusion of new metrics to assess progress. The accompanying planning guidance, published on 25 March 2021, specified that local systems work together to support staff recovery, address inequalities, maintain the response to and recovery from COVID-19, and accelerate delivery against the commitments in the long term plan. ${ }^{32}$ Despite lingering uncertainty about the future course of the pandemic, ICSs were tasked with developing plans for the year ahead by 3 June 2021..$^{33}$ 


\section{Progress against the plan}

In the sections that follow, we assess the NHS's progress against the goals set out under the long term plan's six themes. For each theme, we take NHS England's 'headline metrics' for the plan and use available data to assess progress. We also include evidence of how relevant services have been affected by the pandemic. The implications are explored in the Discussion.

\section{1. 'A new service model for the 21 st century'}

\section{Primary and community services}

\section{Summary}

- $\quad$ Official measures of progress for developing new service models were mostly undeveloped. The one concrete measure was for an increase in the percentage of overall NHS revenue spent on primary and community services. Other measures, such as patient reported access to primary care and development of new community teams, were 'to be confirmed'.

- $\quad$ New PCNs were established by July 2019. These involve the large majority of GP practices, contracted to deliver defined services. The pandemic disrupted general practice, forcing changes to the way care is delivered. PCNs have played a key role in vaccine delivery, but there have been delays to implementing four out of the seven new PCN services.

- $\quad$ New 'rapid response' community services were piloted before the pandemic hit. COVID-19 brought disruption to all community services, some of which had to be suspended. In June 2021, NHS England reported that 59\% of services were fully restored. The pandemic also brought an increased role (and funding) for community services in discharging patients from hospital. A 2-hour rapid response service is now expected to be in place by March 2022.

- $\quad$ NHS England's accounts for 2019/20 suggest the share of NHS revenue spent on primary and community services increased, but the pandemic has complicated funding flows across the NHS. Demand for primary and community care services remains high, and the extent to which the additional long term plan funding will meet need is not clear.

The long term plan promised to 'finally dissolve the historic divide between primary and community services'. Investment in primary medical and community health services was to increase as a share of NHS spending over 5 years. GP practices were to be brought together into PCNs, covering populations of around 30,000 to 50,000 people, with formal agreements between practices and the capacity to hold contracts with NHS England.

Billed as an 'essential building block of every Integrated Care System', PCNs would coordinate and deliver new services for their local populations, such as earlier cancer diagnosis and better health care for care home residents. The details were to be set out in 
seven 'service specifications' to be finalised after further consultation with the sector. PCNs were expected to work closely with community services to deliver more coordinated care and support.

In parallel, the community services working most closely with acute services were expected to become more responsive with 'the ambition of freeing up to a million bed days'. Within 5 years, all community health crisis response services were to be available within 2 hours of referral (where clinically appropriate), with reablement care for eligible patients within 2 days of referral.

\section{Progress prior to the pandemic}

More detail about how PCNs would work was set out in a new GP contract, published in January 2019. ${ }^{34}$ Although technically voluntary, the new contract created powerful financial incentives for practices to sign up to the new networks. $£ 1.8 \mathrm{bn}$ of the $£ 2.8 \mathrm{bn}$ additional 5-year funding to primary and community care was accessible only via the new PCNs.

PCNs formed rapidly. Over 99\% of GP practices came together into over 1,200 PCNs by September 2019. ${ }^{35}$ While many practices were already in some form of collaborative relationship, the formation of the new, nationally specified networks involved considerable work to build relationships and set up new governance arrangements to meet a tight deadline. ${ }^{36}$

The seven service specifications for PCNs were agreed prior to the pandemic. These covered medication reviews, improved care in care homes, earlier cancer diagnosis, 'anticipatory' care for patients with complex needs, 'personalised' care (such as 'social prescribing' programmes to link patients with non-medical services), improvements in cardiovascular care, and action on inequalities. Revisions were made after the profession raised concerns about their capacity to deliver the specifications with the available resources. ${ }^{37}$ Changes included cutting back requirements for structured medication reviews, agreeing extra payments to cover workload associated with nursing homes, and postponing the personalised and anticipatory care specifications until April 2021.

Once formed, PCNs could access funding to recruit additional primary care professionals, including social prescribing link workers, pharmacists and physiotherapists to meet the long term plan commitment of 26,000 additional staff over 5 years. The range of roles that PCNs could recruit has broadened, and the amount of funding available for recruitment increased. Data on progress against these commitments are incomplete, making it difficult to track progress. An early milestone was to recruit 1,000 social prescribers by the end of 2020: by this date, 852 full-time equivalent (FTE) link workers were in post, but only $60 \%$ of PCNs had reported data to NHS Digital. ${ }^{38}$

Pilots of new rapid response community services were launched in seven areas in January 2020, with a plan to begin rolling out the new services nationally from April 2020. ${ }^{39}$ However, the long term plan commitments on community services were expected to be implemented over a longer timeframe, with a substantial increase in capacity needed to achieve the 2 hour/ 2 day standards by $2023 / 24 .^{40}$ 


\section{Impact of the pandemic}

Major changes were made to primary and community services in response to the pandemic. These aimed to maintain 'COVID secure' access to essential services, while supporting acute hospitals to manage the expected surges in critically ill patients.

All GP practices were instructed to switch to a non-face-to-face appointment system and offer remote consultations, seeing patients in person when deemed clinically necessary. Many practices used their PCNs to set up a designated local 'hot' site, where suspected COVID-19 positive patients could be seen. The pandemic brought delays to four out of the seven service specifications that were due to start in April 2021, including action on prevention, cardiovascular disease diagnosis and health inequalities. ${ }^{41}$ From November 2020, NHS England used the PCN structure as the backbone of the mass vaccination campaign - coordinating staffing, logistics and data. ${ }^{42}$

Community services were tasked with supporting the rapid discharge of patients from acute hospitals with the aim of freeing up 15,000 beds for patients with COVID-19 by the end of March 2020. ${ }^{18}$ 'Discharge to assess' arrangements were put in place for patients who were expected to need support after leaving hospital: assessments took place in patients' homes (instead of hospital) and arrangements made for any therapy, care and equipment they might need. ${ }^{43}$ Funding was provided by the NHS, with financial eligibility assessments temporarily suspended for social care and NHS continuing care. Services were expected to be reprioritised to free up staff and ensure infection control. This included a complete stop for NHS health checks, and a 'partial stop' for a wide range of services where providers were expected to segment patients to continue services for those at highest risk. Other services, such as end of life care, were advised to continue and 'prepare for increased demand'. ${ }^{44}$

Primary and community services face a daunting set of challenges in the wake of COVID-19. While NHS England believes that the pandemic 'has proven beyond doubt the value and potential of PCNs ${ }^{\prime}{ }^{45}$ they are still relatively new entities. There is a need for continuing support to develop managerial skills within PCNs and increase capacity to engage strategically with larger local partners, particularly ICSs. ${ }^{46}$

PCNs are also expected to have recruited 15,500 new FTE roles by the end of 2021/22. Latest data (from the $68 \%$ of PCNs reporting staff numbers) suggest just over 5,000 new FTE staff were in place by the end of March $2021 .{ }^{47}$ Barriers to PCNs recruiting new staff are not yet fully understood. PCNs will continue to play a central role in the COVID-19 vaccination programme for the foreseeable future, at the same time as their constituent practices manage a rebound in demand for appointments. In March 2021, 28.4 million appointments took place in general practice, compared with 24 million in March 2020.48

The community services dataset shows a fall in overall contacts in community services, but gaps in data from before the pandemic make it hard to interpret the trend in activity. Most community services are thought to have backlogs of people waiting for non-COVID-19 care, ${ }^{49}$ but the number waiting cannot be quantified. In June 2021, NHS England reported that in six out of seven regions at least half of their community services were at pre-COVID levels or higher and $59 \%$ of services were 'fully restored'. ${ }^{50}$ 
Implementation of the 2 hour/ 2 day standards was delayed, with technical guidance on measuring performance not published until November $2020 .{ }^{51}$ Data collection began in July 2020, but not all areas are submitting data. ${ }^{52}$ The discharge to assess model has now been made permanent, although the funding for services after discharge from hospital was reduced from 6 weeks to 4 with no funding commitment beyond July 2021. NHS England collect data on the number of people discharged, how quickly and where to, but these are not published. ${ }^{5}$

Leaders of NHS community services have raised concerns that there may not be enough capacity to deliver the long term plan commitments alongside discharge to assess, restoring normal services and the anticipated increase in demand for rehabilitation services for patients admitted to hospital with COVID-19. ${ }^{54}$ The 2021/22 planning guidance promised additional funding to support an accelerated rollout of the 2-hour crisis response standard by April 2022, contingent on operational plans and commitments to submit complete and accurate data to the Community Services Data Set. ${ }^{33}$

\section{Integrated Care Systems (ICSs)}

\section{Summary}

- $\quad$ NHS England aimed to establish ICSs in every part of England by 2021. It set a headline metric of increasing the 'percentage of population covered by ICS'.

- $\quad$ By this measure, the plan's goal has been achieved: NHS England announced that all local systems had become ICSs by March 2021. But exactly what an ICS is and how they differ from previous arrangements has not always been clear.

- $\quad$ The pandemic brought delays to the process of drawing up and publishing ICS plans to improve services and population health. NHS England expects ICSs to lead the recovery of local NHS services, especially the reduction of the backlog for hospital treatment.

- $\quad$ Legislation has been introduced to formally establish ICSs as new NHS agencies in April 2022. This will strengthen the powers of local partnerships but may also cause disruption.

The long term plan described ICSs as 'central' to delivering its objectives. ICSs were not new and built on existing partnerships called STPs, made between NHS agencies, local government, and others in 44 areas of England ${ }^{55}$ NHS England described ICSs as more 'mature' versions of STPs ${ }^{56}$ - and the long term plan committed to establishing them across England by April 2021. ICSs would be responsible for coordinating local services and improving population health.

The plan set out expectations for what ICSs should look like. Each ICS would have a partnership board with representatives from NHS commissioners, providers, PCNs, local authorities, the voluntary and community sector, and others. They would also have a non-executive chair, 'sufficient' clinical and management capacity, and needed to achieve 'full engagement' with primary care (including through a named accountable clinical director of each PCN). NHS commissioning arrangements would be 'streamlined' to align more closely with ICSs, which would 'typically' mean clinical commissioning groups (CCGs) merging to fit ICS areas. Wider policy changes were promised to support the shift to ICSs, including a greater emphasis on system working in CQC inspections. 
The plan set out how ICSs would be developed within current NHS rules and structures. But it also argued that legislative changes were needed to 'significantly accelerate progress' on local integration, and included a list of proposed legal changes. These included establishing ICSs as formal partnership boards and removing 'overly rigid' competition and procurement rules.

All local systems - whether currently STPs or already ICSs - were expected to produce 5-year plans for how they would deliver the plan's objectives later in 2019.

\section{Progress prior to the pandemic}

NHS England developed and published further guidance for ICSs throughout 2019. In June 2019, NHS England published a basic framework for how ICSs were intended to work. It described three different levels for decision making within ICSs: 'systems' (covering populations of 1-3 million - where agencies agree overall objectives and set strategic direction); 'places' (covering populations of around 250,000-500,000 people - where health and care providers work together to redesign local services); and 'neighbourhoods' (covering populations of around 30,000-50,000 people - where groups of GPs work with other community services in multidisciplinary teams). It also introduced an ICS 'maturity matrix', outlining the capabilities that local systems would need to develop to 'mature' and 'thrive', such as strong clinical leadership and the successful development of new models of integrated care. ${ }^{56}$

NHS England pushed back the deadline for submitting 5-year plans from November 2019 to 2020. In September 2019, NHS England also published more detailed proposals to government for a set of 'targeted' changes to NHS legislation to support the development of ICSs. ${ }^{15}$

\section{Impact of the pandemic}

The pandemic brought initial delays to the development of ICSs. Much local planning related to ICSs and the long term plan was paused, along with planned CCG mergers after April 2020. ${ }^{57}$

But by August 2020, NHS England expected ICSs and STPs to play a central role in restoring elective care, asking them to develop new local plans for recovering services. ${ }^{20}$ NHS leaders reported that the pandemic had enhanced local partnership working. ${ }^{58,59,60}$ And the then health secretary, Matt Hancock, stated in early 2021 that 'collaboration across health and social care has accelerated at a blistering pace' during the pandemic. ${ }^{61}$ Assessments of local collaboration by the CQC, however, found a much more mixed picture. ${ }^{62}$ Collaboration was often effective where there were good pre-existing relationships and clear governance. But the CQC found confusion and duplication in areas where these were lacking. It also reported concerns that social care providers were not sufficiently involved in system working - and some felt 'overwhelmed and isolated'. 
NHS England continued to announce new ICSs during 2020, with the final 13 STP areas becoming ICSs in March 2021 (with 42 ICSs in total). This meant that the long term plan milestone of 'full coverage' of ICSs by April 2021 was met $^{63,64}$ - though in practice the difference between ICSs and STPs is often hard to discern. There is limited publicly available information on the composition and plans of the new ICSs.

There has also been progress towards 'streamlined commissioning', with mergers in 2020 and 2021 reducing the total number of CCGs to 106 (as of April 2021). This means that the majority of ICS areas are operating with a single NHS commissioner, though just over a third still have more than one in their geographical area - including Greater Manchester (10 CCGs) and South Yorkshire and Bassetlaw (five CCGs), both among the first round of ICSs announced in 2017.

The pandemic did not halt progress on developing legislation to more formally develop ICSs. Government published a white paper on NHS reform in February $2021,{ }^{65}$ and a Health and Care Bill in July 2021. ${ }^{66,67}$ Under the plans, ICSs will be formally established as a new regional tier of the NHS in England. Each system will be made up of two new bodies: an integrated care board - area-based NHS agencies responsible for controlling most NHS resources to improve health and care for their local population - and an integrated care partnership - looser collaborations between the NHS, local government, and other agencies, responsible for developing an integrated care plan to guide local decisions.

CCGs will be abolished and replaced by the new integrated care boards. Requirements to competitively tender clinical services will be scrapped. These changes go beyond the more pragmatic legislative changes proposed by NHS England before the pandemic. National NHS bodies and government would like the new system in place by April 2022.

\section{Same day emergency care (SDEC)}

\section{Summary}

- $\quad$ The long term plan committed to increase the percentage of people discharged from hospital on the same day after being admitted in an emergency from a fifth to a third. This was to be achieved by establishing specialist units to deliver 'same day emergency care' (SDEC) in every major emergency department, open 7 days a week by 2019/20.

- $\quad$ NHS England reports that in April 2021,37\% of emergency admissions were discharged on the same day, but it is not clear whether these patients have been treated in SDEC units.

- $\quad$ The pandemic brought disruption to emergency departments, as infection control and staff shortages limited the number of patients that could be seen safely. In early 2020, there were steep falls in emergency attendances, but pressures have rebounded as demand for emergency care has returned.

The long term plan made a number of commitments to reduce the growing pressures on emergency hospital services. For several years, A\&E attendances and emergency admissions to hospital had been steadily increasing, with admissions growing by an average of $1.9 \%$ per year between $2000 / 01$ and $2017 / 18 .{ }^{68}$ Delays admitting patients due to a lack of available beds had also increased, especially during winter, leading to overcrowding in hospital emergency departments. However, the likelihood of a patient being admitted to 
hospital via major emergency departments had been falling, despite a steady increase in the acuity and complexity of patient needs. ${ }^{69}$ This was due, at least partly, to advances in diagnostic and treatment practices that allow patients to be treated and discharged without needing an overnight stay in hospital.

SDEC - also known as Ambulatory Emergency Care - is a set of care processes whereby patients referred or self-presenting to hospital in an emergency can be assessed, receive clinically appropriate treatment and go home the same day, for conditions such as pulmonary embolisms, anaemia and urinary tract infections. ${ }^{70}$ Analysis of hospital data from 2018/19 suggested that although these conditions represented a small proportion of emergency admissions (3\%), ${ }^{71}$ SDEC could avoid overnight hospital stays, improving patient experience. ${ }^{72}$

The long term plan committed that every acute trust with a major A\&E department would implement a comprehensive model of SDEC, operating for at least 12 hours a day, 7 days a week, by the end of 2019/20. The national rollout of SDEC was expected to increase the proportion of acute admissions discharged on the day of attendance from a fifth to a third. A related commitment was made to record $100 \%$ of patient activity on the new Emergency Care Dataset by March 2020, to monitor the use of SDEC as distinct from non-SDEC zero day stays.

\section{Progress prior to the pandemic}

NHS England reported in March 2020 that a large majority (92\%) of acute trusts with a major A\&E department had implemented SDEC in line with the commitment in the long term plan. ${ }^{73}$

However, the reality behind these figures was likely more complex. An audit of 141 same day emergency care units, conducted by the Society of Acute Medicine (SAM), found that $45 \%$ were used as extra bed areas at times of high demand, as hospitals grappled with winter pressures in 2019/20. ${ }^{74}$ An inquiry into the care of patients with pulmonary embolisms - one of the conditions suitable for treatment in same day emergency care units - found that although $93 \%$ of hospitals offered a same-day service, 35\% were only open on weekdays. ${ }^{75}$

\section{Impact of the pandemic}

The SAM reported in June 2020 that many of the staff typically working in SDEC across hospitals had been redeployed to help with COVID-19 patients in intensive care, but at the same time a lot of 'SDEC activity has been displaced or is not presenting at all' ${ }^{76}$ Nevertheless, the SAM was concerned about the challenges of restarting SDEC with COVID-19 in circulation, which would require additional space and staff to do so safely. Pressure on emergency departments fell sharply in the early stages of the pandemic but has since increased to above pre-pandemic levels. NHS England reported that in May 2021, over 2 million patients were seen in emergency departments, double the level in May 2020, and 11\% higher than April 2021..$^{77}$ 
The percentage of relevant trusts that have fully implemented SDEC has not been mentioned in NHS England board reports since March 2020. But NHS England has started to publish data on length of stay for patients following non-elective and emergency admissions. This analysis is drawn from the Secondary Uses Service and Emergency Care Data Set, breaks down admissions by zero day and 1+ day lengths of stay, and shows the number of zero day stays as a percentage of all non-elective and emergency admissions. This is published alongside the monthly A\&E activity and performance statistics (though these data lag by a month). In April 2021, 37.2\% of emergency admissions and 36.0\% of non-elective admissions were zero day stays, ${ }^{78}$ broadly in line with the long term plan ambition for a third of patients to be discharged on the same day. However, it is not clear from these data whether all patients admitted and discharged on the same day actually benefited from using an SDEC service.

The Department for Health and Social Care announced an additional $£ 150 \mathrm{~m}$ in capital funding to upgrade A\&E departments in September 2020. ${ }^{79} \mathrm{NHS}$ England has committed to the expansion of SDEC services in its planning guidance for 2021/22, and to avoid unnecessary hospital admissions by maximising utilisation of SDEC. The Royal College of Emergency Medicine has welcomed this pledge, but in a briefing for MPs in April 2021 reminded policymakers that, 'The value of SDEC is not being realised as provision is patchy and highly variable across England. ${ }^{80}$

\section{2. 'More action on prevention and reducing inequalities'}

\section{Inequalities}

Summary

- $\quad$ The long term plan promised a new metric for assessing local progress in reducing inequalities, but this has not been developed.

- $\quad$ ICSs are intended to be the main vehicle for identifying and reducing health inequalities, but local plans to reduce inequalities were not published before the pandemic began. National measures of inequalities, including gaps in life expectancy, showed that the gaps between the most and least deprived areas of the country were widening or static before COVID-19.

- $\quad$ Death and illness from COVID-19 have been unequally distributed, reflecting underlying health inequalities by socioeconomic and ethnic group. Multiple initiatives have been launched by NHS England to tackle inequalities in the wake of the pandemic.

The plan committed the NHS to stronger action on the prevention of ill health and promised a 'more concerted and systematic approach to reducing health inequalities and addressing unwarranted variation in care'. ${ }^{81}$ Additional funding was be targeted at areas with higher health inequalities from 2019/20 to 2023/24, with local systems to develop 5 and 10-year plans to address health inequalities in their local areas. To support these plans, NHS England promised it would set out 'measurable goals for narrowing inequalities'. Specific commitments were also made on improving access to health services 
for people with severe mental illness, learning disabilities or autism, better maternity services for the most vulnerable women, and specialist mental health support for people affected by homelessness.

\section{Progress prior to the pandemic}

Progress on planning commitments related to inequalities before the pandemic was slow. The Long Term Plan Implementation Framework emphasised that progress would depend on local systems (STPs and ICSs) producing plans for reducing health inequalities in their area, and the creation of more specific goals in a forthcoming green paper on prevention. ${ }^{22}$ Guidance on developing the plans was published alongside the implementation framework, but details of the national inequalities metrics were not, and the deadline for submitting plans was subsequently pushed back from November 2019 to 2020 . While several local areas published a version of their plans before the deadline, it was (and remains) unclear what action to reduce health inequalities was being planned nationally prior to the pandemic. The green paper published in July 2019, Advancing our health: prevention in the 2020s, again promised that, 'The NHS will set out specific, measurable goals for narrowing inequalities, including those relating to poverty, through the service improvements set out in the plan. ${ }^{83}$

Official national measures of inequalities suggest that differences between the health outcomes of people living in the least and most deprived areas were static or widening before the pandemic. The annual report of the Department of Health and Social Care, published in January 2021, covering the period ending 31 March 2020, reported a widening of inequalities in 6 out of 11 overarching indicators drawn from the NHS and

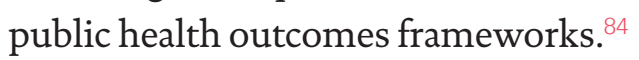

For example, the gap has widened in the rate of unplanned hospitalisation for conditions such as diabetes and high blood pressure. Data produced for the CCG Improvement and Assessment Framework show that rates of unplanned admissions for these conditions decreased from 2003/04 until 2013/14, after which they started to increase (Figure 1). ${ }^{85}$ While the trend was the same across all deprivation deciles, rates of unplanned hospitalisations were consistently around triple in the most deprived decile compared to the least deprived (with 1,634.8 unplanned hospitalisations per 100,000 in the most deprived decile and 527.3 in the least deprived decile in 2019/20). ${ }^{86}$ 
Figure 1: Unplanned hospitalisations for chronic ambulatory care sensitive conditions by most and least deprived decile of population, admissions per 100,000; England, 2003/04 to 2019/20
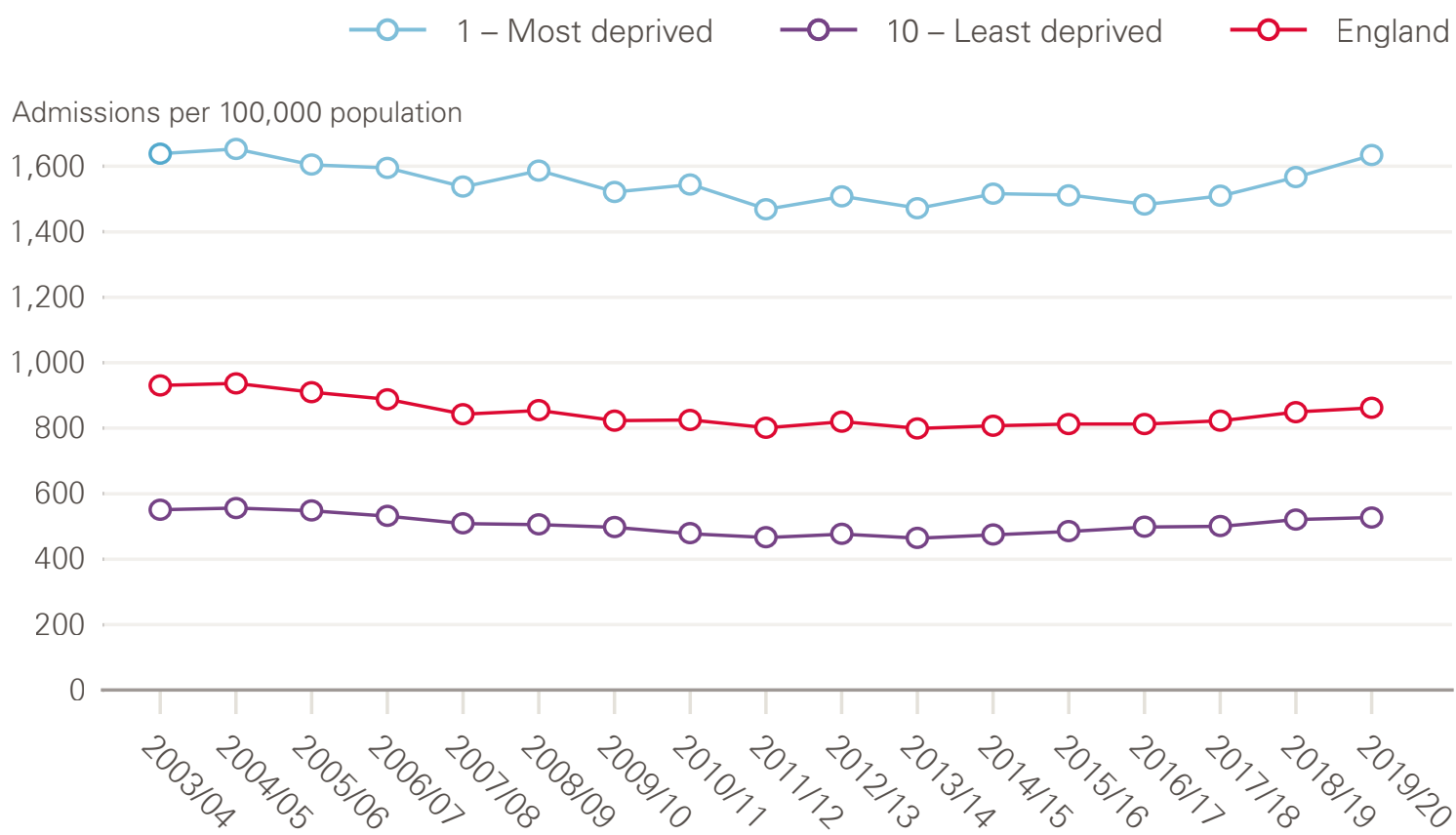

Other indicators where there had been a statistically significant widening of inequalities since the baseline were life expectancy at birth (for men and women), life expectancy at 75 years (for men and women) and emergency admissions for acute conditions that should not usually require hospital admission. There was no reduction of inequalities in mortality rates for those younger than 75 from cardiovascular disease, infant mortality or healthy life expectancy, all of which had been broadly stable. The only indicator where inequalities had narrowed since the baseline year or period was cancer mortality rates for those younger than 75 .

Independent analyses have confirmed some of these trends. Research by QualityWatch found widening inequalities in the decade prior to the long term plan between the most and least deprived parts of England, for example in A\&E waiting times and rates of hip replacements. ${ }^{87}$ Separate analysis by the Strategy Unit found socioeconomic inequalities in access to elective care services had widened in the years before the pandemic, even after adjusting for differences in need..$^{8}$

\section{Impact of the pandemic}

As the pandemic unfolded, so did evidence of the unequal harm it inflicted. Inequalities emerged not just in terms of the risk of serious illness and death, but also the risk of unemployment, capacity to work at home, self-isolate and confidence to be vaccinated. This has reignited a debate about the importance of tackling health inequalities.

In May 2020, the ONS reported a disproportionately high death rate from COVID-19 in the most deprived areas, in excess of the normal differences between areas. ${ }^{89}$ In August 2020, Public Health England summarised the emerging evidence on disparities in risks and outcomes of COVID-19, finding a higher risk of death for those from ethnic minority 
than white backgrounds, and for those working in face-to-face roles, such as caring professions. ${ }^{90}$ Subsequent analysis showed how pre-existing inequalities in social and economic conditions contributed to the high and unequal death toll. ${ }^{91}$

In response to this growing body of evidence, in August 2020 NHS England set out eight 'urgent actions' to address health inequalities within the NHS as part of the pandemic recovery. ICSs and STPs, working in partnership with local communities and partners, were urged to oversee an 'increase in the scale and pace of progress in reducing inequalities' and to ensure regular assessment of progress. ${ }^{92}$ This included directions to: make digital forms of care more inclusive, accelerate prevention for those at greatest risk of poor health; support those with mental ill health; strengthen leadership and accountability; and improve the completeness and timeliness of data collection - including on ethnicity - to underpin the response to inequalities.

In June 2020, the Prime Minister instructed the Government Equalities Office and Race Disparity Unit to lead cross-government work on the disproportionate impact of COVID-19 on ethnic minority groups and to publish quarterly progress reports. The second quarterly report, published in February 2021, said 'significant progress has continued to be made' against the eight actions outlined to NHS leaders, and 'the majority of NHS organisations' had appointed executive leads for health inequalities. ${ }^{93}$ Research by the Nuffield Trust and NHS Race and Health Observatory, published in June 2021, highlighted significant problems with ethnicity coding in NHS datasets and called for NHS England to develop new guidance. ${ }^{94}$

All NHS organisations were expected to improve data collection and monitoring in relation to inequalities by 31 December 2020, while ICSs and STPs were required to submit an update on delivery of the eight urgent actions by 31 March 2021. However, information is not publicly available on whether these actions were completed..$^{95}$ The $2021 / 22$ planning guidance asks ICSs to prioritise early action in five areas, drawn from the eight urgent actions, alongside system-level priorities to reflect local circumstances. ${ }^{96}$ The five areas are: restoring NHS services inclusively; mitigating against digital exclusion; ensuring data are complete and timely; accelerating health prevention programmes for those at greatest risk; and strengthening system leadership and accountability. ${ }^{33}$ The guidance also makes 'addressing health inequalities' one of five gateway criteria for accessing additional funding for the elective backlog. 


\section{Prevention: alcohol, smoking and obesity}

\section{Summary}

- $\quad$ The long term plan was clear that the NHS alone could not prevent ill health and that wider action from national and local government was needed.

- Three areas where the NHS could target action were included as 'headline metrics': setting up alcohol care teams in hospitals with the highest rate of alcohol dependencerelated admissions; reducing obesity by increasing the number of people supported through the diabetes prevention programme; and offering smoking cessation services to all smokers admitted to hospital.

- $\quad$ Data are not available to assess progress towards the alcohol and smoking goals. Evidence suggests an increase in alcohol-related harm during the pandemic, which also disrupted wider NHS smoking cessation services.

- $\quad$ The diabetes prevention programme has continued to increase the numbers accessing its services, which were moved to virtual formats to reduce infection risk.

The long term plan set out a range of actions to prevent ill health, including reducing air pollution and antimicrobial resistance. It also aimed to make more of people's contacts with the NHS to promote targeted action on smoking, alcohol and obesity, to complement the wider work on health prevention led by national and local government. The plan emphasised a 5-year funding commitment would be needed for the public health grant to local government in the next Spending Review, noting that the level of the grant 'directly affects demand for NHS services'.

On smoking, the plan committed to a new smoke-free pregnancy pathway for expectant mothers and their partners and the offer of tobacco treatment services for all people admitted to hospital who smoke by $2023 / 24 .{ }^{97}$ A new smoking cessation offer for people using specialist mental health and learning disability services was also promised, including the option to switch to e-cigarettes.

On alcohol, specialist 'alcohol care teams' would be established in up to 50 hospitals with the highest rate of alcohol dependence-related admissions, with the aim of preventing up to 50,000 alcohol-related hospital admissions over 5 years. ${ }^{98}$

On obesity, the plan committed to doubling the number of people offered support from or accessing support through the diabetes prevention programme. This programme identifies people at high risk of developing diabetes and offers help with maintaining a healthy weight and increasing exercise to prevent or delay onset of the disease. The plan also promised to increase access to weight management services in primary care, although no target was set for this.

\section{Progress prior to the pandemic}

The new hospital-based tobacco treatment services were due to be adopted by pilot sites in 2020/21, before being expanded nationally. The headline measure was for an increase in the percentage of people admitted to hospital offered NHS-funded tobacco treatment services, but data on this measure have not been published. 
The percentage of hospitals with the highest rate of alcohol dependence-related admissions that have alcohol care teams (ACTs) in place is not publicly available. An assessment, published in 2019, found that while there has been a major increase in the number of ACTs in UK hospitals since 2010, many are 'not resourced to provide an optimal 7-day service'. ${ }^{99}$ Evidence submitted as part of the recent Commission on Alcohol Harm also underlines that most hospitals are unable to provide a 7 -day service and highlights that $17 \%$ of hospitals do not have a single alcohol specialist nurse. ${ }^{100}$

The number of people offered support via the diabetes prevention programme increased by $38 \%$ following publication of the long term plan. 687,730 people were offered support from January to September 2020, up from 497,125 in the same months in 2019. However, there has been considerable variation between areas - the percentage of eligible patients offered support through their CCG in the same period ranged from $1 \%$ to $86 \%$, with the highest rates in Westminster and the lowest in Bolton. Not all offers of support via the diabetes prevention programme translate into support being accessed; of those offered access to the programme in 2020,36\% declined compared with $37 \%$ in $2019 .{ }^{101}$

\section{Impact of the pandemic}

The need to limit face-to-face contacts and redeploy staff during the pandemic has set back the implementation some of the prevention commitments made in the plan. In March 2020, the National Centre for Smoking Cessation and Training recommended that stop smoking service providers in the NHS and in the community immediately cease all face-to-face advice and carbon monoxide monitoring. ${ }^{102}$ Findings from an annual survey of local authority tobacco control leads, published in early 2021, suggested capacity within smoking cessation services fell in many areas, as did referrals from NHS providers to specialist stop smoking services, particularly those from secondary and maternity care. ${ }^{103}$ Activity to improve alcohol treatment services was suspended in April 2020, with funding for the first round of early implementor ACT sites also pushed back to October 2020. By contrast, the diabetes prevention programme continued to expand despite the pandemic, replacing face-to-face meetings with virtual meetings. ${ }^{104}$

A review of alcohol consumption and harm during the pandemic by Public Health England found that the pandemic had accelerated existing trends of increasing alcohol-related hospital admissions and deaths. Emergency admissions for alcoholic liver disease increased by $13 \%$ between 2019 and 2020, and total alcohol-specific deaths were $20 \%$ higher in 2020 than 2019. ${ }^{105}$

At the same time, greater awareness of the risk factors for COVID-19 may have helped to generate interest in and commitment for action to improve health. The percentage of smokers who reported that they had tried to stop smoking over the past year increased from 29.1\% in 2019 to 36\% between January and May 2021, and the success rate for those who tried increased from $14.2 \%$ to $26.3 \%{ }^{106}$

After Public Health England reported the risk of death from COVID-19 increased by $90 \%$ in people with a BMI over $40,{ }^{107}$ the government's obesity strategy published in July 2020 committed to a further expansion of NHS weight management services beyond the 
commitment in the long term plan. ${ }^{108}$ The strategy also committed to accelerating the expansion of the diabetes prevention programme so 'tens of thousands more people will be able to access these services than was originally included in the long term plan'.

\section{Prevention: increase uptake of screening and immunisation}

Summary

- $\quad$ The plan's headline metrics promised to increase the coverage of the three main screening programmes for cancer (breast, bowel and cervical) and immunisation for MMR in children

- $\quad$ The pandemic brought major disruption to screening programmes, which have now resumed. Childhood immunisation rates have also fallen.

A number of commitments to increase uptake of screening and immunisation were outlined in the plan. Headline metrics focused on improving coverage of bowel, breast and cervical cancer screening and increasing MMR vaccination uptake for children younger than 5. Modernisation of the bowel cancer screening programme (through use of faecal immunochemical testing) was promised 'to detect more cancers, earlier', and a target set for implementing HPV primary screening for cervical cancer across England by 2020. The plan also promised to take forward findings from the independent review of cancer screening programmes led by Sir Mike Richards. Improvements in childhood immunisation were also highlighted as a priority, with an objective 'to reach at least the base level standards in the NHS public health function agreement'.

\section{Progress prior to the pandemic}

The final report of the independent review of adult screening programmes was published in October 2019. ${ }^{109}$ It concluded that while each screening programme was broadly achieving its intended goal of reducing mortality, there is 'a sense that we are now slipping' and that each of the programmes 'could undoubtedly do better'. The review noted that while there were signs of improvement, uptake for bowel cancer screening was the lowest out of all screening programmes and failed to meet its standard target in 2017/18. It also highlighted a slow decline in the number of people taking up screening out of those eligible for breast and cervical screening. The review concluded with a call for 'urgent change to ensure screening programmes can be readied and resourced to maximise the opportunities they bring'.

\section{Progress since and impact of the pandemic}

Prior to the pandemic, the coverage of the bowel cancer screening programme - the proportion of the eligible population screened for bowel cancer within a given time period - was improving. However, uptake - the proportion of people invited to bowel cancer screening who were screened - had started to fall after improving from 2017 to mid-2019. During the early phase of the pandemic, the bowel cancer screening programme was paused and the main diagnostic tests limited to emergency settings. 
The number of people invited to bowel cancer screening fell dramatically during the early stages of the pandemic, with only 604 people invited for screening from April to June 2020 , compared with over a million in the same period in 2019. This increased to 741,406 people from July to September 2020 (still 38\% lower than the same months in 2019), but towards the end of 2020 screening services began to recover lost ground, screening over 300,000 more people between October and December 2020 than in the same period in 2019. ${ }^{110}$

Rates of colonoscopy (a test to look inside the bowel) have fallen, with $46 \%$ fewer people receiving colonoscopies between April and October 2020 compared with the same months in 2019. One study found that over 3,500 fewer people in England were diagnosed and treated for colorectal cancer from April to October 2020 than would have been expected. ${ }^{111}$ Cancer charities remained concerned about the number of people waiting for bowel cancer investigations in 2021, which, by May 2021, was five times higher than pre-pandemic. ${ }^{112}$

The coverage of the breast cancer screening programme had started to fall in mid-2019 after a period of stability from 2017 , and fewer people had taken up invitations to attend breast cancer screening. Official performance indicators for the breast cancer screening programme have not been published for the period covering the pandemic. $65.8 \%$ of eligible women were screened for breast cancer from October to December 2019, which fell to $55.1 \%$ from January to March 2020 - a period that overlaps with the initial stage of the pandemic. ${ }^{13}$ Although the breast screening programme restarted in mid-2020, the charity Breast Cancer Now reported in January 2021 that services were operating at $60 \%$ of their pre-pandemic capacity and estimated that over a million fewer women in England were screened in 2020 as a result of COVID-19.114

Prior to the pandemic, coverage of the cervical cancer screening programme had been fairly stable but uptake had been falling until improvements started in 2019. Cervical cancer data are reported based on the percentage of eligible women screened in the previous 3.5 years. Therefore the full impact of the pandemic is not yet clear, but data to the end of 2020 show a clear reduction in the percentage of eligible women screened in the previous 3.5 years, from $68.1 \%$ of women aged $25-49$ and $75 \%$ of women aged $50-64$ screened from October to December 2020, compared with $70.7 \%$ and $76.4 \%$ in $2019 .{ }^{115}$

Overall, provisional data indicate that early pauses to cancer screening as a result of the pandemic have had an impact. Cancer Research UK estimated that 3 million fewer people were screened between March and September 2020, and that the number of people beginning treatment for cancer following a referral from cancer screening was down by 42\% in England from April 2020 to March 2021, compared with the same period a year earlier. ${ }^{116}$ It also notes that numbers of people being screened has recovered 'fairly steadily' since July 2020, with the number of people starting treatment after diagnosis through screening 3\% higher in March 2021 compared with March 2020, with 'no sign of a backlog coming through yet'.

The most recent childhood monthly vaccination coverage statistics point towards a 'sustained decrease' in children receiving routine childhood immunisations in 2020 including for MMR - compared with 2019. ${ }^{117}$ Public Health England's assessment of 
MMR1 (first dose) coverage measured at 18 months of age is described as falling 'far short of the WHO target of $95 \%$ coverage by 24 months of age'. Coverage measured at 18 months of age remained around 1 to $2 \%$ lower than the 2019 estimates, since the initiation of social distancing. Public Health England's analysis notes that the initial decrease in vaccination 'may be associated with COVID-19 messaging about staying home initially, overwhelming the messaging that the routine immunisation programme was to remain operating as usual'. It also highlights anecdotal information that some GPs had to reschedule appointments in the initial weeks to ensure social distancing within GP practices.

\section{3. 'Further progress on care quality, access and outcomes'}

In contrast to the previous NHS national plan (the Five year forward view), the long term plan gave much more prominence to a broader set of conditions and population groups, including targets for respiratory conditions and cardiovascular care. The headline metrics in the implementation framework were more limited in scope, however, covering childbirth, mental health, cancer, care for people with learning disabilities and waiting times.

\section{Maternal and children's health}

\section{Summary}

- While the plan contained a number of initiatives to improve maternal and children's health, the headline goal focused on improvements in the outcomes of maternity care. The target was for a ' $50 \%$ reduction in stillbirth, neonatal and maternal deaths and brain injury by $2025^{\prime}$.

- $\quad$ Lags in data prevent assessment of progress following the interventions begun after the long term plan was published. The most recent data (to 2019) suggest a $25 \%$ reduction in the rate of stillbirths. Neonatal deaths in babies over 24 weeks gestation have also fallen, at a rate consistent with meeting the 2025 target.

- There has been less progress in reducing brain injuries and maternal deaths, which are not on track to meet the target.

- Data to assess the impact of COVID-19 on these outcomes are not yet available. There were reductions in some antenatal appointments and restrictions on partners attending appointments and births, and disrupted services are likely to have contributed to the deaths of a small number of pregnant women.

For maternity services, the plan brought forward an existing goal of halving the rates of stillbirths, neonatal and maternal deaths and brain injury by 2030 to 2025 . The target was set in $2015^{118}$ (against a baseline of 2010) and much of the actions needed to achieve it began in 2016, in response to failings in maternity care identified at Morecambe Bay. ${ }^{119}$ Progress to reduce maternal and baby deaths was to be achieved by the adoption of consistent practices (known as the Saving Babies Lives Care Bundle); expanding continuity of care schemes so that 'most women' would receive 'continuity of carer' before, during and 
after birth by March 2021, with an initial focus on women most at risk of poor outcomes; and all trusts becoming part of a National Safety Collaborative (a programme to improve the quality and safety of maternity and neonatal units).

\section{Progress prior to the pandemic}

According to the Department of Health and Social Care and NHS England in 2021, every trust 'is actively implementing' the latest version of the Saving Babies Lives Care Bundle aimed at reducing pre-term birth (including through smoking cessation for pregnant women and active fetal monitoring during birth) and the National Safety Collaborative is in place everywhere. ${ }^{120}$

It is too early to assess whether the plan's actions have improved outcomes. NHS England and the Department of Health and Social Care believe that there is 'clear progress' towards the ambition of halving deaths in mothers and babies, while data from 2019 suggest that still births have reduced by $25 \%$ since 2010 and are ahead of the target rate of reduction. According to the National Clinical Director of Maternity and Women's Health, the picture is more complicated for neonatal mortality rates, where the data suggested 'we had not made much progress' ${ }^{121}$ This is because recording practice has changed, with more neonatal deaths recorded in babies born at under 24 weeks gestation that would have been classified as miscarriages before 2010. When only deaths in babies over 24 weeks are counted, the neonatal mortality rate decreased by 10\% between 2013 and 2017. The overall rate of brain injuries during or soon after birth 'shows no trend downwards' between 2010 and 2017, while the 3-year average of maternal deaths has reduced by $14 \%$ between 2010 and 2015-17. ${ }^{120}$

The Health Committee gave a less positive assessment, concluding that brain injuries 'required improvement', while the status of progress on maternal deaths was graded 'inadequate'.'122

Since the long term plan was published, the safety of maternity services has been under intense scrutiny in the wake of evidence of serious failings dating back over a decade in two NHS trusts - Shrewsbury and Telford, and East Kent. An independent inquiry into Shrewsbury and Telford issued its first report in December 2020, ${ }^{123}$ and the investigation into East Kent began in early 2021. NHS England issued a list of 12 'immediate and essential actions' for trusts to take in December $2020^{124}$ and released details of funding for additional workforce and training in March 2021. ${ }^{125}$

\section{Impact of the pandemic}

Maternity services continued during the pandemic, but services were adapted to minimise the risk of COVID-19 infection. This included reductions in antenatal appointments during the first wave of the pandemic and restrictions on partners attending appointments, scans and labour. ${ }^{126,127}$ In December 2020, NHS England advised that NHS trusts 'should find creative solutions' to allow women to have someone with them during maternity care and birth while minimising the risk of infection. ${ }^{128}$ 
A rapid review of 10 COVID-positive maternal deaths during the first 3 months of the pandemic concluded that pregnant women were not at higher risk of severe COVID-19, but pointed to inadequate care contributing to their deaths. ${ }^{129} \mathrm{~A}$ subsequent study of the deaths of 17 more women between June 2020 and March 2021 also highlighted failures in care (including inadequate remote consultations which missed complications), and noted that women 'are fearful of seeking care'. ${ }^{130}$ In both reviews, the majority of cases reviewed involved women from ethnic minority backgrounds, and the increased risk of poor outcomes among this group has now become a much more prominent focus of efforts to improve maternity services. Government introduced a new target for NHS England in its 2021/22 mandate, namely 'year on year reductions in the difference in the stillbirth and neonatal mortality rate per 1,000 births between that for black, Asian and minority ethnic women and the national average'. ${ }^{131}$

Overall, the Health Committee's evaluation of the government's commitments on maternity care concluded that COVID-19 has exacerbated, but is not solely to blame for, delays in improving care. It notes that 'staffing shortages persist across all maternity professions'.

\section{Improve cancer survival}

\section{Summary}

- $\quad$ The long term plan promised improvements in cancer screening, diagnosis and treatment, which would improve survival rates for people with cancer. The measures of progress were two-fold: increases in the 1- and 5-year survival rates for cancers, and a target of $75 \%$ of cancer patients diagnosed at earlier stages of their cancer (stage 1 or 2) by 2028 .

- Data for survival rates and the $75 \%$ earlier diagnosis target is not yet available beyond 2019. Before the pandemic, new rapid diagnostic hubs and bowel cancer screening techniques were being introduced.

- In 2020, COVID-19 brought significant disruption to cancer services. New cancer diagnoses fell by two-thirds between April and May 2021, and surgery for cancer also fell by two-thirds between April and July 2020. Screening services were paused in March 2020.

- $\quad$ Screening services have reopened and the number of urgent referrals for suspected cancer are now higher than before the pandemic. The number of diagnoses and treatments has also recovered, but services are still struggling with infection control and staff absences. In February 2021, over 20,000 patients were waiting more than 2 months for diagnosis or treatment.

The plan set a new ambition that by 2028, the proportion of cancers diagnosed at stages 1 and 2 would rise from around half to three-quarters of cancer patients. Prior to the long term plan, the proportion of cancers diagnosed at stages 1 and 2 was fairly stable with an average of 54\% between 2013 and 2018. ${ }^{132}$ Earlier diagnosis of cancers is the most important route to improving survival. NHS England calculated that if this target was achieved by 2028 , it would mean 55,000 more people each year would survive cancer for at least 5 years. Earlier diagnosis requires multiple efforts across a range of services, including general practice, screening services, diagnostic services and acute care. 
By 2021, the plan promised to have begun the rollout of rapid diagnostic centres nationally, introduce a faster diagnosis standard (of 28 days from referral to diagnosis), deliver improvements to bowel cancer screening by introducing a new screening technique and cervical cancer (HPV screening), and personalised care plans for all patients with a diagnosis of cancer. Increased uptake of the three main screening programmes (for breast, bowel and cervical cancer) was also included in the implementation framework metrics.

\section{Progress prior to the pandemic}

Progress was visible against some of these goals before the pandemic, against a backdrop of rising demand for cancer services. In March 2020, NHS England reported that 20 rapid diagnostic centre pathways were open and that the new bowel cancer screening technique had boosted uptake by $6 \%$ between June and December 2019, but also flagged the steady growth in the urgent referrals for cancer investigations, which had more than doubled since $2010 / 11 .^{73}$

\section{Impact of the pandemic}

The arrival of the pandemic had a significant impact on cancer services. NHS England advised trusts to continue with cancer treatment, but data suggest that much cancer surgery was disrupted. Surgery for all cancer groups dropped by two-thirds between April and July 2020 compared with the previous year, before recovering by November 2020 to between $75 \%$ and over $100 \%$ of the previous year's levels. ${ }^{73}$

Behind these figures are patients whose surgery has been cancelled or postponed, but also patients who may not have got into the system at all. There was a steep fall in the number of new cancer diagnoses, by two-thirds in April and May 2020 (which also began to recover from September 2020). But cancer charities have expressed concern about the 40,000 fewer people starting cancer treatment than would have been expected over the period, likely to be 'living with cancer without knowing it'. ${ }^{134}$ One possible consequence of this has been an increase in the proportion of cancers diagnosed after presentation at $A \& E$ departments (emergency presentations). The proportion of emergency presentations had been falling slowly for 5 years, reflecting efforts to increase earlier diagnosis, but data released in March 2021 showed that the rate rose from 17.5\% (of all cancers diagnosed) in January to March 2020 to $27.4 \%$ in April to June 2020, improving slightly to $23.4 \%$ between July and September (Figure 2). ${ }^{135}$ Public Health England noted that this was the highest proportion for 5 years. Subsequent monitoring by Cancer Research UK suggested this trend may have stabilised, but it may not be known until 2023 whether COVID-19 has led to more people developing later stage cancers. ${ }^{116}$ 
Figure 2: The percentage of first hospital cancer admissions that were emergencies increased during the pandemic

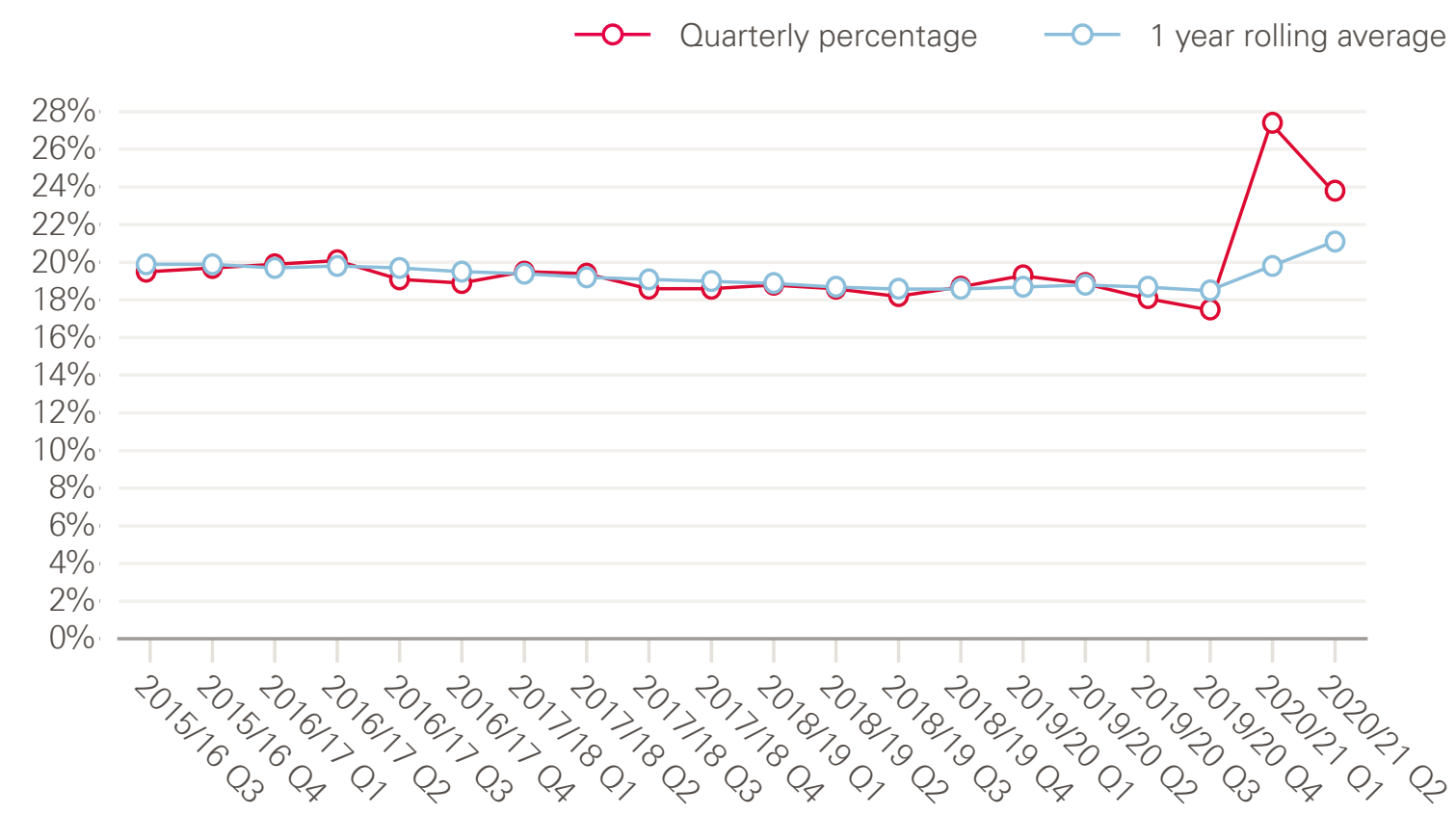

Source: PHE, Emergency presentations of cancer, 2021

One contributory factor Public Health England identified for the rise of emergency presentations was the reduction in screening activity. Screening services for bowel and breast cancer were paused in March 2020, but by December 2020 NHS England reported that services 'were now running across the country'. ${ }^{136}$

In December 2020, NHS England published a cancer recovery plan, aimed at restoring cancer services to pre-pandemic levels and getting the long term plan commitments back on track. ${ }^{136}$ The recovery plan said that the rate of new referrals for suspected cancer had recovered during the second half of 2020 to above pre-pandemic levels, following successful national campaigns to encourage patients to see their GPs if they had symptoms. By April 2021, urgent referrals for suspected cancer were 105\% higher than pre-pandemic levels. ${ }^{73}$ But in the recovery plan, NHS England also acknowledged that delays were occurring after referral and the number of patients waiting over 2 months for diagnostic tests and treatments was still too high. NHS England has published data on patients urgently referred by their GP for suspected cancer, showing the combined total of patients waiting over 62 days split between those with a decision to treat but still waiting to start treatment, and those awaiting a definitive diagnosis to confirm or exclude cancer. It shows that at the peak of the first wave, this was three times as high as pre-pandemic levels (Figure 3).

Although cancer diagnostic and treatment services managed to keep more services going during the second wave, at the end of winter in 2021 nearly 20,000 patients were waiting more than 2 months. ${ }^{77}$ There are also variations in rates of diagnosis and treatment by 
cancer type. For example, while first consultant appointments for breast cancer were $38 \%$ higher in March 2021 than before the pandemic, appointments for lung cancer were still $16 \%$ lower. ${ }^{138}$

\section{Figure 3: Monthly total of patients waiting over 62 days following an urgent referral for suspected cancer, England, March 2020-April 2021}

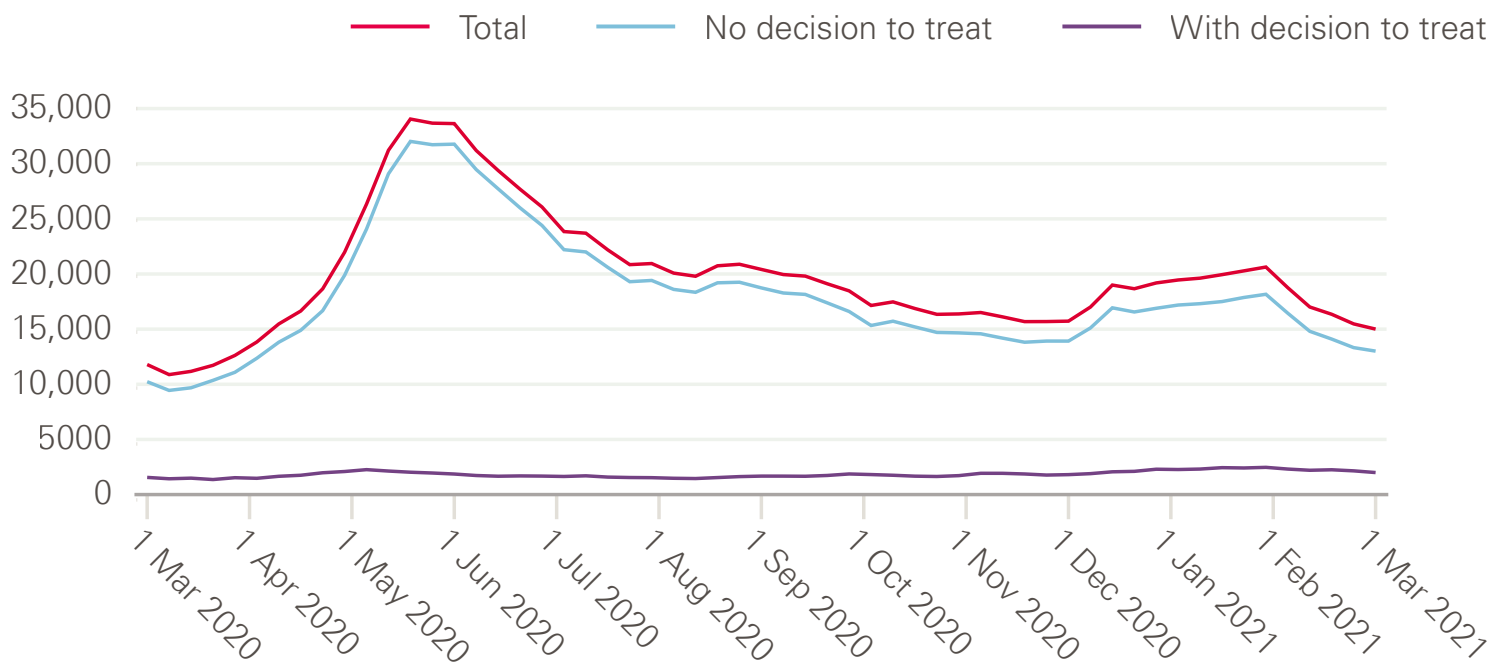

Source: NHSE, Management information on cancer, 2021

The recovery plan encouraged local areas (cancer alliances) to continue with long term plan commitments 'wherever possible', including Targeted Lung Health Checks, Rapid Diagnostic Hubs and personalised stratified follow up, which could release outpatient slots. Concern remains about the capacity of diagnostic services to meet the additional activity associated with the long term plan cancer commitments, at the same time as reducing the COVID-19 backlog of hospital treatment. In November, an independent review of diagnostic services commissioned by NHS England published its findings. ${ }^{139}$ It found that infection control procedures needed during the pandemic had slowed activity in many of the diagnostic services needed for cancer, particularly CT scanning and endoscopy, and had exacerbated backlogs in diagnostic services already under pressure beforehand. The national standard of no more than $1 \%$ of patients waiting for longer than 6 weeks for a diagnostic test had not been met since November 2013. The pandemic has delivered a major shock to diagnostic services (Figure 4). 
Figure 4: Percentage of patients waiting 6 or more weeks for diagnostic tests, England, January 2006-January 2021

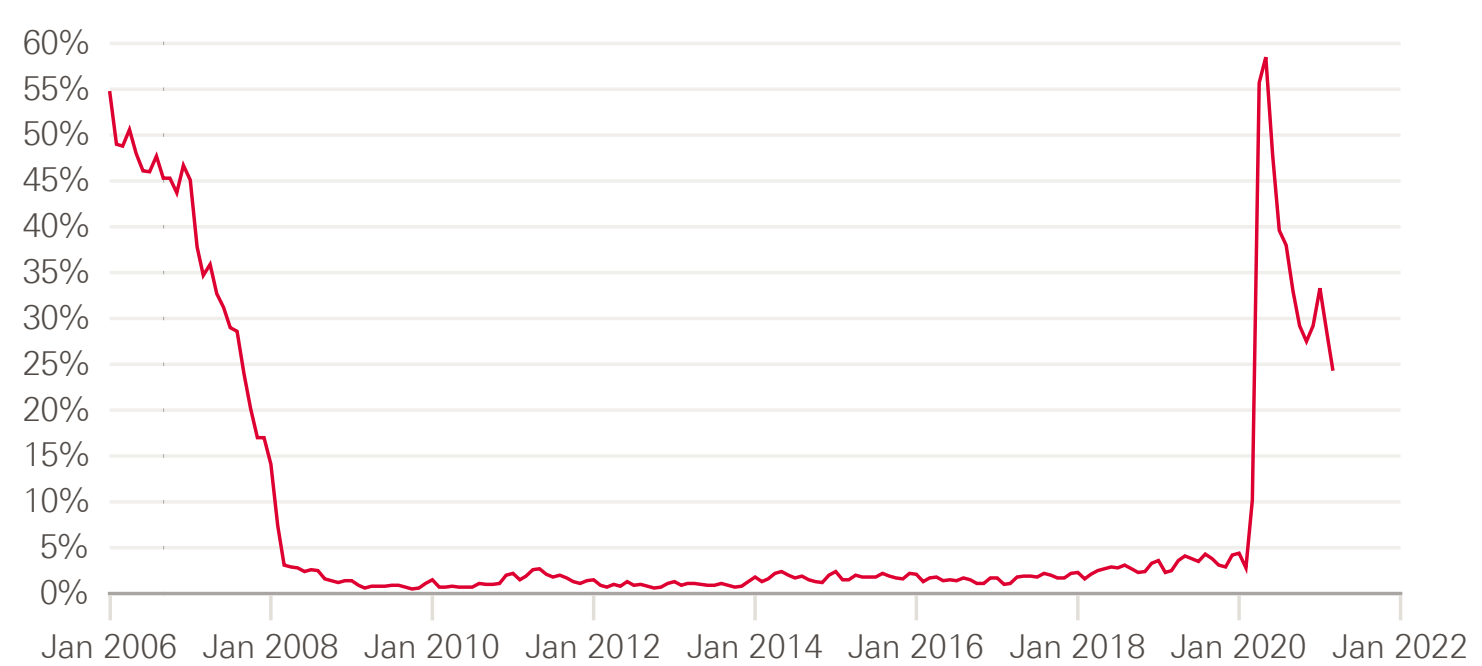

Source: NHSE, Monthly Diagnosis Data, 2021

Figure 4 includes data related to all diagnostic tests, but cancer-specific tests have been badly affected. The proportion of patients waiting more than 6 weeks for endoscopy saw a 40\% increase between February 2020 and February 2021; for CT scans the increase was $16.5 \% .{ }^{140}$ The independent review recommended significant investment in equipment and staff was needed if the long term plan cancer goals were to be achieved, including a doubling of CT scanners and increasing the number of radiologists and radiographers by 5,500 over the next 5 years.

\section{Learning disabilities and autism}

\section{Summary}

- $\quad$ The long term plan contained two headline metrics to capture the improvements made to care for people with learning disabilities and autism. The first was to reduce the reliance on inpatient care by halving the inpatient rate by $2023 / 24$. The second was to increase the proportion of people receiving physical health checks to $75 \%$ of those older than 14 on the learning disability register.

- $\quad$ Prior to the pandemic, slow progress was being made towards the goal of reducing the number of people in inpatient units and the target looked unlikely to be met within the timeframe. COVID-19 may have led to a temporary increase in the inpatient rate.

- The pandemic led to falls in the number of people with learning disabilities receiving health checks from their GP, but the rate has recovered since to meet the target.

- $\quad$ People with learning disabilities were much more likely to be hospitalised and die from COVID-19. Concern remains about their vulnerability to severe illness while the pandemic continues. 
The long term plan promised a range of actions to make sure that 'all people with a learning disability, autism, or both can live happier, healthier and longer lives'. Improvements promised by national NHS bodies included faster autism diagnosis for children, better access to health care and more support for people to live independently in the community.

Two headline metrics were selected out of these various commitments. The first was based on a pre-existing commitment, set in the wake of serious abuse at Winterbourne View Hospital, ${ }^{141}$ to reduce the number of people with learning disabilities and autism in inpatient mental health units and enable them to receive care in the community. The plan promised to reduce inpatient provision to $50 \%$ of 2015 levels by $2023 / 24$, with at most 30 adults with a learning disability and/or autism per million (and at most 15 children per million) cared for in inpatient units.

The second metric was a new target to increase uptake of the existing annual health check for people with a learning disability from 55\% (in 2017/18) to at least $75 \%$ of people aged 14 and older on the GP learning disability register each year. First introduced in 2009, the purpose of these health checks is to proactively identify and address previously unmet health needs.

\section{Progress prior to the pandemic}

Limited progress has been made towards the 2015 target to reduce inpatient provision of care by $50 \%$ (Figure 5$).{ }^{142}$

\section{Figure 5: Number of people with learning disabilities and autism in inpatient care, England, March 2015-December 2020}

- Number of inpatients (submissions at month end)

- - Long term plan target for 2023/24 (50\% of revised 2015 baseline)
- Number of inpatients (revised submissions as of March 2021)

- - Upper target for March 2019 (50\% of 2015 levels as recorded at month end)

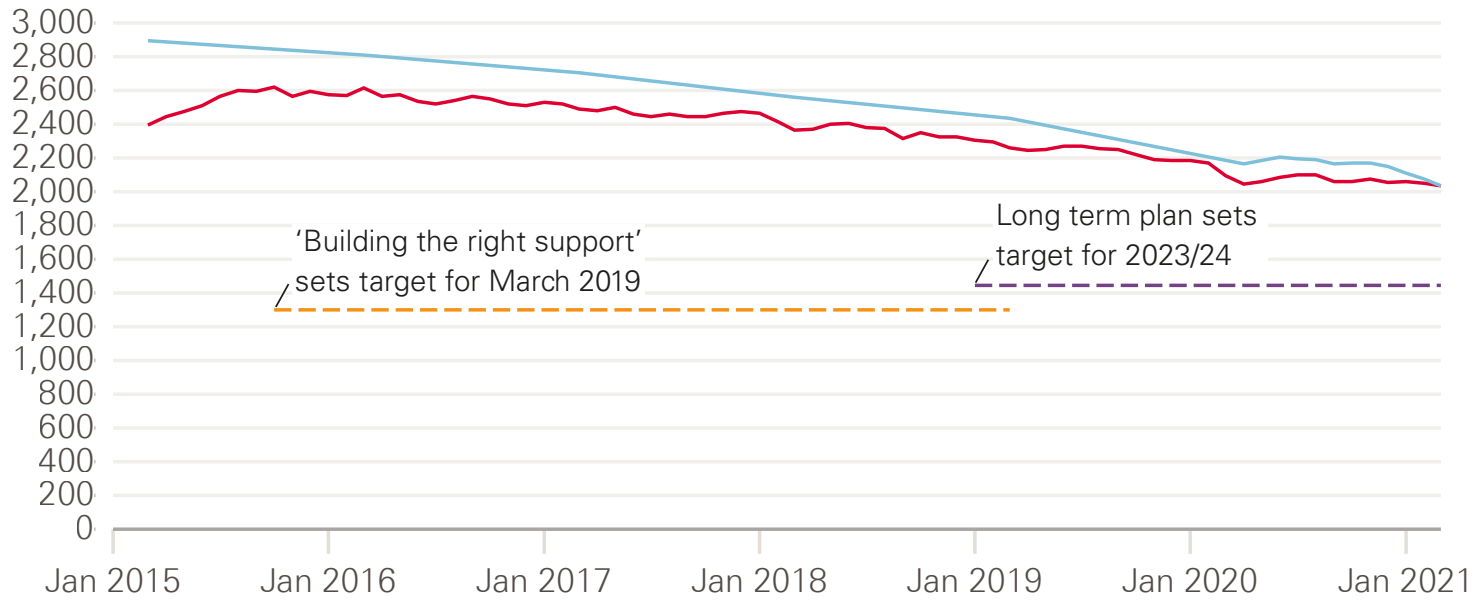


In March 2020, government missed a pre-existing interim target to reduce the total number of inpatients by $35 \%$ and the rate of inpatients with a learning disability and autism to 18.5 adults per adult million population. ${ }^{143}$ The total number of inpatients reported in March 2020 was 2,095 - 27\% less than the revised baseline of 2,890.

In February 2020, the Secretary of State for Health and Social Care faced legal action from the Equalities and Human Rights Commission to declare the Department of Health and Social Care in breach of the European Convention on Human Rights over the continuing failure to move people from inpatient care to community-based settings. When launching its challenge, the Commission stated it had held discussions with the Department of Health and Social Care and NHS England but was not satisfied the new deadline set by the long term plan would be met, suggesting a 'systemic failure to protect the right to a private and family life'. ${ }^{144}$

The plan did not include a target date for increasing uptake of learning disability health checks to $75 \%$. NHS digital data indicate poor progress against this target prior to the pandemic. In contrast with previous years, there was a decrease between 2018/19 and 2019/20 in the percentage of health checks received among both women and men (see Figure 6). This decrease in the uptake of the annual health check affected all age groups apart from $14-17$ year-olds. ${ }^{145}$

\section{Figure 6: Percentage of patients with a learning disability who received a health check, by sex, 2015/16-2019/20}

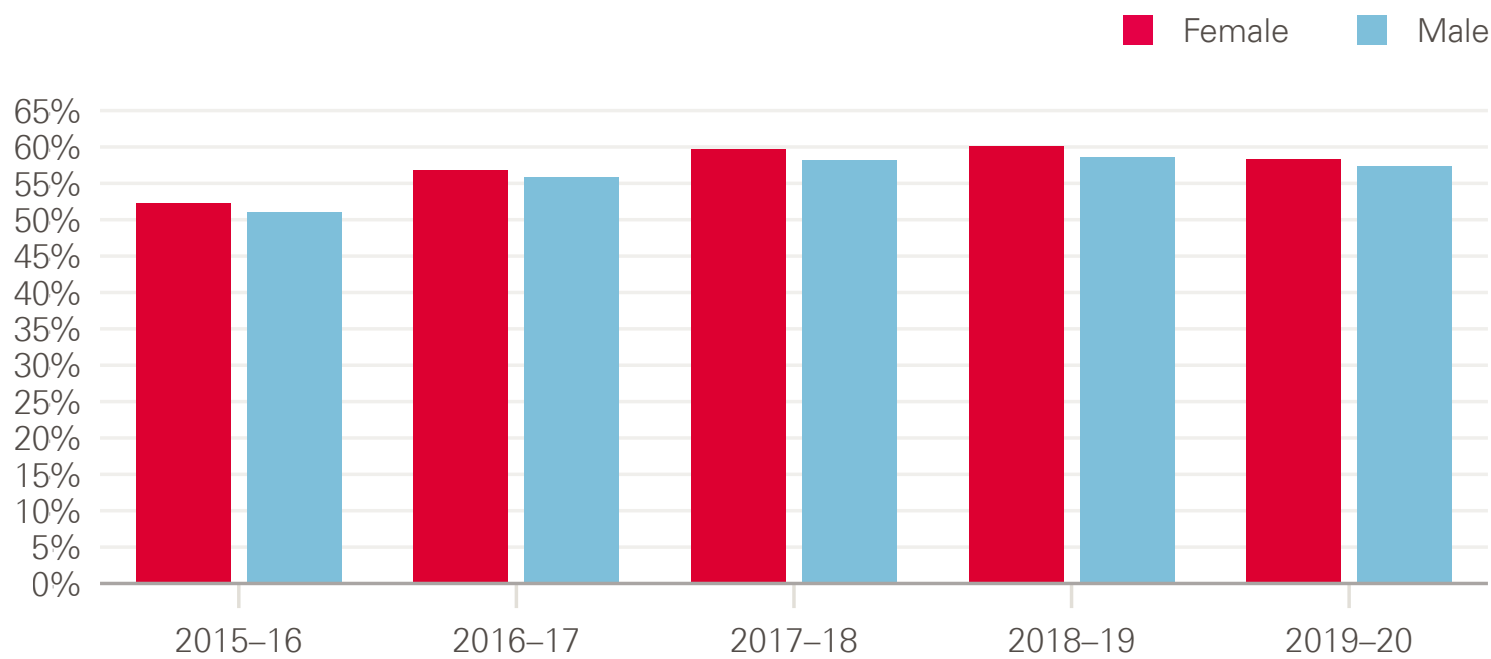

Source: NHS Digital. Health and Care of People with Learning Disabilities Experimental Statistics 2019 to 2020; January 2021 (https://digital.nhs.uk/data-and-information/publications/statistical/health-and-care-of-people-with-learningdisabilities/experimental-statistics-2019-to-2020/health-checks).

\section{Impact of the pandemic}

Data to monitor progress on reducing inpatient numbers are published every month but revised retrospectively, which means they are not reliable for real-time monitoring. Compared with previous trends, initial data showed a relatively large fall in the numbers of people in inpatient units in March and April 2020 (when the COVID-19 pandemic hit), followed by an increase in inpatient numbers until August 2020. This may be partly 
due to delays in reporting as this pattern is less clear in revised data. On annual health checks, COVID-19 initially looked to have threatened progress on this commitment. A study involving over 600 people with learning disabilities during the pandemic (using data collected between December 2020 and February 2021) found that almost half of participants had not had a health check since March 2020. ${ }^{146}$ NHS England advised clinicians that annual health checks should continue during the pandemic, ${ }^{147}$ and ran a public campaign during the winter to encourage uptake. ${ }^{148}$ Data published by NHS Digital suggest the number of checks increased substantially towards the end of 2020/21, and NHS England issued a statement that the target had been met early as a result. ${ }^{149}$

Concern remains about the impact of the pandemic on the health and wellbeing of people with learning disabilities and autism, and their access to services. The Learning Disabilities Mortality Review programme reviewed the deaths of people with learning disabilities with COVID-19 and pointed to difficulties accessing health care before and during the pandemic (including people not being offered annual health checks). It found that in $28 \%$ of the 163 COVID-19 deaths and 30\% of the 43 deaths from other causes, there were problems accessing timely and appropriate health care. ${ }^{150}$

Overall, the ONS estimated that the risk of death involving COVID-19 between 24 January and 20 November 2020 was 3.7 times greater for people with a learning disability compared with those the same age without one. ${ }^{151}$ A study that looked across both waves of the pandemic from March 2020 to March 2021 found the risk of hospitalisation for adults with a learning disability was five times higher than the general population and the risk of death eight times higher. ${ }^{152}$

There is no equivalent information available about the impact of COVID-19 on autistic people. A survey published in September 2020 found that $85 \%$ of autistic people reported that their anxiety had got worse, and were seven times more likely to be chronically lonely than the general population. ${ }^{153}$ 


\section{Mental health}

\section{Summary}

- $\quad$ The long term plan promised a range of improvements to mental health services. The headline goals were to increase the number of adults accessing psychological therapies and increase the number of children and young people using mental health services.

- $\quad$ The plan promised investment in mental health services would increase as a share of the NHS budget by at least $£ 2.3 \mathrm{bn}$ a year by $2023 / 24$, and promised to implement new standards to shorten waiting times for mental health services.

- $\quad$ The number of adults accessing the Increasing Access to Psychological Therapies (IAPT) programme has risen each year, but not quickly enough to meet an earlier target of reaching $25 \%$ of those in need of the service by $2020 / 21$.

- $\quad$ The number of children accessing NHS mental health services has also risen since 2019 and in 2019/20 exceeded a target to reach 34\% of children who needed services that year.

- $\quad$ The commitment to increase investment in mental health services was met for 2019/20, but the pandemic delayed the implementation of new access standards.

- $\quad$ Following the pandemic, there is evidence of increased demand for mental health services, including from children and young people, with urgent referrals $58 \%$ higher in March 2021 than March 2020, and total referrals in March 2021 the highest on record.

The long term plan built on commitments to improve access to mental health services set out in the Five year forward view for mental health. The plan set a number of specific targets for expanding services for children, young people and adults as well as support for common and severe mental health conditions. The Mental Health Implementation Plan, published in July 2019, set out what needed to happen next, including estimates of the spending and workforce needed. ${ }^{154}$ The headline metrics in the implementation framework were limited to four:

1. Increase the number of people accessing Improving Access to Psychological Therapies (IAPT) services.

2. Increase the number of children and young people accessing NHS-funded mental health services.

3. Implement mental health access standards once agreed.

4. Increase the percentage of overall NHS revenue funding spent on mental health services.

National NHS bodies had already committed to expanding IAPT - a programme to provide talking therapies for common mental health problems - to reach 1.5 million people a year by $2020 / 21$. The long term plan extended that target to 1.9 million by $2023 / 24$, including maintaining standards for IAPT waiting times and recovery rates.

Targets also existed for expanding community-based mental health services for children and young people, with the aim of reaching $35 \%$ of children with a diagnosable mental health need by 2020/21 (based on prevalence data from 2004). The long term plan 
expanded this commitment so 'at least an additional 345,000' children could get specialist help by $2023 / 24$, with an ambition to make services available to all who need them by the end of the decade.

The plan also committed to developing a comprehensive set of waiting time standards for mental health services (standards were already in place for IAPT, eating disorder services and early intervention in psychosis). The new standards for emergency mental health services were to come into effect from 2020, with the standards for community-based care to be developed over a longer timeframe to mirror the planned expansion of these services.

The long term plan committed to increase investment in mental health services. Since 2015/16, NHS England has monitored a 'mental health investment standard' to ensure that increases in funding for mental health services were rising in line with overall increases in CCGs' budgets. From 2019/20, investment was required to increase at a faster rate than other parts of the NHS, and CCGs declared spending on mental health was to be independently validated.

\section{Progress prior to the pandemic}

Referrals to IAPT have grown steadily over time: by 2019/20, there were just under 1.7 million referrals, and 1.1 million people entered treatment. However, the goal set for IAPT in the Five year forward view for mental health was for $25 \%$ of people with depression or anxiety to access IAPT services by $2020 / 21$, with targets set for each quarter. In the final quarter of 2019/20,4.86\% of people with depression and anxiety accessed IAPT services against a target of 5.5\%, with the earlier targets in the year also narrowly missed. ${ }^{155}$

According to the most recent data, $36.8 \%$ of children and young people with a diagnosable mental health condition received at least two contacts with services in 2019/20 exceeding the $34 \%$ target for the year. ${ }^{155}$ A 2018 national survey since suggested an increase in the prevalence of diagnosable mental health needs, but NHS England calculated that the trajectory to expand services was still on track.

An assessment by The Office of the Children's Commissioner, drawing on a wider data set than available publicly, offered a more mixed picture. ${ }^{156}$ It found average waiting times had improved (43 days in 2019/20 from 53 days in 2018/19), but that referrals had risen at a faster rate than the number of children accessing treatment: 538,564 children were referred in 2019/20 (an increase of 35\% from 2018/19), while 391,340 had accessed treatment (an increase of $4 \%$ compared with 2018/19).

The interim report of the clinically led review of standards, published in March 2019, set out proposed standards for field testing with selected trusts, community teams and STPs to start by October 2019. ${ }^{157}$ 


\section{Impact of the pandemic}

According to an assessment published by the national mental health team in June 2021, the pandemic has had a 'significant impact on mental health'. ${ }^{158}$ The pandemic brought some positive developments, such as the creation of 24/7 mental health crisis lines (also promised in the plan). But in common with other NHS services, infection control has affected the volume of services that can be delivered, despite the expansion of remote consultations. New mental health problems are likely to have arisen as a result of the pandemic: the national mental health team notes that 'there is consensus that demand will increase'. 159

Data from the IAPT programme show a large fall in referrals in early 2020 (Figure 7). Referrals and treatments (started) recovered from mid-2020 but had not fully returned to their pre-pandemic levels by April 2021.

\section{Figure 7: Impact of the pandemic on IAPT service activity by month, England, January 2020-April 2021}

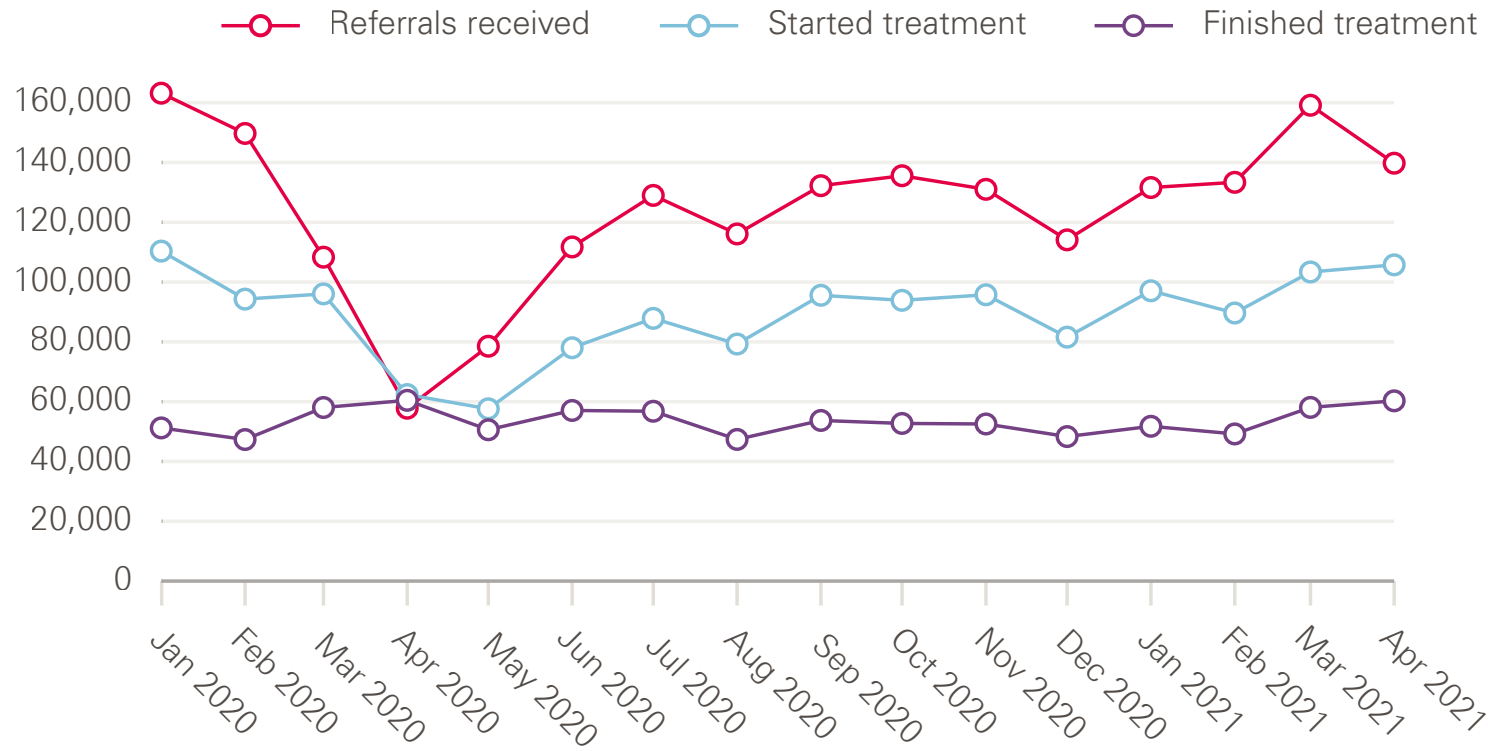

Source: NHS Digital, Reports on the use of IAPT services, 2021

There is evidence the pandemic has increased demand for mental health services for children and young people. NHS Digital's national prevalence survey, published in July 2020 , showed an increase in reported ill health, rising from one in nine 5-16 year olds to one in six. ${ }^{160}$ The Children's Commissioner's analysis showed that if this higher prevalence was sustained, the long term plan's goal of $35 \%$ of children with a diagnosable condition accessing services would not be achieved until 2026/27, assuming services expanded at current rates. The report concluded that, 'The gap between children's needs and the services available, which was already considerable, is likely to have grown much greater." ${ }^{161}$ The latest NHS data suggest that these fears are being realised. Urgent referrals in March 2021 were up 58\% compared with March 2020, while total referrals in March 2021 were the highest on record for a single month. ${ }^{162}$ 
The review of waiting times standards was initially delayed by the pandemic, but final proposals for five new waiting time guarantees were published for consultation in July 2021. These include maximum 4-week waiting times for children and adults referred to community mental health teams to receive some sort of help, intervention or onward referral. Those classified as 'urgent' or 'very urgent' should be seen within 24 hours or 4 hours respectively, while children referred from A\&E should be seen within 1 hour by mental health liaison teams within hospitals. ${ }^{163}$

According to NHS England data, 99\% of CCGs were on track to meet the mental health investment standard for 2020/21, and mental health spending as a result was due to make up $14.4 \%$ of local health spending in 2020/21, compared with 13.1\% in 2015/16. Despite this, bodies that represent commissioners and mental health providers have argued that the mental health investment standard is not adequately linked to need or value, underspending CCGs are not required to improve quickly enough, ${ }^{164}$ and that the inclusion of spending on prescribing can mean that the "standard can be achieved without investing in services'. ${ }^{165}$

\section{Waiting times}

\section{Summary}

- $\quad$ The plan promised to implement a range of new waiting times and clinical standards from April 2020, covering urgent and emergency care, elective care, cancer and mental health.

- Until these were in place, the plan sought to maintain and improve performance against existing cancer treatment, A\&E and elective care standards.

- Work had begun on replacing the old waiting times standards before the plan was published. Details of proposed new standards and pilots were published in 2019, but the pandemic temporarily halted further work on them. New proposed standards have now been developed for mental health, and urgent and emergency care.

- $\quad$ Performance against the original standards was declining before the plan was published. Waiting times continued to deteriorate in 2019, and the pandemic has worsened these, with record numbers of people waiting for elective treatment.

The government signalled possible changes to how the NHS measures and manages waiting times in June 2018, when the National Medical Director was asked to review whether patients would be better served by 'updating and supplementing some of the older targets currently in use'. ${ }^{166}$ The work of the clinically led review of access standards was not complete by the time the long term plan published. As a result, the plan committed to maintaining existing standards and, when agreed, implementing the new standards.

\section{Progress prior to the pandemic}

The interim report of the review, published in March 2019, proposed a range of changes to the existing standards - including to how waiting times and access to A\&E, elective care, cancer care and mental health services would be measured. The aim was to align performance measures with the service changes set out in the long term plan, help improve quality and outcomes of care, and offer a more rounded picture of patient experience. Some 
of the measures had been recommended before, such as a 28-day standard from urgent referral to diagnosis for cancer patients. Others were more tentative and presented as options, such as measuring average waiting times for patients rather than the percentage of patients treated within a fixed time.

A progress report, published in October 2019, set out how the new standards were being tested and early lessons. ${ }^{167}$ In early 2020, NHS England promised that final recommendations from the review would be made for cancer, and urgent and emergency care in spring 2020, and for elective care and mental health by April 2021. ${ }^{168}$ Meantime, delivery of the existing standards continued to steadily deteriorate, despite the expectation that performance would be maintained and improved until the new standards were introduced. This included the percentage of patients in A\&E transferred, discharged or admitted within 4 hours; the percentage of patients starting cancer treatment within 62 days of GP referral; the percentage of patients waiting 18 weeks or fewer to start consultant led treatment; the number of patients waiting more than 52 weeks to start consultant-led treatment; and the elective waiting list size.

\section{Impact of the pandemic}

The pandemic has had a major impact on activity and waiting times across the NHS (Figure 8). New referrals fell as services were only able to accept urgent patients, while the decision to postpone elective care from April 2020 created additional delays for the patients already waiting. A\&E attendances fell substantially after the first national lockdown was imposed in March 2020, before starting to return to pre-pandemic levels by the end of the year. 
Figure 8: Performance against selected waiting time standards, England, January 2019-April 2021

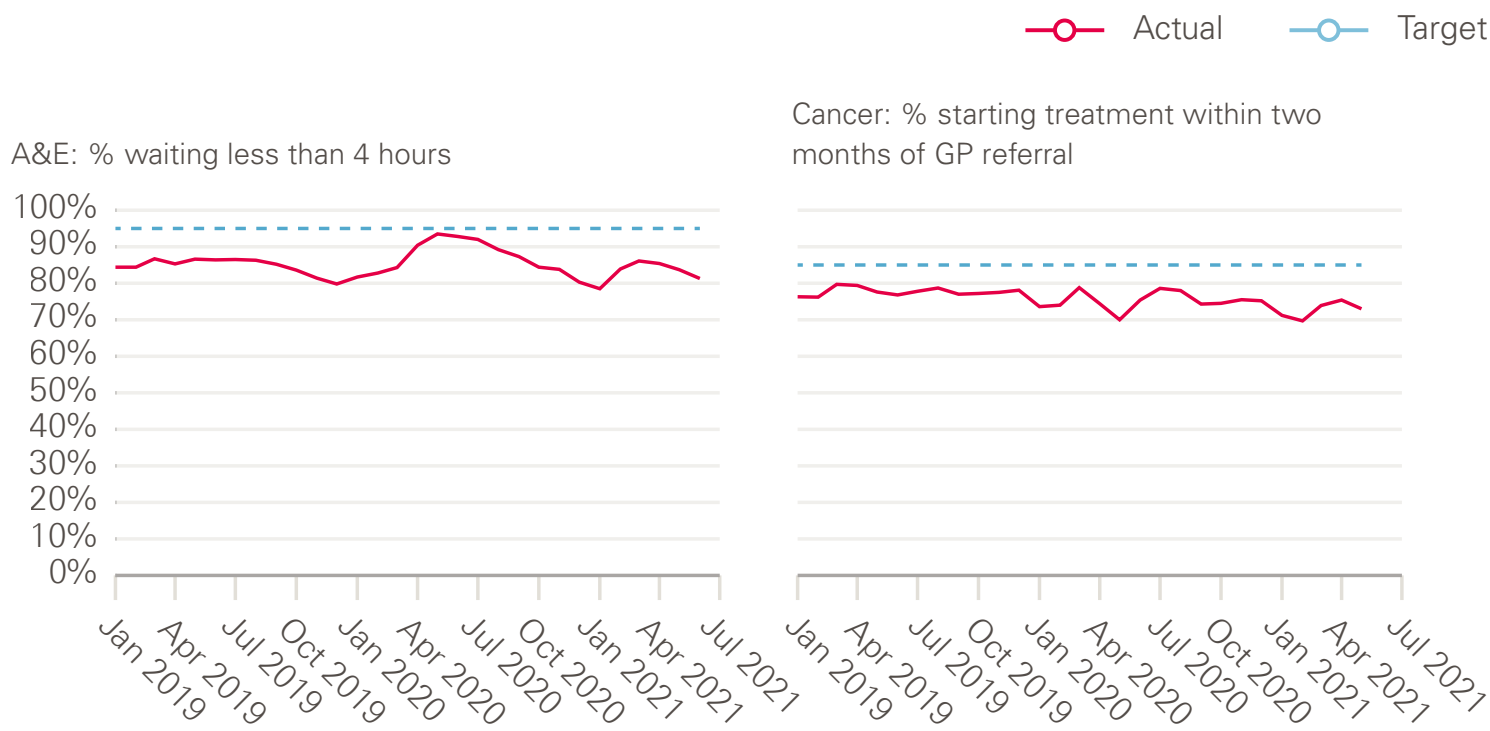

Elective care: \% waiting 18 weeks or less

Elective care: \% waiting 52 weeks or more
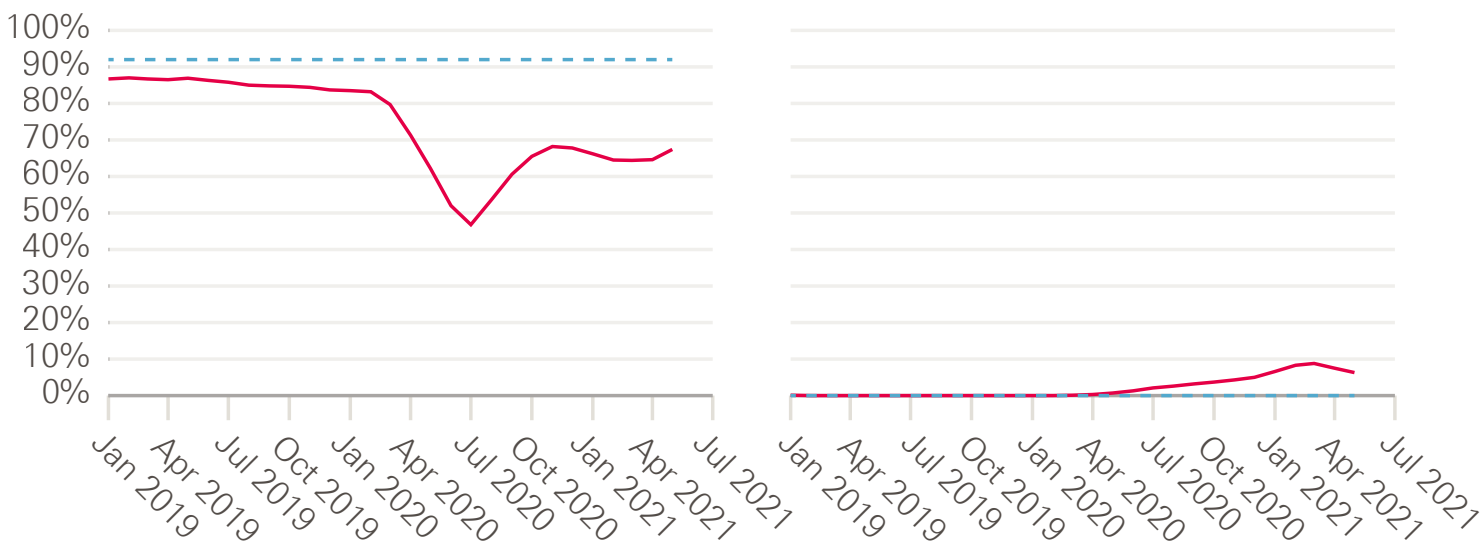

Source: NHSE, A\&E Attendances, 2021, NHSE, RTT waiting times, 2021, NHSE, Cancer waiting times, 2021

Work on the clinically led review of standards was delayed as the pandemic took hold, but concern about infection control in crowded emergency departments led NHS England to prioritise work to replace the 4-hour standard in A\&E. Final proposals for 10 new measures spanning arrival by ambulance and the journey through the emergency department to admission were published for consultation in December 2020. ${ }^{169}$ Instead of recording the number of patients admitted, discharged or transferred within 4 hours of arrival in A\&E, new measures would include: the percentage of patients seen within 15 minutes of arrival; average time spent in the emergency department; the percentage of patients spending more than 12 hours in A\&E from arrival; and performance against time standards for specific urgent conditions (details of which have not been published). A summary of responses to the consultation, published on 26 May 2021, noted the need to clarify how the new standards would be phased in, and how data on performance will be published. ${ }^{170} \mathrm{~A}$ full implementation plan has been promised, subject to approval of the proposals by the Department of Health and Social Care. 
The proposed changes to the urgent care standards received support from the Royal College of Emergency Medicine, which argued that replacing a single measure with multiple measures reduces the risk of gaming and perverse incentives. But it also warned this approach could dilute focus within hospitals, and called for a better performance framework to manage inadequate bed capacity and 'exit block', which leads to overcrowded A\&Es. ${ }^{171}$ Research conducted by Healthwatch England to support the development of new standards found that the overall length of waiting time in A\&E was less important to patients than other factors, including clear communication and measures that support the NHS 'to do things differently, not just count things differently'. ${ }^{172}$

On cancer, the publication of data on performance against the new 28-day 'faster diagnosis' standard began from the start of 2021/22 - 12 months later than the commitment in the long term plan. In June $2021,73.4 \%$ of patients received a cancer diagnosis or a definitive exclusion of cancer within 28 days of an urgent screening referral or urgent GP referral for suspected cancer or breast symptoms. ${ }^{173}$ NHS England expects that performance will reach 75\% between October and December 2021.

\section{4. 'NHS staff will get the backing they need'}

\section{Summary}

- $\quad$ Meeting the long-term plan's ambition to expand the NHS workforce depended on multi-year government investment. This was not in place when the plan was published, and has not been put in place since. No long-term workforce plan for the NHS has been developed.

- $\quad$ New workforce metrics were promised as part of the long-term workforce plan, but until then, 'interim placeholder metrics' were specified, such as reductions in staff sickness and turnover rates, improvements in staff wellbeing and increases in GP numbers.

- $\quad$ Against these, there have been some improvements since the plan was published, including a reduction in staff turnover between 2017 and 2020, and more organisations judged as 'well-led' by the COC.

- $\quad$ Progress is slow on other measures critical to the delivery of new services, such as reducing the nurse vacancy rate and increasing the number of GPs.

- $\quad$ The impact of the pandemic on the workforce has been severe and is still unfolding, with rising rates of sickness absence and mounting concerns about staff wellbeing.

The long term plan acknowledged that in order to make its proposed changes a reality, the 'NHS would need more staff, working in rewarding jobs and a more supportive culture'. Much of the funding needed for expanding the workforce, however, depended on agreeing budgets allocated by government for training, education and continuing professional development, and not covered by the multi-year revenue settlement for NHS England. At the time the plan was published, it was expected that a comprehensive workforce implementation plan, with longer term goals, would emerge in 2019. 
The plan committed to expanding the number of nurses, midwives and allied health professionals in the NHS. It did not quantify the numbers needed, but the 2019 Conservative party manifesto promised an additional 50,000 nurses over the course of the next parliament.

The plan set a target of reducing vacancy rates in nursing from over 12\% in June 2019 to 5\% by 2028 . There were also commitments to growing the medical workforce, including a net increase of 5,000 GPs 'as soon as possible', and to recruit 26,000 professionals in primary care (such as physiotherapists and pharmacists) by 2023/24.

Goals were also set to maximise the capacity of the existing workforce by improving staff retention by at least $2 \%$ by 2025 (the equivalent of 12,400 extra nurses), and reducing the NHS staff sickness absence rate from $4 \%$ to $2.9 \%$ (the public sector average in 2019). The plan also promised action to increase staff wellbeing, with a new metric to be developed.

The quality of leadership was also targeted for improvement, to be assessed by the proportion of organisations judged to be 'good' or 'outstanding' in the 'well-led' domain by the CQC. Finally, the plan conceded that there was more progress to be made in valuing and 'ensuring fair treatment and respect' for the diverse NHS workforce, particularly in relation to staff from minority ethnic backgrounds. The plan promised additional investment in the Workforce Race Equality Standard (a programme set up in 2015 to collect and publish data on ethnic minority groups, of which the NHS is the largest employer in England). It also promised to develop a workforce diversity measure.

\section{Progress prior to the pandemic}

Limited progress had been made on increasing staff numbers. By December 2019, the registered FTE nurse vacancy rate had declined only marginally to $10.7 \% .{ }^{174}$

Between June 2017 and December 2019, the overall number of FTE GPs in England increased by 488 . But, once the numbers of GPs in the final stages of training and locums are excluded, the number of qualified permanent GPs fell by $734 .{ }^{175}$

NHS Digital does not regularly publish data around joiner and leaver rates, but the national retention programme has indicated that in the 2 years to July 2019, national nursing staff turnover rates fell from $12.5 \%$ to $11.9 \%$, and mental health clinical staff turnover rates fell from $14.3 \%$ to $13.4 \%$. Recently published data indicate that the staff leaver rate for hospital and community services doctors in England fell slightly from 7\% to 6.7\% between 2017 and 2019, with the leaver rate for HCHS nurses also falling from $11.7 \%$ to $10.9 \%{ }^{176}$

In the 2 years to December 2019, the NHS sickness absence rate increased from $4.6 \%$ to $4.9 \% .{ }^{177}$ There was some regional variation, with absence rates varying between $4 \%$ (London) and 5.7\% (the North West) in December 2019.

There are limited data to assess progress on leadership, staff wellbeing and diversity in the NHS. We next discuss overall progress against these measures. 
Impact of the pandemic

COVID-19 led to delays in long-term NHS workforce planning. The government published the Interim NHS People Plan in June 2019 and a further people plan in July 2020. But both documents are interim reports and function as 'stop-gaps'. A full people plan is yet to emerge.

Little progress has been made on reducing nursing vacancy rates. The latest available vacancy data from NHS Digital show that the registered FTE nurse vacancy rate in the NHS hospital and community health sector in England remains high, at 9.2\% (in March 2021). ${ }^{174}$ Vacancy rates vary considerably across regions and sectors in the NHS - for example, 21\% of nursing vacancies were in mental health nursing in March 2021 compared with 3\% in community services. And the registered FTE nurse vacancy rate in London (11.6\%) was substantially higher than the rate in the South West of England (6.8\%).

Overall GP numbers in England increased by 480 FTE between December 2019 and June 2021. But the number of qualified permanent GPs (excluding GPs in the final stages of training and locums) fell by 83 FTE, continuing its declining pre-pandemic trend. As NHS Digital introduced significant methodological changes to general practice workforce data in their latest release, understanding the full impact of the pandemic on GP numbers will take time. ${ }^{175}$

It is too early to discern the impact of the pandemic on staff retention. Between September 2019 and September 2020, staff leaver rates for hospital and community services doctors and nurses fell from $6.7 \%$ to $6.1 \%$ (doctors) and from $10.9 \%$ to $9.6 \%$ (nurses). ${ }^{176}$ Staff sickness absence rates have increased since the pandemic, with much of the increase attributable to COVID-19. In January 2021, the rate for England was 5.7\%, ${ }^{178}$ a steep rise relative even to December 2020 (5.1\%) and significantly higher than in January 2020 (4.8\%). $29 \%$ of days lost to sickness in January 2021 were due to COVID-19 across all staff groups (close to a peak of $31 \%$ recorded in April 2020). ${ }^{178}$ The sickness absence rate fell to $4 \%$ in March 2021, with COVID-19 accounting for 11\% of absences.

The plan set out a range of policies to improve leadership, with progress to be measured by the proportion of providers rated 'outstanding' or 'good' by the CQC in the 'well led' domain. Data from CQC State of Care reports ${ }^{179}$ suggest that there have been some improvements. The proportion of NHS acute trusts with an 'outstanding' or 'good' rating increased from 82\% (2018) to 85\% (2020) for mental health trusts.

The plan committed to improving staff wellbeing and developing a composite measure of wellbeing as part of the people plan, which has yet to appear. The NHS staff survey provides an overall theme score for health and wellbeing, based on a number of questions, including levels of stress, opportunities for flexible working and perceptions of trusts taking action on health and wellbeing. ${ }^{180}$ The score declined slightly from 6.0 (2015-2017) to 5.9 in 2019, but recovered to 6.1 in 2020. Interpreting trends is complicated by the impact of COVID-19, with the long-term effect on staff wellbeing not yet known. In $2020,44 \%$ of respondents reported feeling unwell within the past 12 months because of work related stress, up from $40.3 \%$ in 2019 , although there was an improvement in the proportion of people saying their trust definitely took action on staff wellbeing (from 29\% in 2019 to $33 \%$ in 2020 ). 
National planning guidance for 2021/22 asks ICSs to prioritise support for the health and wellbeing of the workforce. There were expectations that all staff should have more flexibility over using annual leave and be able to access occupational health and wellbeing support, including rapid access to psychological and specialist support. The urgency of action to improve the wellbeing of staff after the pandemic was underlined by the Health Committee in June 2021. 'Burnout', according to the committee, 'was described by many as the highest in the history of the NHS and care systems and, as such, it is an extraordinarily dangerous risk to the future functioning of both services. ${ }^{181}$

The pandemic has also increased the sense of urgency to improve conditions for minority ethnic staff. The people plan for 2020/21 noted that 'BAME colleagues have lost their lives in greater numbers than any other group', declaring it 'a time of national awakening'. ${ }^{182}$ In the absence of a new diversity metric, the NHS Staff Survey shows that there is considerable scope for improvement. 13.1\% of respondents in 2020 reported having experienced discrimination at work, with ethnic background being the most common reported reason for discrimination (48.2\% of those who said they have experienced discrimination at work), an increase of over 5 percentage points since 2018 . These findings were amplified in early 2021 with the publication of the performance of the NHS against the Workforce Race Equality Standard in 2020, which showed that there had been increases in the number of very senior managers from minority ethnic backgrounds (from 108 in 2017 to 153 in 2020) and board members (10\% from minority ethnic backgrounds in 2020, up from $7 \%$ in 2017), but no improvement in experience of bullying or harassment, or beliefs about equality in the workplace among minority ethnic staff. ${ }^{183}$

National NHS planning guidance for 2021/22 asks ICSs to develop improvement plans based on the latest Workforce Race Equality Standard findings to improve diversity in recruitment and promotion processes, and accelerate the delivery of 'model employer' goals. 


\section{5. 'Digitally-enabled care will go mainstream across the NHS'}

Summary

- $\quad$ Three headline metrics were proposed to capture progress on the spread of digital technology across the NHS: an increase in the number of people using the NHS app, increasing access to online GP consultations, and providing more digital consultations in outpatient appointments.

- $\quad$ Although some progress had been made before the pandemic, COVID-19 has brought large and rapid increases in the use of digital technologies. Over 10 million people are reported to have downloaded the NHS app (the majority of this growth following the addition of COVID-19 vaccine status in May 2021).

- $\quad$ All general practices were required to implement digital methods for patients to book appointments from March 2020, and remote consultations, including telephone, rose to $70 \%$ of all consultations in the early phases of the pandemic. The proportion of remote versus face to face has since fallen but is still much larger than before the pandemic.

- $\quad$ Data are not published on the proportion of outpatient appointments conducted remotely. Research suggests the proportion of consultations conducted remotely rose from 4\% before COVID-19 to 25\% of all appointments by October 2020.

The long term plan offered an expansive vision of a 'digitally-enabled' future NHS, with technology playing a 'central role' in realising the plan, bringing significant benefits for patients, clinicians and more efficient services. For example, the plan promised that by 2024 hospital services would be 'fully digitised' across all settings, locations and departments'. The headline metrics of progress were focused on three areas: increasing the number of patients accessing their records via the NHS app, improving digital access to primary care and outpatient appointments.

Summary care records contain information based on a patient's GP record and are generated automatically unless a patient has opted out. The record is accessed by the NHS app. The plan promised that by 2020 every patient with a long-term condition would have access to their record via the NHS app. Progress was to be assessed by the proportion of the population who had downloaded the app.

The plan promised to make significant progress in offering patients options to access care digitally. In primary care, all patients were promised 'a new right to choose' a digitalfirst option to see a GP within the next 5 years, defined as 'quick telephone or online consultations'. The implementation framework set goals for ICSs to support delivery in each practice to offer online consultations by April 2020. This was underpinned by changes to the GP contract and $£ 15 \mathrm{~m}$ per year investment for general practice until $2023 / 24 .{ }^{11}$ The development of digital first primary care was to be informed by evaluation from pilot sites, and the findings of a consultation launched in 2019 to find ways to ensure that funding and contracts would support digitally based services.

The plan also aimed to halt the growth in outpatient visits, which had doubled in number over the past decade, by expanding the number of online consultations alongside the redesign of outpatient services. According to the plan, a combination of better online 
booking systems, use of digital appointments and better support for GPs to avoid referrals, was expected to contribute to a goal of reducing the number of face-to-face outpatient appointments by a third (equivalent to 30 million visits) within 5 years.

\section{Progress prior to the pandemic}

In July 2019, NHSX was created, bringing together the Department of Health and Social Care, NHS England and NHS Improvement, to coordinate policy and implementation of new technology and digital tools in the NHS. Data to assess progress against three headline long term plan commitments are limited.

In relation to the NHS app, data are regularly collected on the app's uptake, including new registrations and usage, but these are only available to NHS staff. ${ }^{184}$ In a January 2020 press release, NHS Digital reported that the number of registered users of the NHS app was 'over 200,000' compared with 91,000 at the end of September 2019, following a campaign led by the Chief Nurse to encourage patient and staff uptake. ${ }^{185}$

In general practice, data are collected on the different types of consultations, but only partially capture digital activity (as we explain below). During the period before the pandemic, there was little evidence of increase in either telephone or video consultations in general practice (Figure 9).

Data on whether outpatient appointments were conducted face to face or remotely are not published. In 2019, the Royal College of Physicians, (which has campaigned for reform of outpatient services including greater use of technology), ${ }^{186}$ ran a survey among its members about changes to outpatients. $90 \%$ of respondents had not used video consultations for their outpatient appointments, and $18 \%$ said they had conducted between a tenth and a fifth of consultations by telephone. ${ }^{187}$

\section{Impact of the pandemic}

The pandemic has greatly accelerated the use of digital technology. National bodies led the procurement of digital tools to enable remote consultations across the NHS and provided guidance on information governance to permit the use of non-specialist tools such as Skype. ${ }^{188}$

Use of the NHS app had already started to grow from March 2020 and increased sharply from May 2021, after COVID-19 vaccine status was added to the app, increasing by 6 million to a total of 10 million. ${ }^{189}$

During the pandemic, the NHS developed a separate COVID-19 app, which contained information about COVID-19 risk levels and supported contract tracing. By the beginning of May 2021, the app had been downloaded over 23.5 million times. ${ }^{190}$

COVID-19 has brought significant changes in the delivery of GP appointments, with practices asked to implement remote triage to establish whether patients needed face-toface appointments, or a telephone, video or other kind of remote consultation. GP appointments data collected by NHS Digital are classified as 'experimental data', and only 
partially capture telephone triage and online consultations. ${ }^{191}$ Nevertheless, the data show a sharp fall in face-to-face appointments and subsequent rise in telephone consultations (Figure 9).

\section{Figure 9: Numbers of face-to-face, telephone and online consultations in general practice, England, January 2019-December 2020}

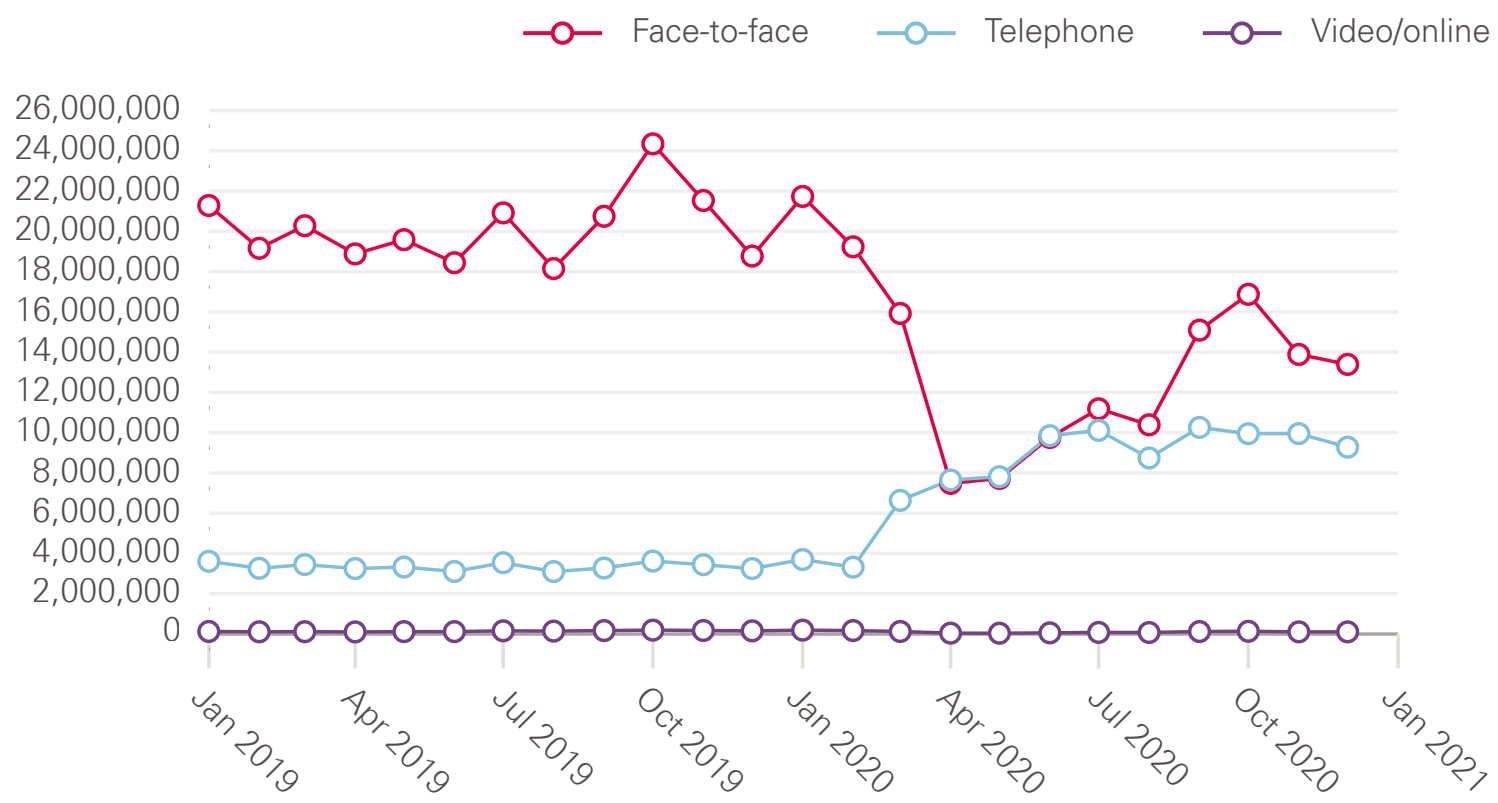

Using data from a smaller sample of practices, the Royal College of General Practitioners reports that during the first national lockdown in 2020, 70\% of GP appointments were conducted remotely (via telephone or video), compared with $70 \%$ conducted face to face pre-pandemic. ${ }^{192}$ The proportion of face-to-face appointments in general practice was higher in subsequent lockdowns, but by March 2021 remote consultations still exceeded the proportion of face to face for all practice appointments (accounting for $54 \%$ of all appointments versus face to face, which represented $46 \%$ of all appointments).

In May 2020, NHS England announced that progress towards the long term plan goal had been accelerated, with $99 \%$ of GPs using 'remote consultation platforms' with 'millions of patients getting expert support from family doctors from the comfort of their own homes'. 193

Doubts emerged later in the pandemic about the extent to which patients had a choice of mode of appointment, as originally envisaged. On 13 May 2021, NHS England advised general practices to ensure that patients were able to choose face-to-face appointments (unless there were clinical reasons not to). It also advised that appointments should be available to patients who visit practice receptions, not just via online or phone triage systems, which had been required at the start of the pandemic to minimise risk of infection. ${ }^{194}$ A second metric, 'access to GP appointments', has yet to be developed.

Data on the proportion of outpatient appointments conducted remotely are collected (through Hospital Episode Statistics) but not published. A study of hospital outpatient data between December 2018 and October 2020 found that remote consultations 
(by telephone or telemedicine) accounted for $4 \%$ of all outpatient attendances before the pandemic. The impact of COVID-19 led to a significant increase in the proportion of remote consultations, rising to a high of $35 \%$ in April 2020 before falling back to $25 \%$ of all consultations in October 2020 (despite an increase in the overall number of consultations as services recovered after the first wave of COVID-19). ${ }^{195}$

\section{6. 'Taxpayers' investment will be used to maximum effect'}

\section{Summary}

- $\quad$ The government set five financial tests for the NHS in return for the increase in funding granted in 2018. These were for the NHS to return to financial balance, improve productivity, reduce growth in demand for care through better integration, reduce variation in performance across the health system, and make better use of capital investment.

- In 2019/20, the NHS was in overall financial balance and the percentage of organisations in financial balance increased. Large increases in funding were released to the NHS to respond to COVID-19, but it is not yet known what impact this will have on the finances of individual organisations.

- Improvements in productivity had slowed in 2018/19 before the pandemic. The impact of COVID-19 on productivity is not yet known. Infection control measures brought in response to the pandemic has reduced the number of NHS patients that can be treated, but digital access may have had improved productivity in some areas.

- $\quad$ Although some funding has been released for both COVID-19 and non-COVID-19 capital projects since the plan was published, a multi-year capital budget has still not been agreed.

In return for the 2018 funding settlement underpinning the long term plan, NHS England agreed to put the NHS 'back onto a sustainable financial path'. To achieve this, the government set five financial 'tests' that had to be met.

The first test was that the NHS would continue to achieve 'overall financial balance' every year. It would also need to reduce the overall NHS provider sector deficit (with the sector to achieve financial balance by 2020/21), and reduce the number of individual NHS organisations in deficit (with all organisations to be in financial balance by 2023/24). The percentage of organisations in financial balance was the key measure of this.

Achieving cash-releasing productivity growth of at least $1.1 \%$ per year formed the basis of the second test. As the plan pointed out, NHS productivity had increased more rapidly than in the wider economy in recent years. The plan therefore set out a series of measures to secure better value for money, including using e-rostering to make more use of clinical staff time and extending the large-scale procurement of clinical equipment.

The third test was to reduce growth in the demand for care through better integration of services and preventive interventions, which was to be measured by change in elective hospital activity. Reducing unjustified variation in performance across the NHS was the fourth financial test. Many of the plan's goals to improve care for conditions and population groups mentioned reducing unwarranted variation in the provision of services. 
The fifth and final test was to make 'better use' of capital investment and existing NHS assets to drive transformation in services. The plan acknowledged that in recent years, investment in capital had been lower than other comparable OECD countries as share of GDP, with the UK ranked 21st lowest out of 27 countries in 2018. A long-term capital settlement was expected in the 2019 Spending Review.

\section{Progress prior to the pandemic}

Even though the NHS as a whole was in financial balance in 2018/19, the NHS provider sector was not, and had been in deficit since 2013/14. ${ }^{196}$ The plan promised to create a new financial recovery fund to target support to the most financially challenged NHS organisations. Before the pandemic, the NHS was on track to achieve overall financial balance for 2019/20, ${ }^{197}$ with a reduction in the number of providers in deficit from 107 in 2018/19 to 55 in 2019/20. ${ }^{198}$

In relation to the second test, measuring productivity is complex. The ONS produces productivity estimates - though these are not necessarily the yardstick used by NHS England. The most recently available annual data from the ONS (covering the period up to March 2019) estimated that health care productivity in the UK declined by $0.5 \%$ (in 2018/19), the first annual decline since 2009/10. ${ }^{199}$ This was driven by faster growth in inputs (for example the cost of labour, drugs and equipment) than growth in outputs (such as the volume of treatments given). However, quality measurement remains a matter of contention. On a quality adjusted basis (which accounts for factors such as health gain and waiting times), the ONS estimated that annual UK health care productivity fell by $0.9 \%$ in 2018/19.

Reducing growth in hospital activity by closer integration of services (the third test) was dependent, according to the plan, on the creation of ICSs. Evidence that integration can achieve these objectives is limited. While more integrated services may improve patient satisfaction, access to services, and perceived quality of care, evidence on reductions in resource use is inconsistent and limited - and potential benefits, where they exist, are likely modest and take time to be delivered. ${ }^{200,201,202}$ Despite multiple pilots and initiatives to improve integration between 2008/09 and 2018/19, emergency admissions grew $1.5 \%$ a year, 0.4 percentage points per year more than would be expected from population growth and ageing. ${ }^{68}$

On reducing variation, the plan had promised to develop a measure and 'radically improve transparency' in relation to this goal. The plan emphasised the work already begun via programmes such as Getting It Right First Time, the Model Hospital and NHS RightCare. All of these initiatives generate data for organisations to use for improvement, but are not designed to assess progress at a national level.

Although the plan highlighted the UK's poor performance on capital investment relative to comparable OECD countries, a multi-year settlement for all Department of Health and Social Care capital spending did not materialise. The government increased capital spending limits by $£ 1.1$ bn for 2019/20 and published its Health infrastructure plan. This set out a 5-year plan for new hospitals, equipment and other improvements to be underpinned by a future long-term capital review. ${ }^{203}$ By 2019/20 , backlog maintenance costs in the NHS had grown to $£ 9 b n .^{204}$ 
Impact of the pandemic

COVID-19 led to significant increases in NHS spending. NHS England also temporarily changed financial arrangements, including by allocating money directly to local areas to avoid delays in reorganising services. ${ }^{18}$ In June 2021, NHS England's draft accounts reported that an additional $£ 7.8 \mathrm{bn}$ COVID-19 funding was allocated directly to local areas during the previous 12 months.

NHS England estimates that in 2020/21 COVID-19 cost NHS providers $£ 2.1 \mathrm{bn}$ in lost income, $£ 2.7 \mathrm{bn}$ in additional pay costs, and a further $£ 2.4 \mathrm{bn}$ in other costs. But set against the additional funding provided by government to cover costs relating to COVID-19, NHS organisations ended the financial year in 2020/21 with a small surplus. ${ }^{205}$

The pandemic is likely to have led to a fall in NHS productivity because of the major changes to services to control infection. Quarterly experimental data from the ONS (not adjusted for quality) suggest that public service productivity as a whole fell by $22.4 \%$ between July and September 2020, driven by increased health care and social protection spending and a fall in the provision of education and health and social care services due to the pandemic. ${ }^{206}$ The resumption of some public services (including health services) saw an improvement between October and December 2020, but productivity nevertheless fell by $13 \%$ compared with the same quarter in 2019. ${ }^{207}$

The full impact on productivity will not be known for some time, given lags in data required to measure this in the NHS. Ongoing debates around measuring productivity will also need careful consideration, particularly in terms of defining quality in a highly unusual year and understanding the impact of shifts in care, such as the rapid adoption of digital technology. ${ }^{208}$

It is not straightforward to disentangle the implications of COVID-19 for capital spending from longer term capital investment initiatives driven by pre-pandemic government priorities. The arrival of the pandemic brought additional and urgent demands on capital spending, as organisations rapidly reconfigured services. The government injected a further $£ 1.5 \mathrm{bn}$ of funding into NHS buildings and capacity in June 2020. ${ }^{209}$ The March 2021 Budget allocated a total of $£ 13$ bn to capital spending in health and social care in 2020/21 ( $£ 8.5 \mathrm{bn}$ in core funding and $£ 4.5 \mathrm{bn}$ in COVID-19 funding), but the proportion allocated to the NHS capital budget is unclear. ${ }^{26}$ NHS England's estimates suggest that there was an overall capital underspend of 1.2\% for the financial year ending March 2021, (with providers estimated to have spent $£ 7.1 \mathrm{bn}) .{ }^{18}$

From a longer term perspective, previous Health Foundation analysis suggested that the 2020/21 NHS capital budget would need to see sustained increases to $£ 10.5 \mathrm{bn}$ by $2023 / 24$ to meet the plan commitments. This analysis suggested that the 40 new or redeveloped hospitals promised by the government would require far in excess of the $£ 6 \mathrm{bn}$ allocated to them so far. Moreover, any construction delays resulting from the COVID-19 lockdowns are likely to have pushed back this infrastructure agenda. It also called for significant increases in capital investment over the next few years, particularly in mental health and diagnostic services. 


\section{Discussion}

COVID-19 is the biggest challenge the NHS has faced in its 72-year history. The impacts of the pandemic on people's health and the health service are likely to be felt for many years to come. In this context, it is no surprise that the NHS's previous plan for improvement and reform has been significantly blown off course. Our assessment of progress against the headline ambitions of the NHS Long Term Plan illustrates how no part of the NHS has been unaffected by the pandemic.

The impacts of COVID-19 are not all negative: some progress has been accelerated, most notably in digital access to services - though these changes come with risks and may have unintended consequences. Fledgling PCNs have played a vital role in delivering vaccinations on a massive scale. And the principle of collaboration underpinning the recent direction of NHS policy was activated on a large scale as the health and care system rapidly reorganised services.

But in many other areas, the overall picture is one of major delay, disruption and increased demands on services. There have been delays to new community rapid response services, developing new waiting time standards, and developing new services within PCNs. There has also been serious disruption to elective care and screening, and a major backlog of people waiting for routine treatment is compounded every day by limitations on services while the virus remains in circulation. The need to make progress on existing priorities has also been amplified - including the need for stronger action to address the heath inequalities exacerbated by COVID-19.

What does this all mean for the future direction of the NHS? How should priorities be refocused? In this section, we draw out the implications from our assessment of progress against the long term plan for NHS policy and priorities as it plans its recovery from the pandemic.

\section{Waiting times}

\section{There are insufficient resources to address the growing backlog and lengthening waits}

The health service's response to the acute phase of the pandemic has been widely praised. But it has come at heavy cost. Some routine services were deprioritised or suspended entirely at the height of the pandemic. Where non-COVID-19 services continued, they were redesigned to support infection control, which reduced the number of patients that could be seen. The crisis erupted into a hospital sector that was already struggling to reduce waiting times. ${ }^{210}$ As services started to recover from mid-2020, the numbers of patients newly referred onto waiting lists were added to the numbers of patients whose treatment was postponed because of the pandemic. 
The result is a large and growing backlog: the number of people waiting for routine hospital care in England has now reached 5.45 million. ${ }^{211}$ There is limited evidence available about the experience of patients waiting. Insights from patients collected by National Voices suggest that many people on waiting lists are anxious and concerned about their conditions getting worse. ${ }^{212}$ Other research suggests that delays to surgery are likely to have serious consequences: higher mortality in cancers, ${ }^{213}$ and worse outcomes for patients needing joint replacements, ${ }^{214}$ to take just two examples.

The long term plan devoted limited attention to the challenge of reducing waiting lists, based on a calculation that the additional funding for NHS services would enable a year-on-year improvement. It instead offered a vision of progress in outcomes against major diseases, such as cancer and stroke. But the pandemic is likely to have had a major impact on many of these goals.

Take cancer as an example. Cancer charities are concerned that the disruption caused by COVID-19 may stall or even reverse improvements in cancer survival across the UK. ${ }^{215}$ Achieving the long term plan commitment to increase early diagnosis of cancer may take much longer than expected, given the cumulative impact of delays to urgent referrals, suspension of screening services, increases in emergency presentations, and the backlog of over 62-day waits. A cancer recovery plan has been launched by NHS England, but cancer charities argue that government needs to do more than just return cancer services to pre-pandemic levels. Delivering earlier diagnosis, getting clinical trials up and running again and building personalised support for cancer patients will need sustained action. This includes investment to address the shortages in workforce and diagnostic capacity already apparent before COVID-19. For example, Cancer Research UK has estimated that an additional 41,000 clinical staff will be needed by 2029, over and above existing planned increases, in order to deliver improvements to services. ${ }^{216}$

\section{New pressures from COVID-19}

For mental health services, COVID-19 will have directly generated additional demand beyond that envisaged in the long term plan. Estimates vary, from 10 million people needing new or additional mental health support ${ }^{217}$ to 1.8 million people with new, recurring or worsening mental health problems over the next 3 years. ${ }^{218}$ Mental health charities report a surge in demand for help, driven by the impact of the pandemic, including bereavement and loss of employment. ${ }^{219}$ The Royal College of Psychiatrists has warned that progress on some wider national policy goals has stalled, including reducing out of area placements, reducing waiting times for eating disorders and expanding physical health checks for people with severe mental illness. ${ }^{220}$ As with cancer services, workforce shortfalls are hampering progress, with 71 new consultant psychiatrist posts expected be recruited on current trends, against a target of 470 by 2023/24, and 257 mental health nurses by the same date against a target of 7,000.221

COVID-19 has also created novel sources of pressure on NHS capacity. The national vaccination programme is an unexpected additional demand on resources, which will likely need to be maintained in some form for the foreseeable future. This will have implications for general practice and PCNs, which have been central to the success of the programme thus far. At the same time as running a large proportion of the vaccination programme, 
demand for general practice had rebounded in excess of pre-pandemic levels, leading to warnings of burnout from the profession. ${ }^{222} \mathrm{~A}$ well-functioning general practice sector is central to many of the long term plan goals, including early cancer diagnosis and health care for those with learning disabilities, and people in care homes.

General practice will also be the first point of contact for those with chronic side effects from COVID-19. NHS England has allocated $£ 100 \mathrm{~m}$ for 'long COVID' care, including $£ 30 \mathrm{~m}$ for general practice. ${ }^{223}$ The National Institute for Health and Clinical Excellence has published guidance on the range of staff who might be needed for these services, including specialists from respiratory medicine, physiotherapy, occupational therapy, psychiatry and rehabilitation medicine. ${ }^{224}$ All these services will need to be provided in addition to existing long term plan priorities, and as the virus continues to circulate, the numbers of patients will undoubtedly increase.

The government has recognised these challenges and has increased funding, but considerable uncertainty remains about the extent to which COVID-19 will continue to disrupt services. In March 2021, the government announced a cross-government recovery plan for mental health and wellbeing. ${ }^{225}$ This included details of an additional $£ 500 \mathrm{~m}$ to be spent in 'recognition of the pressures mental health services are likely to face in the coming years'. At the same time it also released $£ 1$ bn for the first half of $2021 / 22$ to reduce the elective care backlog. The experience of the 2000s shows that the NHS and its staff can reduce long waiting times, given sufficient time and resources to do so. ${ }^{226}$

In September 2021, the government announced additional funding for the NHS to clear the backlog, amounting to an extra $£ 2$ bn a year from $2023 / 24$ to $2024 / 25$. 27 Projections by the REAL Centre suggest that, to put the NHS on course to clear the backlog by $2024 / 25$, NHS England's budget needs to increase by a minimum of $£ 7.1 \mathrm{bn}$ in $2022 / 23$. This would cover increases in underlying pressures, the costs of implementing existing long term plan commitments and meeting increased demand for mental health services - but does not include the immediate costs of dealing with COVID-19 or, crucially, any ongoing impact of the virus on the NHS's ability to deliver care.

\section{Prevention and inequalities}

\section{Stronger NHS action and broader measures are needed to tackle inequalities}

Addressing the major backlog in elective care is likely to be a highly visible and political priority for the NHS as it recovers from the pandemic. The Prime Minister has said that his government will do 'whatever it takes' to 'beat the backlog'. ${ }^{228}$ But there is a risk that wider objectives - particularly those that lack clear goals and measures of progress - receive less attention. 
Before the pandemic, the long term plan made ambitious statements about increasing the NHS's role in tackling health inequalities and preventing ill health. But the plan was lacking detail about how this would be done beyond specific goals on smoking, alcohol and obesity. Local 5-year plans - backed by the allocation of funding according to unmet need and the development of a new set of inequalities measures - were intended to be the primary vehicle for NHS action on inequalities. But the ICS planning process had already been delayed prior to its suspension at the outset of the pandemic, and the new measures have still not been published. Previous versions of these 5-year plans focused primarily on individual level approaches to disease prevention and few included interventions addressing the wider determinants of health. ${ }^{229}$

COVID-19 has exposed and amplified existing health inequalities in England, with the most socioeconomically deprived communities facing the greatest risks to health. National NHS leaders have responded by setting what actions local areas should be taking to reduce health inequalities as part of the COVID-19 recovery, such as restoring NHS services inclusively and strengthening leadership and accountability. But detail on how these actions should be delivered is limited and it is unclear how much progress has been made. A more detailed framework of priorities, interventions, and measures for NHS agencies on tackling inequalities will be needed to ensure that greater awareness of inequalities is translated into tangible action to reduce them.

NHS services for smoking, alcohol and obesity are resuming post-pandemic, but comprehensive action to address these risk factors is also dependent on wider central government policy, which has been affected by the pandemic. The publication of next steps for delivering on the government's ambition for a smoke-free society, ${ }^{230}$ for example, was delayed by the pandemic and was expected as part of the new Tobacco Control Plan for England due in summer 2021. ${ }^{231}$ The 2021 Budget announced over $£ 70 \mathrm{~m}$ for weight management services, with investment to be focused on parts of the country most affected by COVID-19.

The NHS cannot prevent disease and reduce inequalities on its own. ${ }^{232}$ Greater action on prevention and inequalities within the health care system must be supported by a much broader range of public policy interventions designed to give more people the opportunity to live a healthy life. ${ }^{233}$ The government has announced a white paper on 'levelling up' for later in 2021, but it is not clear whether it will cover health. Government currently has no national strategy for reducing health inequalities in England. And, after the allocation of the public health grant of $£ 3.3 \mathrm{bn}$ for $2021 / 22$, local government faces a real terms per capita reduction of $24 \%$ compared with $2015 / 2016 .{ }^{234}$

\section{Innovation}

\section{Service changes made during COVID-19 need evaluation to prevent widening inequalities}

As part of the COVID-19 response, a number of long term plan commitments were accelerated - notably, improving access to online consultations in primary care and reducing the number of face-to-face outpatient appointments. The almost overnight 
switch to online and mainly telephone-based services in the NHS was hailed in July 2020 by Matt Hancock as one of the successful and irreversible changes brought about by the pandemic: 'From now on, all consultations should be teleconsultations unless there's a compelling clinical reason not to. ${ }^{235}$

However, it would be premature to 'lock in' the current volume of remote appointments in primary and secondary care until more is known about their impact on both patients and staff. Public polling suggests that people with experience of technology-enabled care during the pandemic were generally positive that their care had been able to happen, but most believed it was no better than face-to-face care and some thought it was worse. ${ }^{236}$ A similar mixed picture has emerged from research with patients. A survey of patients using mental health services conducted by Mind during 2020 found that $49 \%$ of patients who took up the offer of mental health support on the phone or online said it was easy to use, but $35 \%$ reported finding it difficult, often because of unreliable technology. ${ }^{237}$ An exploration of the experiences of patients known to be 'digitally excluded' because of poor access to technology found that remote access to general practice brought benefits for some, for example carers or patients with mobility problems, while others struggled to navigate remote booking systems and failed to access care. ${ }^{238}$

There is also limited understanding of the impact on staff of using remote methods to consult with patients. Researchers who modelled the impact of digital-first consultations in general practice found it had the potential to increase workload by up to a third. ${ }^{239}$

Robust evaluation of the complex service changes introduced during the pandemic will be needed to understand what worked, for whom, and in what contexts. ${ }^{240}$ There are real risks that inequalities in access to care could be widened, because not all people have access to technology, have enough digital skills, or live in homes where private consultations cannot take place. ${ }^{241}$

\section{Delivering improvements}

\section{Creating new structures will not be enough to deliver improvements}

The long term plan was based on the idea that greater collaboration would improve care and manage resources more efficiently. NHS leaders have made progress in establishing the new structures designed to deliver this: PCNs and ICSs. 1,200 PCNs were established in 2019, and NHS England announced that 42 ICSs had been created by April 2021. New legislation is likely to put ICSs on a statutory footing from 2022.

But these new structures are still early in their development ${ }^{242}$ and there is a risk that the expectations being placed on them are unrealistic. Past evidence from 'large scale' general practice suggests that implementation will take several years and - even then - clinical or financial benefits are not a given. ${ }^{243}$ Evidence is also limited that closer collaboration between organisations and services improves health outcomes. ${ }^{244}$ Both PCNs and ICSs will require time and resources to operate effectively. Establishing new agencies is something that the NHS is good at, but making collaboration work in practice depends on culture, 
management, resources, and other factors. Organisational change in the NHS risks disruption. ${ }^{245}$ It is still unclear how ICSs will operate and what role PCNs will play in the new NHS structure.

PCNs have played a central role in delivering COVID-19 vaccines, but the implementation of other planned services has been delayed and expectations for PCNs will need to be reset. The role that ICSs have played since the long term plan is more challenging to assess. Lack of transparency was a key concern in the early development of STPs. ${ }^{246}$ An STP 'dashboard' was produced - once - in 2017, but the metrics to assess performance were skewed towards hospital care and the overall ratings produced were contentious. ${ }^{247}$ If ICSs are to become statutory bodies, clarity on their objectives and how they will be assessed and publicly reported is essential. NHS England has produced a framework on how ICSs will be assessed and managed, using more than 70 performance metrics, but it is not yet clear whether these will be published. ${ }^{248}$

More broadly, data on progress against the objectives in the long term plan were difficult to find and the available metrics often fail to align with the original commitments. Metrics on alcohol care teams, for example, are based on the number of hospital sites with services, rather than the number of trusts with comprehensive services. Data on participation in the Diabetes Prevention Programme is based on offers of participation rather than acceptance of support. Plans for a metric on SDEC utilisation have not yet led to published dataand progress reported by NHS England is at odds with reports from the Royal College of Emergency Medicine, Society of Acute Medicine, and others. There are some exceptions, such as the Mental Health Dashboard, which contains some data at ICS and CCG level, and shows progress against national targets. The National Cancer Registration and Analysis Services also publishes a wealth of data, much of it available at sub-national levels. Future national plans for the NHS should have clear measures of progress that are transparently tracked and reported.

\section{Wider spending and reform}

\section{Progress depends on wider government spending and reform}

The long term plan made clear that progress in achieving the NHS's objectives could only go so far without additional policy action and investment from central government. Improving NHS services depended on government investment in education and training budgets and decisions on NHS capital spending. And improving people's health depended on adequate investment in social care and public health services, and wider policy action to improve social and economic factors that shape health. Yet government action on these issues has been limited and largely short term.

For the NHS, the most glaring gap in government support is the continued omission of a fully funded, long-term plan for expanding and supporting the NHS workforce. The addition of manifesto commitments on workforce, such as the promise of 50,000 additional nurses, is not a substitute for this. Increasing the nursing workforce will 
need to take account of varying patterns of regional workforce demand and respond to demographic shifts in the nursing workforce (such as the implications of an ageing community nursing workforce). ${ }^{249}$

Praise for NHS staff has yet to be translated into a comprehensive programme of reward and support. The pandemic has seen many NHS staff working under enormous pressure for an extended period, leading to growing concerns about retention and health and wellbeing. The government's response to the pay review body report has not resolved broader questions about the value the government attaches to the work of all NHS staff, particularly nurses and other non-physician roles. ${ }^{250}$ While COVID-19 has raised interest in NHS careers, recruitment will continue to be constrained by the time taken to train new recruits and limited funding for expanding training places. Relying on international recruitment to plug the gap is complicated by COVID-19, as well as the post-Brexit immigration system.

Although a 5-year Health infrastructure plan has been published for the NHS, without a long-term funding commitment this remains incomplete and largely aspirational. There is no long-term certainty over funding for local government public health services, while other broader national strategies for improving health have been delayed during the pandemic. Government plans for levelling up the country after the pandemic have been largely silent on health. ${ }^{251}$

Successive prime ministers have made commitments to 'fix' adult social care, but plans have only now partially emerged. After repeated delays, plans for a cap on social care costs were announced in September 2021. While a bold and positive step forward that will start protecting people from incurring catastrophic costs, this falls well short of what is needed to stabilise the current system and deliver the comprehensive reform needed to increase access and improve the quality of care. 


\section{Conclusion and recommendations}

COVID-19 has had a fundamental impact on health and health care in England. The long term plan set out a 10-year strategy for improvement and reform in the NHS. The core principles set out in the plan - of expanded primary and community services, stronger action on prevention and health inequalities, better access to high quality care - remain as relevant now as they were before COVID-19. But implementation of the plan has been derailed by the pandemic and new pressures and priorities have emerged.

The scale of the challenges facing the NHS after the pandemic is enormous - including addressing the growing backlog of unmet health care need, fixing longstanding staffing shortages, boosting action on wide and unjust health inequalities, and more. Resources to address these challenges are constrained. There needs to be an updated strategy for improvement and reform that accounts for the impact of COVID-19. Our analysis points to several priorities for the NHS and government to guide this:

- Government must recognise the urgency of reducing care backlogs but also the importance of improving health and reducing inequalities across the population. Significant investment will be needed over the long term - including to expand the NHS workforce and improve NHS infrastructure.

- National NHS bodies must give a realistic assessment of the time and resources needed to address unmet need for NHS services, alongside new demands created by the pandemic. This should include goals for what can be delivered by when, given constraints on the NHS workforce.

- National NHS bodies must also set out the investment needed in primary, community, mental health, and other services to achieve the plan's vision for better prevention of ill health, earlier diagnosis, and care for major conditions. Ambitions in the long term plan must be reassessed.

- Action to address the backlog in elective care must not come at the expense of interventions to prevent disease and reduce health inequalities. A more detailed framework of priorities and interventions for NHS agencies to tackle health inequalities is needed to help ensure progress.

- Wider government investment is also needed to improve health and reduce health inequalities, not just increased spending on the NHS. This includes investment in social care, public health, and other services that shape health. Continued underinvestment will hold back NHS progress.

- As new NHS integrated care systems are developed, greater clarity is needed on their objectives and how progress against them will be assessed and publicly reported. Future national plans for the NHS should include clear measures of progress that are transparently tracked and publicly reported each year. 


\section{References}

1. UK government. The Prime Minister's Office PM Speech on the NHS; June 2018 (www.gov.uk/government/ speeches/pm-speech-on-the-nhs-18-june-2018).

2. BBC News. Election results 2019: Boris Johnson's victory speech in full. BBC News; 13 December 2019 (www.bbc.co.uk/news/election-2019-50777071).

3. UK government. Coronavirus (COVID-19) in the UK: Deaths in the UK. Gov.uk; 2021 (https://coronavirus.data. gov.uk/details/deaths).

4. Office for National Statistics. Prevalence of ongoing symptoms following coronavirus (COVID-19) infection in the UK. ONS; 4 June 2021 (www.ons.gov.uk/peoplepopulationandcommunity/healthandsocialcare/ conditionsanddiseases/bulletins/prevalenceofongoingsymptomsfollowingcoronaviruscovid19infectionintheuk/ 4june2021).

5. Resolution Foundation. Jobs market enters new phase as firms go on hiring spree but UK still has 4.2 million 'Covid employment gap' to fill. Resolution Foundation; May 2021 (www.resolutionfoundation.org/press-releases/ jobs-market-enters-new-phase-as-firms-go-on-hiring-spree-but-uk-still-has-4-2-million-covid-employment-gapto-fill).

6. Suleman M, Sonthalia S, Webb C, Tinson A, Kane M, Bunbury S et al. Unequal pandemic, fairer recovery: The COVID-19 impact inquiry report. The Health Foundation; 2021 (https://doi.org/10.37829/HF-2021-HL12).

Shembavnekar N, Allen L, Idriss O. How is COVID-19 impacting people working in adult social care? The Health Foundation; 2021 (www.health.org.uk/news-and-comment/blogs/how-is-covid-19-impacting-people-working-inadult-social-care).

8. National Audit Office. COVID-19 cost tracker. NAO (www.nao.org.uk/covid-19/cost-tracker).

9. Kraindler J, Rocks S, Charlesworth A, Tallack C, Barclay C, Idriss O, et al. Spending Review 2020: Managing uncertainty. COVID-19 and the NHS long term plan. The Health Foundation; 2020 (www.health.org.uk/ publications/long-reads/managing-uncertainty).

10. National Audit Office. NHS financial management and sustainability. NAO; 2020 (www.nao.org.uk/report/nhsfinancial-management-and-sustainability).

11. NHS England. NHS Long Term Plan Implementation Framework. NHS England; 2019 (www.longtermplan.nhs. uk/wp-content/uploads/2019/06/long-term-plan-implementation-framework-v1.pdf).

12. NHS England. Long Term Plan Headline Metrics. NHS England (www.longtermplan.nhs.uk/headline-metrics).

13. Dunn P, Allen L, Cameron G, Malhotra AM, Alderwick H. COVID-19 policy tracker. The Health Foundation; 2021 (www.health.org.uk/news-and-comment/charts-and-infographics/covid-19-policy-tracker).

14. NHS England. Implementing the NHS Long Term Plan: Proposals for possible changes to legislation. NHS England; 2019 (www.longtermplan.nhs.uk/wp-content/uploads/2019/02/nhs-legislation-engagementdocument.pdf).

15. NHS England and NHS Improvement. The NHS's recommendations to Government and Parliament for an NHS Bill. NHS England; 2019 (www.england.nhs.uk/wp-content/uploads/2019/09/BM1917-NHSrecommendations-Government-Parliament-for-an-NHS-Bill.pdf).

16. NHS England. NHS Operational Planning and Contracting Guidance 2020/21. NHS England; 2020. (www. england.nhs.uk/wp-content/uploads/2020/01/2020-21-NHS-Operational-Planning-Contracting-Guidance.pdf).

17. Ferguson N, Laydon D, Nedjati-Gilani G, Imai N, Ainslie K, Baguelin M, et al. Report 9: Impact of nonpharmaceutical interventions (NPIS) to reduce COVID-19 mortality and healthcare demand. Imperial College COVID-19 Response Team; 2020 (www.imperial.ac.uk/media/imperial-college/medicine/sph/ide/gidafellowships/Imperial-College-COVID19-NPI-modelling-16-03-2020.pdf).

18. Stevens S, Pritchard A. IMPORTANT AND URGENT - NEXT STEPS ON NHS RESPONSE TO COVID-19. Letter to chief executives of all NHS trusts and foundation trusts and others on 17 March 2020. NHS England; March 2020 (www.england.nhs.uk/coronavirus/wp-content/uploads/sites/52/2020/03/20200317-NHS-COVID-letterFINAL.pdf)

19. Stevens S, Pritchard A. IMPORTANT - FOR ACTION - SECOND PHASE OF NHS RESPONSE TO COVID-19. Letter to chief executives of all NHS trusts and foundation trusts and others on 29 April 2020. NHS England; 2020 (www.england.nhs.uk/coronavirus/wp-content/uploads/sites/52/2020/04/second-phase-of-nhs-responseto-covid-19-letter-to-chief-execs-29-april-2020.pdf).

20. Stevens S, Pritchard A. IMPORTANT - FOR ACTION - THIRD PHASE OF NHS RESPONSE TO COVID-19. Letter to chief executives of all NHS trusts and foundation trusts and others on 31 July 2020. NHS England; 2020 (www.england.nhs.uk/coronavirus/wp-content/uploads/sites/52/2020/07/20200731-Phase-3-letter-final-1.pdf).

21. Department of Health and Social Care. The future of public health. Speech by Rt Hon Matt Hancock MP. DHSC; August 2020 (www.gov.uk/government/speeches/the-future-of-public-health). 
Pritchard A, Kelly J. Important - for action - Operational priorities for winter and 2021/22. Letter to chief executives of all NHS trusts and foundation trusts and others on 23 December 2020. NHS England; 2020 (www.england.nhs.uk/coronavirus/wp-content/uploads/sites/52/2020/12/important-for-action-operationalpriorities-winter-and-2021-22-sent-23-december-2020.pdf).

23. Department of Health and Social Care. Covid-19 alert level: update from the UK Chief Medical Officers. DHSC; 4 January 2020 (www.gov.uk/government/news/covid-19-alert-level-update-from-the-uk-chief-medical-officers).

24. NHS England and NHS Improvement. Board meetings held in common: operational performance update. NHS England; 28 Jan 2021 (www.england.nhs.uk/wp-content/uploads/2021/01/28-jan-2021-item-3-BM2102Puoperational-performance-report.pdf).

25. Cabinet Office. COVID-19 Response - Spring 2021 (Roadmap). Cabinet Office; 2021 (www.gov.uk/government/ publications/covid-19-response-spring-2021).

26. HM Treasury. Budget 2021: documents. HM Treasury; March 2021 (www.gov.uk/government/publications/ budget-2021-documents).

27. Department of Health and Social Care. Oral statement to Parliament: NHS and social care funding. DHSC; 2021 (www.gov.uk/government/speeches/nhs-and-social-care-funding).

28. Department of Health and Social Care. Public health grants to local authorities: 2021 to 2022. DHSC; 2021 (www.gov.uk/government/publications/public-health-grants-to-local-authorities-2021-to-2022).

29. Zaranko B. The Chancellor's spending plans are even tighter than they seem. Institute of Fiscal Studies; 18 March 20201 (www.ifs.org.uk/publications/15365).

30. Prime Minister's Office, 10 Downing Street. Queen's Speech 2021. No.10; 2021 (www.gov.uk/government/ speeches/queens-speech-2021).

31. Department of Health and Social Care. NHS mandate 2021 to 2022. DHSC; 2021 (www.gov.uk/government/ publications/nhs-mandate-2021-to-2022).

32. NHS England. 2021/22 priorities and operational planning guidance. NHS England; 2021 (www.england.nhs.uk/ publication/2021-22-priorities-and-operational-planning-guidance).

33. NHS England. 2021/22 priorities and operational planning guidance: Implementation guidance. NHS England; 2021 (www.england.nhs.uk/publication/implementation-guidance).

34. British Medical Association, NHS England. Investment and evolution: A five-year framework for GP contract reform to implement The NHS Long Term Plan. NHS England; 2019 (www.england.nhs.uk/wp-content/ uploads/2019/01/gp-contract-2019.pdf).

35. NHS England and NHS Improvement. Board meetings held in common: operational performance update. NHS England; September 2019. (www.england.nhs.uk/wp-content/uploads/2019/09/BM1920-operationalperformance-report.pdf).

36. Smith J, Parkinson S, Harshfield A, Sidhu M. Early evidence of the development of primary care networks in England: a rapid evaluation study. Southampton: NIHR Health Services and Delivery Research Topic Report; 2020 (doi: https://doi.org/10.3310/hsdr-tr-129678).

37. NHS Confederation. One year on and one pandemic later. NHS Confederation; July 2020 (www.nhsconfed.org/ publications/one-year-and-one-pandemic-later).

38. NHS Digital. Primary Care Network Workforce 31 March 2021. NHS Digita/; May 2021 (https://digital.nhs.uk/ data-and-information/publications/statistical/primary-care-network-workforce/31-march-2021).

39. NHS England. Rapid NHS response teams to help people stay well at home. NHS England; Jan 2020 (www.england.nhs.uk/2020/01/rapid-nhs-response-teams-to-help-people-stay-well-at-home).

40. NHS Confederation. Community network responds to the long term plan. NHS Confederation; 2019 (www.nhsconfed.org/news/2019/01/community-network-responds-to-long-term-plan).

41. British Medical Association. GP contract agreement England 2021/2022. BMA; Jan 2021 (www.bma.org.uk/payand-contracts/contracts/gp-contract/gp-contract-england-202122).

42. Kanani N, Lawson E and Waller E. Urgent: preparing for general practice to contribute to a potential covid-19 vaccination programme. Letter to GPs, practice teams and CCGs. NHS England; Nov 2020 (www.england.nhs. uk/coronavirus/wp-content/uploads/sites/52/2020/03/C0856_COVID-19-vaccineletter_9-Novrevb.pdf).

43. UK government/Department of Health and Social Care. Hospital Discharge Service Requirements. DHSC; Mar 2020 (https://assets.publishing.service.gov.uk/government/uploads/system/uploads/attachment_data/ file/911541/COVID-19_hospital_discharge_service_requirements_2.pdf).

44. NHS England. COVID-19 Prioritisation within community health services. NHS England; April 2020 (https://web.archive.org/web/20200416164738/https://www.england.nhs.uk/coronavirus/wp-content/uploads/ sites/52/2020/03/C0145-COVID-19-prioritisation-within-community-health-services-1-April-2020.pdf).

45. NHS England. 2021/22 priorities and operational planning guidance. NHS England; Mar 2021 (www.england. nhs.uk/wp-content/uploads/2021/03/B0468-nhs-operational-planning-and-contracting-guidance.pdf).

46. Fisher R. Smith J, Sidhu M, Parkinson S, Alderwick H. NHS reform: Five key questions about the future of primary care networks in England. The Health Foundation; 2021 (www.health.org.uk/publications/long-reads/nhs-reform).

47. NHS Digital. Primary Care Network Workforce 31 March 2021. NHS Digital; 2021 (https://digital.nhs.uk/dataand-information/publications/statistical/primary-care-network-workforce/31-march-2021).

48. NHS Digital. Appointments in general practice March 2021. NHS Digital; 2021 (https://digital.nhs.uk/data-andinformation/publications/statistical/appointments-in-general-practice/march-2021). 
49. NHS Providers. The impact of COVID-19 on community health services. NHS Providers; 2020 (https:// nhsproviders.org/resource-library/reports/the-impact-of-covid-19-on-community-health-services).

50. NHS England and NHS Improvement. Board meetings held in common. COVID-19 response and recovery. NHS England; June 2021 (www.england.nhs.uk/wp-content/uploads/2021/06/240621-board-meeting-item-4iiicovid-19-response-and-recovery.pdf).

51. NHS England. Urgent community response - two-hour and two-day response standards 2020/21 Technical data guidance. NHS England; 2020 (www.england.nhs.uk/wp-content/uploads/2020/11/B0252-Urgent-communityresponse-2-hour-and-2-days-standards-guidance-30-November-2020.pdf).

52. NHS Digital. Community Services Data Set. CSDS: Waiting Time Measurement codes in Referral to Treatment (RTT) Jul-Mar 2021. NHS Digital; June 2021 (https://digital.nhs.uk/data-and-information/supplementaryinformation/2021/csds-uses-of-waiting-time-measurement-type-codes-in-cyp104-referral-to-treatment-table-julyto-march-2021).

53. Department of Health and Social Care. Hospital discharge service: policy and operating model. DHSC; 2021 (www.gov.uk/government/publications/hospital-discharge-service-policy-and-operating-model/hospitaldischarge-service-policy-and-operating-model\#section-11-reporting).

54. NHS Providers and NHS Confederation. Comprehensive Spending Review 2020: Submission from the Community Network. NHS Providers; 2020 (https://nhsproviders.org/media/690185/community-networksubmission-to-the-csr-2020-final.pdf).

55. NHS England. Delivering the Forward View: NHS planning guidance 2016/17-2020/21. NHS England; 2015 (www.england.nhs.uk/wp-content/uploads/2015/12/planning-guid-16-17-20-21.pdf).

56. NHS England. Designing Integrated Care Systems (ICSs) in England. NHS England; 2019 (www.england.nhs.uk/ publication/designing-integrated-care-systems-icss-in-england/).

57. Pritchard A. NHS England. Reducing burden and releasing capacity at NHS providers and commissioners to manage the COVID-19 pandemic. Letter to chief executives of all trusts and other. NHS England; Mar 2020 (www.england.nhs.uk/coronavirus/wp-content/uploads/sites/52/2020/03/C0113-reducing-burden-and-releasingcapacity-at-nhs-providers-and-commissioners.pdf).

58. NHS Providers. Written submission to NHS England and NHS Improvement on Integrating Care: Next steps to building strong and effective integrated care systems across England. NHS Providers; 2021 (https://nhsproviders. org/media/690759/nhs-providers-written-submission-to-nhs-england-and-nhs-improvement-on-integrating-carefinal.pdf)

59. NHS Confederation. Case studies from pcn network and community network. NHS Confederation; 2020 (www.nhsconfed.org/resources/2020/07/case-studies-from-pcn-network-and-community-network).

60. NHS Providers. What next for the NHS? NHS Providers; 2020 (https://nhsproviders.org/recovery-position-whatnext-for-the-nhs).

61. Hancock, M. Our NHS reform builds on innovations of the Covid pandemic. The Times; 11 Feb 2021 (www.thetimes.co.uk/article/matt-hancock-nhs-red-box-j8b8tskgh).

62. Care Quality Commission. The state of health care and adult social care in England 2019/20. CQC; 2020 HC799. (www.cqc.org.uk/sites/default/files/20201016_stateofcare1920_fullreport.pdf).

63. NHS England. Six million more to benefit as the NHS locks in the benefits of stronger partnerships. NHS England; 2020 (www.england.nhs.uk/2020/05/six-million-more-to-benefit-as-nhs-locks-in-the-benefits-ofstronger-partnerships)

64. NHS England. NHS chief confirms 11 new integrated care systems serving 14 million people. NHS England; 2020 (www.england.nhs.uk/2020/12/nhs-chief-confirms-11-new-integrated-care-systems-serving-14-millionpeople).

65. Department of Health and Social Care. Integration and Innovation: working together to improve health and social care for all. CP 381. DHSC; 2021 (https://assets.publishing.service.gov.uk/government/uploads/system/uploads/ attachment_data/file/960549/integration-and-innovation-working-together-to-improve-health-and-social-care-forall-print-version.pdf).

66. UK Parliament. Health and Care Bill. House of Commons, session 2021-22 (https://bills.parliament.uk/ bills/3022)

67. Alderwick H, Gardner T, Mays N. England's new health and care bill. BMJ. 2021; 374: n1767 (doi:10.1136/bmj. $\mathrm{n} 1767)$.

68. Tallack C, Charlesworth A, Kelly E, McConkey R, Rocks S. The bigger picture: Learning from two decades of changing NHS care in England. REAL Centre; 2020 (https://doi.org/10.37829/HF-2020-RC10).

69. Wyatt, S. Waiting Times and Attendance Durations at English Accident and Emergency Departments. The Strategy Unit; 2019 (www.strategyunitwm.nhs.uk/index.php/publications/waiting-times-and-attendancedurations-english-ae-departments).

70. Royal College of Emergency Medicine and Society of Acute Medicine. Joint Statement RCEM and SAM regarding Same Day Emergency Care. RCEM; 2019 (www.rcem.ac.uk/RCEM/News/News_2019/Joint_ Statement_RCEM_and_SAM_regarding_Same_Day_Emergency_Care.aspx).

71. Dr Foster. Examining the impact of recording same day emergency care activity in the emergency care data set Dr Foster; Feb 2020 (https://drfoster.com/2020/02/12/examining-the-impact-of-recording-same-day-emergencycare-activity-in-the-emergency-care-data-set/\#_ftnref1).

72. SAM. SAMBA18 Interim Report. SAM; 2018 (www.acutemedicine.org.uk/samba18-interim-report). 
73. NHS England and NHS Improvement. Board meetings held in common. Operational Performance Report. NHS England; Mar 2020 (www.england.nhs.uk/wp-content/uploads/2020/03/bm2012-operational-performancereport-draft.pdf).

74. lacobucci G. Plans for same day emergency care are being 'grossly derailed' by winter pressures. BMJ. 2020; 368: m55 (https://doi.org/10.1136/bmj.m55).

75. National Confidential Enquiry into Patient Outcome and Death. Know the Score: A review of the quality of care provided to patients aged over 16 years with a new diagnosis of pulmonary embolism. NCEPOD; 2019 (www.ncepod.org.uk/2019pe/PE_Full\%20report.pdf).

76. Society of Acute Medicine. Written Evidence to Health Committee. June 2020 (https://committees. parliament. uk/writtenevidence/6696/html).

77. NHS England and NHS Improvement. Board meetings held in common: operational performance update. NHS England; June 2021 (www.england.nhs.uk/wp-content/uploads/2021/06/240621-board-meeting-item-4iioperational-performance-update.pdf).

78. NHS England. Non-elective admission growth. NHS England; 2021 (www.england.nhs.uk/statistics/statisticalwork-areas/ae-waiting-times-and-activity/ae-attendances-and-emergency-admissions-2021-22).

79. Department of Health and Social Care. New measures to improve patient care ahead of winter. DHSC; Sep 2020 (www.gov.uk/government/news/new-measures-to-improve-patient-care-ahead-of-winter).

80. Royal College of Emergency Medicine. Improving access to emergency care. RCEM; June 2021(https://cem. informz.net/informzdataservice/onlineversion/pub/bWFpbGluZOluc3RhbmNISWO9OTkyMDk4OQ==).

81. NHS England. The NHS Long Term Plan. NHS England; January 2019 (www.longtermplan.nhs.uk/wp-content/ uploads/2019/08/nhs-long-term-plan-version-1.2.pdf) (p 39).

82. NHS England. NHS Long Term Plan Implementation Framework. NHS England; June 2019 (www.longtermplan. nhs.uk/wp-content/uploads/2019/06/long-term-plan-implementation-framework-v1.pdf) (p 5).

83. UK government. Advancing our health: prevention in the 2020s. HM Government; 2019 (https://assets. publishing.service.gov.uk/government/uploads/system/uploads/attachment_data/file/819766/advancing-ourhealth-prevention-in-the-2020s-accessible.pdf) (p 46).

84. Department of Health and Social Care. Department of Health and Social Care Annual Report and Accounts 2019-20 (For the period ended 31 March 2020). DHSC; January 2021 (https://assets.publishing.service.gov.uk/ government/uploads/system/uploads/attachment_data/file/956804/Department_of_Health_and_Social_Care_ Annual_Report_and_Accounts_2019-20.pdf) (pp 35-38).

85. NHS England. Launch of the Equality and Health Inequalities RightCare Pack. NHS England; December 2018 (www.england.nhs.uk/rightcare/wp-content/uploads/sites/40/2018/12/letter-equality-health-inequality-rightcarepacks-dec-18.pdf).

86. NHS England. Inequality in unplanned hospitalisation for chronic ambulatory care sensitive conditions. NHS England (www.nhs.uk/Scorecard/Pages/IndicatorFacts. aspx?Metricld=463).

87. QualityWatch. How have inequalities in the quality of care changed over the last 10 years? Nuffield Trust and The Health Foundation; 2020 (www.nuffieldtrust.org.uk/public/files/2020-01/quality_inequality/v2/\#).

88. Wyatt S, Parsons J. Socio-economic inequalities in access to planned hospital care: causes and consequences. Strategy Unit; 2021 (www.strategyunitwm.nhs.uk/publications/socio-economic-inequalities-access-plannedhospital-care-causes-and-consequences).

89. Office for National Statistics. Deaths involving COVID-19 by local area and socioeconomic deprivation: deaths occurring between 1 March and 17 April 2020. ONS; 2020 (www.ons.gov.uk/peoplepopulationandcommunity/ birthsdeathsandmarriages/deaths/bulletins/deathsinvolvingcovid19bylocalareasanddeprivation/ deathsoccurringbetween 1 marchand17april\#: :text=Between\%201\%20March\%20and\%2017\%20April\%20 2020\%2C\%20there\%20were\%2090\%2C232,coronavirus\%20(COVID\%2D19).

90. Public Health England. Disparities in the risk and outcomes of COVID-19. PHE; 2020 (https://assets. publishing. service.gov.uk/government/uploads/system/uploads/attachment_data/file/908434/Disparities_in_the_risk_and_ outcomes_of_COVID_August_2020_update.pdf).

91. Marmot M, Allen J, Goldblatt P, Herd E, Morrison J. Build Back Fairer: The COVID-19 Marmot Review. The Pandemic, Socioeconomic and Health Inequalities in England. UCL Institute of Health Equity - commissioned by the Health Foundation as part of its COVID-19 impact inquiry; 2020 (www.health.org.uk/publications/build-backfairer-the-covid-19-marmot-review).

92. NHS England. Implementing phase 3 of the NHS response to the COVID-19 pandemic. NHS England; 7 August 2020 (www.england.nhs.uk/wp-content/uploads/2020/08/implementing-phase-3-of-the-nhs-response-tocovid-19.pdf) (p 2).

93. UK government. Second quarterly report on progress to address COVID-19 health inequalities. HM Government; February 2021 (https://assets.publishing.service.gov.uk/government/uploads/system/uploads/attachment_data/ file/967856/Second_Covid_Disparities_Report_Final_01-03-20__1_.pdf) (p 43).

94. Scobie S, Spencer J, Raleigh V. Ethnicity coding in English health service datasets. Nuffield Trust; 2021 (www.nuffieldtrust.org.uk/research/ethnicity-coding-in-english-health-service-datasets).

95. NHSE. Implementing phase 3 of the NHS response to the COVID-19 pandemic. NHS England; 7 August 2020 (www.england.nhs.uk/wp-content/uploads/2020/08/implementing-phase-3-of-the-nhs-response-to-covid-19.pdf) (p 10). 
96. NHS England. 2021/22 priorities and operational planning guidance: Implementation guidance. NHS England; 2021 (www.england.nhs.uk/publication/implementation-guidance).

97. NHS England. The NHS Long Term Plan. NHS England; January 2019 (www.longtermplan.nhs.uk/wp-content/ uploads/2019/08/nhs-long-term-plan-version-1.2.pdf) (p35).

98. NHS England. NHS Long Term Plan will help problem drinkers and smokers. NHS England; 5 January 2019 (www.longtermplan.nhs.uk/nhs-long-term-plan-will-help-problem-drinkers-and-smokers).

99. Moriarty K. Alcohol care teams: where are we now? BMJ Frontline Gastroenterology. June 2020; 11: 293-302 (https://fg.bmj.com/content/11/4/293).

100. Commission on Alcohol Harm. 'It's everywhere' - alcohol's public face and private harm: The report of the Commission on Alcohol Harm. Commission on Alcohol Harm; 2020 (https://ahauk.org/wp-content/ uploads/2020/09//ts-Everywhere-Commission-on-Alcohol-Harm-final-report.pdf) (p 50).

101. NHS Digital. National Diabetes Audit Diabetes Prevention Programme - Quarterly Report: 1 January to 31 December 2020. NHS Digital; 2021 (https://digital.nhs.uk/data-and-information/publications/statistical/ national-diabetes-audit/diabetes-prevention-programme--quarterly-report-1-january-to-31-december-2020).

102. NCSCT. Protecting smokers from COVID-19. NCSCT (www.ncsct.co.uk/usr/pub/COVID-19\%20bulletin\%20 18:03:20.pdf).

103. Action on Smoking and Health (ASH) and Cancer Research UK (CRUK). Stepping Up: The response of stop smoking services in England to the COVID-19 pandemic. ASH/CRUK; 2021 (https://ash.org.uk/wp-content/ uploads/2021/01/ASH-CRUK-Stepping-Up-FINAL.pdf) (p 12).

104. NHS England. NHS launches new online support for people with diabetes. NHS England; 2020 (www.england. nhs.uk/2020/06/nhs-launches-new-online-support-for-people-with-diabetes).

105. Public Health England. Monitoring alcohol consumption and harm during the COVID-19 pandemic: summary. PHE; 2021 (www.gov.uk/government/publications/alcohol-consumption-and-harm-during-the-covid-19pandemic/monitoring-alcohol-consumption-and-harm-during-the-covid-19-pandemic-summary\#conclusion).

106. West R, Kale D, Kock L, Brown J. Top-line findings on smoking in England from the Smoking Toolkit Study. Smoking in England; 2021 (https://smokinginengland.info/graphs/top-line-findings).

107. Public Health England. Excess weight can increase risk of serious illness and death from covid-19. Gov.uk; 2020 (www.gov.uk/government/news/excess-weight-can-increase-risk-of-serious-illness-and-death-from-covid-19).

108. Department of Health and Social Care. Policy paper: Tackling obesity: empowering adults and children to live healthier lives. DHSC; 2020 (www.gov.uk/government/publications/tackling-obesity-government-strategy/ tackling-obesity-empowering-adults-and-children-to-live-healthier-lives).

109. Richards, M. Report of The Independent Review of Adult Screening Programme in England. NHS England; 2019 (www.england.nhs.uk/publication/terms-of-reference-review-national-cancer-screening-programmes-england).

110. Public Health England. NHS population screening programmes: KPI reports 2020 to 2021 and 2019 to 2020. PHE; 2021 (www.gov.uk/government/collections/nhs-population-screening-programmes-kpi-reports).

111. Morris E, Goldacre R, Spata E, Mafham M, Finan P, Shelton J, et al. Impact of the COVID-19 pandemic on the detection and management of colorectal cancer in England: a population-based study. Lancet. 2021 (www.thelancet.com/journals/langas/article/PIIS2468-1253(21)00005-4/fulltext).

112. Bowel Cancer UK. Two in five patients in England waiting too long for bowel cancer tests. Bowe/ Cancer UK; July 2021 (www.bowelcanceruk.org.uk/news-and-blogs/news/two-in-five-patients-in-england-waiting-too-longfor-bowel-cancer-tests).

113. Public Health England. Young person and adult screening KPI data: Q2 summary factsheets (section 4). PHE; 2016. (www.gov.uk/government/publications/nhs-screening-programmes-kpi-reports-2020-to-2021/youngperson-and-adult-screening-kpi-data-q2-summary-factsheets\#breast-screening).

114. Breast Cancer Now. We Respond to Breast Cancer Screening Performance Data for England 2019/20. Breast Cancer Now; January 2021 (https://breastcancernow.org/about-us/media/statements/we-respond-breast-cancerscreening-performance-data-england-201920).

115. Public Health England. Young person and adult screening KPI data: Q3 summary factsheets (section 5). PHE; 2016 (www.gov.uk/government/publications/nhs-screening-programmes-kpi-reports-2020-to-2021/youngperson-and-adult-screening-kpi-data-q3-summary-factsheets\#cervical-screening).

116. Cancer Research UK. Evidence of the impact of COVID-19 across the cancer pathway: Key Stats. CRUK; 2021 (www.cancerresearchuk.org/sites/default/files/cruk_covid_and_cancer_key_stats_june_2021.pdf).

117. Public Health England. Impact of COVID-19 on routine childhood immunisations: early vaccine coverage data to April 2021 in England. PHE; 2021 (www.gov.uk/government/publications/covid-19-impact-on-vaccinationprogrammes).

118. Department of Health and Social Care. New ambition to halve rate of stillbirths and infant deaths. DHSC; 2015 (www.gov.uk/government/news/new-ambition-to-halve-rate-of-stillbirths-and-infant-deaths).

119. NHS England. Maternity Transformation Programme. NHS England (www.england.nhs.uk/mat-transformation).

120. Department of Health and Social Care. Written evidence submitted by the Department of Health and Social Care (MSE0062). DHSC; Sep 2020 (https://committees. parliament.uk/writtenevidence/11114/pdf).

121. Health and Social Care Committee. Oral evidence: Safety of maternity services in England, HC 677; 2021 (Q322) (https://committees.parliament.uk/oralevidence/1637/pdf). 
House of Commons. Health and Social Care Committee. The Health and Social Care Committee's Expert Panel: Evaluation of the Government's progress against its policy commitments in the area of maternity services in England. House of Commons; HC 81; 2021 (https://committees.parliament.uk/publications/6560/ documents/71747/default).

123. House of Commons. Emerging Findings and Recommendations from the Independent Review of Maternity Services at The Shrewsbury and Telford Hospital NHS Trust (Ockenden Report). House of Commons; 2020 (HC1081) (www.donnaockenden.com/downloads/news/2020/12/ockenden-report.pdf).

124. Pritchard A, May R, Powis S. OCKENDEN REVIEW OF MATERNITY SERVICES - URGENT ACTION. Letter to NHS Trust and Foundation Trust Chief Executives. NHS England; Dec 2020 (www.england.nhs.uk/wp-content/ uploads/2021/01/Ockenden-Letter-CEO-Chairs-final-14.12.20-1.pdf).

125. May R, Dunkley-Bent J, Jolly M. Investment in Maternity Workforce and Training. Letter to Chief Executives, Chief Nurses and others. NHS England; April 2021 (www.england.nhs.uk/wp-content/uploads/2021/04/B0532investment-in-maternity-workforce-and-training-letter.pdf).

126. Jardine, J, Relph, S, Magee, LA, von Dadelszen, P, Morris, E, Ross-Davie, M et al. Maternity services in the UK during the coronavirus disease 2019 pandemic: a national survey of modifications to standard care. BJOG. 2021; 128: 880- 889 (https://obgyn.onlinelibrary.wiley.com/doi/10.1111/1471-0528.16547).

127. Royal College of Midwives and Royal College of Obstetricians and Gynaecologists. Joint RCOG \& RCM Statement - Planning for Winter 2020/21: reducing the impact of COVID-19 on maternity services in the UK. RCOG; 2020 (www.rcog.org.uk/globalassets/documents/guidelines/2020-10-08-rcog_rcm_winter_secondwave_ statement.pdf).

128. NHS England. Supporting pregnant women using maternity services during the coronavirus pandemic: actions for NHS providers. NHS England; 2021 (www.england.nhs.uk/coronavirus/wp-content/uploads/sites/52/2020/12/ C1243_Supporting-pregnant-women-using-maternity-services-actions-for-providers_150421.pdf).

129. Knight M, Bunch K, Cairns A, Cantwell R, Cox P, Kenyon S et al on behalf of MBRRACE-UK. Saving Lives, Improving Mothers' Care Rapid Report: Learning from SARS-CoV-2-related and associated maternal deaths in the UK March-May 2020. Oxford: National Perinatal Epidemiology Unit, University of Oxford; 2020 (www.npeu.ox.ac.uk/assets/downloads/mbrrace-uk/reports/MBRRACE-UK_Maternal_Report_2020_v10_FINAL. pdf).

130. Knight M, Bunch K, Cairns A, Cantwell R, Cox P, Kenyon S et al on behalf of MBRRACE-UK. Saving Lives, Improving Mothers' Care Rapid Report 2021: Learning from SARS-CoV-2-related and associated maternal deaths in the UK June 2020-March 2021. National Perinatal Epidemiology Unit, University of Oxford; 2021.

131. Department of Health and Social Care. The Government's 2021-22 mandate to NHS England and NHS Improvement. DHSC; 2021 (https://assets.publishing.service.gov.uk/government/uploads/system/uploads/ attachment_data/file/972947/The_government_s_2021_to_2022_mandate_to_NHS_England_and_NHS_ Improvement.pdf).

132. National Cancer Registration and Analysis Service. National Disease Registration Service: Staging data in England (www.cancerdata.nhs.uk/stage_at_diagnosis).

133. National Cancer Registration and Analysis Survey. COVID-19 rapid cancer registration and treatment data. NCRAS (www.cancerdata.nhs.uk/covid-19/rcrd).

134. Roberts, K. Cancer services during COVID-19: 40,000 fewer people starting treatment. CRUK; Feb 2021 (https://scienceblog.cancerresearchuk.org/2021/02/02/cancer-services-during-covid-19-40000-fewer-peoplestarting-treatment).

135. National Cancer Registration and Analysis Service. Cancer Outcome Metrics. Emergency Presentation Official Statistics (www.ncin.org.uk/cancer_type_and_topic_specific_work/topic_specific_work/cancer_outcome_ metrics).

136. NHS England. NHS Cancer programme. National cancer services recovery plan. NHS England; 2020 (www.england.nhs.uk/coronavirus/wp-content/uploads/sites/52/2020/12/C0821-COVID-19-Cancer-servicesrecovery-plan-14-December-2020.pdf).

137. NHS England. Management information on cancer. NHS England (www.england.nhs.uk/statistics/statisticalwork-areas/cancer-waiting-times/management-information-on-cancer).

138. Davies J. What impact has COVID-19 had on cancer services? QualityWatch, Nuffield Trust; May 2021 (www.nuffieldtrust.org.uk/news-item/what-impact-has-covid-19-had-on-cancer-services).

139. NHS England. Diagnostics: Recovery and Renewal. Report of the Independent Review of Diagnostic Services for NHS England. NHS England; 2020 (www.england.nhs.uk/wp-content/uploads/2020/11/diagnostics-recoveryand-renewal-independent-review-of-diagnostic-services-for-nhs-england-2.pdf).

140. NHS England and NHS Improvement. NHS Diagnostic Waiting Times and Activity Data. February 2021 monthly report. NHS England; 2021 (www.england.nhs.uk/statistics/wp-content/uploads/sites/2/2021/04/DWTA-ReportFebruary-2021.pdf).

141. Department of Health. Transforming care: A national response to Winterbourne View Hospital. Department of Health Review: Final Report. Department of Health; 2012 (https://assets.publishing.service.gov.uk/government/ uploads/system/uploads/attachment_data/file/213215/final-report.pdf).

142. Local Government Association, Directors of Adult Social Services and NHS England. Building the right support. A national plan to develop community services and close inpatient facilities for people with a learning disability and/or autism who display behaviour that challenges, including those with a mental health condition. NHS England; 2015 (www.england.nhs.uk/wp-content/uploads/2015/10/ld-nat-imp-plan-oct15.pdf). 
143. NHS England. NHS Operational Planning and Contracting Guidance 2019/20. NHS England; 2019 (www.england.nhs.uk/wp-content/uploads/2018/12/nhs-operational-planning-and-contracting-guidance.pdf).

144. Equality and Human Rights Commission. Health Secretary faces legal challenge for failing patients with learning disabilities and autism. EHRC; Feb 2020 (https://equalityhumanrights.com/en/our-work/news/health-secretaryfaces-legal-challenge-failing-patients-learning-disabilities-and).

145. NHS Digital. Health and Care of People with Learning Disabilities Experimental Statistics 2019 to 2020. NHS Digital; 2021 (https://digital.nhs.uk/data-and-information/publications/statistical/health-and-care-of-peoplewith-learning-disabilities/experimental-statistics-2019-to-2020/health-checks\#: :text=57.8\%25\%20of\%20 patients\%20(58.4\%25, male)\%20in\%202015\%2D16).

146. Flynn S, Bailey T, Hastings R, Hatton C, Abbott D, Beyer S, et al. Coronavirus and people with learning disabilities study wave 1 results: March 2021 (Full Report). University of Warwick; 2021 (https://warwick.ac.uk/fac/soc/ cedar/covid19-learningdisability/results/wave1 results).

147. NHS England. Annual Health checks. NHS England (www.england.nhs.uk/learning-disabilities/improving-health/ annual-health-checks).

148. Public Health England. Health matters: delivering the flu immunisation programme during the COVID-19 pandemic. PHE; 2020 (www.gov.uk/government/publications/health-matters-flu-immunisation-programme-andcovid-19/health-matters-delivering-the-flu-immunisation-programme-during-the-covid-19-pandemic).

149. NHS England. Three in four people with a learning disability receive NHS annual health check. NHS England; 2021 (www.england.nhs.uk/2021/06/three-in-four-people-with-a-learning-disability-receive-nhs-annual-healthcheck).

150. Learning Disabilities Mortality Review programme. Deaths of people with learning disabilities from COVID-19. University of Bristo/; 2021 (www.bristol.ac.uk/media-library/sites/sps/leder/Deaths\%20of\%20people\%20with\%20 learning\%20disabilities\%20from\%20COVID-19.pdf).

151. Office for National Statistics. Updated estimates of coronavirus (COVID-19) related deaths by disability status, England: 24 January to 20 November 2020. ONS; 2021 (www.ons.gov.uk/peoplepopulationandcommunity/ birthsdeathsandmarriages/deaths/articles/coronaviruscovid19relateddeathsbydisabilitystatusenglandandwales/ 24januaryto20november2020).

152. Williamson EJ, McDonald HI, Bhaskaran K, Walker AJ, Bacon S, Davy S, et al. Risks of covid-19 hospital admission and death for people with learning disability: population based cohort study using the OpenSAFELY platform. BMJ. 2021; 374 (https://doi.org/10.1136/bmj.n1592).

153. National Autistic Society. Left Stranded: The impact of coronavirus on autistic people and their families in the UK National Autistic Society; 2020 (www.autism.org.uk/what-we-do/news/coronavirus-report).

154. NHS England. NHS Mental Health Implementation Plan 2019/20-2023/24. NHS England; 2019 (www.longtermplan.nhs.uk/wp-content/uploads/2019/07/nhs-mental-health-implementationplan-2019-20-2023-24.pdf).

155. NHS England. NHS Mental Health Dashboard. NHS England (www.england.nhs.uk/publication/nhs-mentalhealth-dashboard)

156. Children's Commissioner. The state of children's mental health services 2020/21. Technical report. Children's Commissioner; 2021 (www.childrenscommissioner.gov.uk/wp-content/uploads/2021/01/cco-the-state-ofchildrens-mental-health-services-2020-21-tech-report.pdf).

157. NHS England. Clinically-led review of NHS access standards. NHS England (www.england.nhs.uk/clinically-ledreview-nhs-access-standards).

158. NHS England and NHS Improvement. Board meetings held in common. Update on mental health services NHS England; June 2021 (www.england.nhs.uk/wp-content/uploads/2021/06/240621-board-meeting-item-6update-on-mental-health-services.pdf).

159. Ibid

160. NHS Digital. Mental Health of Children and Young People in England, 2020: Wave 1 follow up to the 2017 survey. NHS Digital; 2020 (https://digital.nhs.uk/data-and-information/publications/statistical/mental-health-ofchildren-and-young-people-in-england/2020-wave-1-follow-up).

161. Children's Commissioner. The state of children's mental health services 2020/21. Children's Commissioner; 2021 (www.childrenscommissioner.gov.uk/wp-content/uploads/2021/01/cco-the-state-of-childrens-mental-healthservices-2020-21.pdf).

162. NHS Digital. Mental Health Services Monthly Statistics Final March, Provisional April 2021. NHS Digital; June 2021 (https://digital.nhs.uk/data-and-information/publications/statistical/mental-health-services-monthlystatistics/final-march-2021).

163. NHS England. NHS England proposes new mental health access standards. NHS England; 2021 (www.england. nhs.uk/2021/07/nhs-england-proposes-new-mental-health-access-standards).

164. NHS Providers. Mental Health Funding And Investment. A digest of issues. NHS Providers; 2020 (https://nhsproviders.org/media/689015/mental-health-funding-and-investment.pdf).

165. Healthcare Financial Management Association. Development of the mental health investment Standard. HFMA 2020 (www.hfma.org.uk/docs/default-source/invoices/development-of-the-mental-health-investment-standard--recommendations-november-2020.pdf?sfvrsn=c0357ce7_2).

166. NHS England. Clinically-led Review of NHS Access Standards Interim Report from the NHS National Medical Director. NHS England; 2019 (www.england.nhs.uk/wp-content/uploads/2019/03/CRS-Interim-Report.pdf). 
167. NHS England. Clinically-led Review of NHS Access Standards. NHS England; 2020 (www.england.nhs.uk/ publication/clinically-led-review-of-nhs-access-standards).

168. NHS England and NHS Improvement. Board meetings held in common. Clinical review of standards. NHS England; 2020 (www.england.nhs.uk/wp-content/uploads/2020/01/board-meeting-item-7-clincial-reviewof-standards.pdf).

169. NHS England. Transformation of urgent and emergency care: models of care and measurement. NHS England; 2020 (www.england.nhs.uk/wp-content/uploads/2020/12/transformation-of-urgent-and-emergency-caremodels-of-care-and-measurement.pdf).

170. NHS England. Clinically led review of urgent and emergency care standards: measuring performance in a transformed system. NHS England; 2021 (www.england.nhs.uk/publication/clinically-led-review-of-urgent-andemergency-care-standards-measuring-performance-in-a-transformed-system).

171. NHS Providers. The clinically led review of NHS access standards in England: The Royal College of Emergency Medicine's view. NHS Providers; Feb 2021 (https://nhsproviders.org/news-blogs/blogs/the-clinically-led-reviewof-nhs-access-standards-in-england-the-royal-college-of-emergency-medicine-s-view).

172. Healthwatch. What matters to people using A\&E. A report for the NHS Clinical review of standards. Healthwatch; Feb 2020 (www.healthwatch.co.uk/sites/healthwatch.co.uk/files/20200219\%20What\%20 matters\%20to\%20people\%20using\%20A\%26E_0.pdf).

173. NHS England. Cancer Waiting Times. NHS England; 2021 (www.england.nhs.uk/statistics/statistical-work-areas/ cancer-waiting-times).

174. NHS Digital. NHS Vacancy Statistics England April 2015-March 2021. NHS Digital; 2021 (https://digital.nhs.uk/ data-and-information/publications/statistical/nhs-vacancies-survey).

175. NHS Digital. General practice workforce official statistics. NHS Digital; June 2021 (https://digital.nhs.uk/dataand-information/publications/statistical/general-and-personal-medical-services/30-june-2021).

176. NHS Digital. Supplementary info. Annual turnover to specified groups Sept 2009-2020PQ133258. NHS Digital (https://digital.nhs.uk/data-and-information/supplementary-information/2020/annual-turnover-to-specifiedgroups-september-2009-to-2020-pq133258).

177. NHS Digital. NHS sickness absence rates official statistics. NHS Digital (https://digital.nhs.uk/data-andinformation/publications/statistical/nhs-sickness-absence-rates).

178. NHS Digital. NHS Sickness Absence Rates January 2021, Provisional Statistics. NHS Digital; June 2021. (https://digital.nhs.uk/data-and-information/publications/statistical/nhs-sickness-absence-rates/january-2021).

179. Care Quality Commission. State of Care 2019/20. COC (www.cqc.org.uk/publications/major-report/state-care).

180. NHS Staff Survey. NHS Staff Survey Results-2020. NHS Staff Survey (www.nhsstaffsurveyresults.com/ homepage/results-2020).

181. Health and Social Care Committee. Workforce burnout and resilience in the NHS and social care. Second Report of Session 2021-22. House of Commons; 2021 (https://committees.parliament.uk/publications/6158/ documents/68766/default).

182. NHS England. We are the NHS: people plan 2020/21 - action for us all. NHS England; 2020 (www.england.nhs. uk/wp-content/uploads/2020/07/We-Are-The-NHS-Action-For-All-Of-Us-FINAL-March-21.pdf).

183. NHS England. Workforce Race Equality Standard. 2020 Data Analysis Report for NHS Trusts and Clinical Commissioning Groups. NHS England; 2021 (www.england.nhs.uk/wp-content/uploads/2021/02/WorkforceRace-Equality-Standard-2020-report.pdf).

184. NHS Digital. NHS App dashboard. NHS Digital (https://digital.nhs.uk/services/nhs-app/nhs-app-dashboard).

185. NHS Digital. Number of NHS App users more than double in 3 months as 'App Ambassadors' set to work. NHS Digital; Jan 2020 (https://digital.nhs.uk/news-and-events/latest-news/number-of-nhs-app-users-more-thandouble-in-3-months-as-app-ambassadors-set-to-work).

186. Royal College of Physicians. Outpatients: the future - adding value through sustainability. RCP; 2018 (www.rcplondon.ac.uk/projects/outputs/outpatients-future-adding-value-through-sustainability).

187. Royal College of Physicians. Survey reveals barriers to providing good care and confidence in new solutions. RCP; 2019 (www.rcplondon.ac.uk/news/survey-reveals-barriers-providing-good-care-and-confidence-newsolutions).

188. Hutchings, R. The impact of Covid-19 on the use of digital technology in the NHS. Nuffield Trust; 2020 (www.nuffieldtrust.org.uk/research/the-impact-of-covid-19-on-the-use-of-digital-technology-in-the-nhs).

189. NHS Digital. More than 10 million people now using the NHS App. NHS Digital; July 2021. (https://digital.nhs. uk/news-and-events/latest-news/more-than-10-million-people-now-using-the-nhs-app).

190. NHS Covid-19 App support. NHS Covid-19 app statistics. NHS Test and Trace (https://stats.app.covid19.nhs. uk/\#app-downloads).

191. NHS Digital. Appointments in general practice. Supporting information. NHS Digital (https://digital.nhs.uk/ data-and-information/publications/statistical/appointments-in-general-practice/appointments-in-general-practicesupporting-information).

192. Royal College of General Practitioners. The future role of remote consultations \& patient 'triage' General practice COVID-19 recovery. RCGP; 2020 (www.rcgp.org.uk/-/media/Files/Policy/future-role-of-remote-consultationspatient-triage.ashx?la=en) 
193. NHS England. Millions of patients benefiting from remote consultations as family doctors respond to COVID-19. NHS England; 2020 (www.england.nhs.uk/2020/05/millions-of-patients-benefiting-from-remote-consultationsas-family-doctors-respond-to-covid-19).

194. Kanani K and Waller E. Updated standard operating procedure (sop) to support restoration of general practice services. NHS England; May 2021 (www.england.nhs.uk/coronavirus/wp-content/uploads/sites/52/2020/03/ B0497-GP-access-letter-May-2021-FINAL.pdf).

195. Morris J, Georghiou T, Appleby J. Changes in English NHS outpatient activity during the early Covid-19 period. 2021 (www.medrxiv.org/content/10.1101/2021.04.28.21256176v1.full.pdf).

196. Anandaciva S. Quarterly monitoring report (OMR) 29: how is the NHS performing? The King's Fund; 2020 (www.kingsfund.org.uk/publications/how-nhs-performing-august-2020).

197. Public Accounts Committee. Oral evidence: NHS Financial Management and Sustainability, HC 344. House of Commons; 2020 (https://committees. parliament.uk/oralevidence/433/html).

198. Department of Health and Social Care. Annual Report and Accounts 2019-20. DHSC; Jan 2021. HC1077 (https://assets.publishing.service.gov.uk/government/uploads/system/uploads/attachment_data/file/956804/ Department_of_Health_and_Social_Care_Annual_Report_and_Accounts_2019-20.pdf).

199. Office for National Statistics. Public service productivity, healthcare, England: financial year ending 2019. ONS; 2021 (www.ons.gov.uk/economy/economicoutputandproductivity/publicservicesproductivity/articles/ publicservicesproductivityestimateshealthcare/financialyearending2019).

200. Baxter S, Johnson M, Chambers D, et al. The effects of integrated care: a systematic review of UK and international evidence. BMC Health Serv Res. 2018; 18: 350 (https://doi.org/10.1186/s12913-018-3161-3).

201. Clarke C, Lloyd T. Integrated care programmes: We need to think long term when implementing and evaluating complex change. The Health Foundation; Sep 2020 (www.health.org.uk/news-and-comment/blogs/integratedcare-programmes-we-need-to-think-long-term-when-implementing-change).

202. Damery S, Flanagan S, Combes G. Does integrated care reduce hospital activity for patients with chronic diseases? An umbrella review of systematic reviews. BMJ Open. 2016; 6: e011952 (doi: 10.1136/ bmjopen-2016-011952).

203. Department of Health and Social Care. Health Infrastructure Plan. A new, strategic approach to improving our hospitals and health infrastructure. DHSC; 2019 (https://assets.publishing.service.gov.uk/government/uploads/ system/uploads/attachment_data/file/835657/health-infrastructure-plan.pdf).

204. NHS Digital. Estates Returns Information Collection Summary page and dataset for ERIC 2019/20. NHS Digital; Jan 2021 (https://digital.nhs.uk/data-and-information/publications/statistical/estates-returns-informationcollection/england-2019-20).

205. NHS England and NHS Improvement. Board meetings held in common. Month 12 financial position update 2020/21. NHS England; June 2021. (www.england.nhs.uk/wp-content/uploads/2021/06/240621-board-meetingitem-4i-month-12-financial-position-update-20-21.pdf).

206. Office for National Statistics. Productivity economic commentary, UK: July to September 2020. ONS; Jan 2021 (www.ons.gov.uk/employmentandlabourmarket/peopleinwork/labourproductivity/articles/ ukproductivityintroduction/julytoseptember2020).

207. Office for National Statistics. Productivity economic commentary, UK: October to December 2020. ONS; Apr 2021 (www.ons.gov.uk/employmentandlabourmarket/peopleinwork/labourproductivity/articles/ ukproductivityintroduction/octobertodecember2020\#public-service-productivity).

208. Coyle D, Driesbeimdieck K, Manley, A. Productivity in UK healthcare during and after the Covid-19 pandemic. The Productivity Institute, ESRC; 2021 (www.bennettinstitute.cam.ac.uk/media/uploads/files/Productivity_in_UK_ Healthcare.pdf).

209. UK government/Prime Minister's Office. 'Build': Prime Minister announces New Deal for Britain. UK government; Jun 2020 (www.gov.uk/government/news/build-build-build-prime-minister-announces-newdeal-for-britain).

210. Thorlby R, Gardner T, Turton C. NHS performance and waiting times: priorities for the new government. The Health Foundation; 2019 (www.health.org.uk/publications/long-reads/nhs-performance-and-waiting-times).

211. NHS England. Statistical Press Notice. NHS referral to treatment (RTT) waiting times data April 2021. NHS England; June 2021 (www.england.nhs.uk/statistics/wp-content/uploads/sites/2/2021/06/Apr21-RTT-SPNpublication-version-54792.pdf).

212. National Voices. Patient. Noun. Adjective. National Voices; 2020 (www.nationalvoices.org.uk/sites/default/files/ public/publications/patient._noun._adjective._october_2020.pdf).

213. Hanna T, King W, Thibodeau S, Jalink M, Paulin G A, Harvey-Jones E, et al. Mortality due to cancer treatment delay: systematic review and meta-analysis BMJ. 2020; 371: m4087 (doi:10.1136/bmj.m4087).

214. Oussedik O, MacIntyre S, Gray J, McMeekin P, Clement N, Deehan D. Elective orthopaedic cancellations due to the COVID-19 pandemic: where are we now, and where are we heading? Bone and Joint. 2021; 2(2) (https://online.boneandjoint.org.uk/doi/full/10.1302/2633-1462.22.BJO-2020-0161.R1).

215. One Cancer Voice. A statement from One Cancer Voice: Plotting a route out of the pandemic and towards world-leading cancer services. One Cancer Voice; Feb 2021 (www.cancerresearchuk.org/sites/default/files/ ocv_statement_feb_2021_final_002.pdf). 
216. George J, Gkousis E, Feast A, Morris S, Pollard J, Vohra J. Estimating the cost of growing the NHS cancer workforce in England by 2029. Cancer Research UK; 2020 (www.cancerresearchuk.org/sites/default/files/ estimating_the_cost_of_growing_the_nhs_cancer_workforce_in_england_by_2029_october_2020_-_full_report. pdf).

217. Centre for Mental Health. Covid-19 and the nation's mental health: October 2020. Centre for Mental Health; 2020 (www.centreformentalhealth.org.uk/publications/covid-19-and-nations-mental-health-october-2020).

218. Strategy Unit. Estimating the impacts of COVI-19 on mental health services in England. Strategy Unit; 2020 (www.strategyunitwm.nhs.uk/sites/default/files/2020-11/Modelling\%20covid-19\%20\%20MH\%20services\%20 in\%20England_20201109_v2.pdf).

219. Mind. Mind responds to the Queen's speech 2021. Mind; May 2021 (www.mind.org.uk/news-campaigns/news/ mind-responds-to-queens-speech-2021).

220. James A, The end of the five year forward view: what is next for mental health? BMJ Opinion; Apr 2021 (https://blogs.bmj.com/bmj/2021/04/15/adrian-james-the-end-of-the-five-year-forward-view-what-is-next-formental-health).

221. House of Commons Health and Social Care Committee. Written evidence submitted by The Royal College of Psychiatrists (WBR0031); 2021 (https://committees.parliament.uk/writtenevidence/11010/html/\#_edn28).

222. Royal College of General Practitioners. 'Simply not enough GPs to meet demand': RCGP responds to HSC report on NHS workforce burnout. RCGP; 2021 (www.rcgp.org.uk/about-us/news/2021/june/simply-not-enoughgps-to-meet-demand.aspx).

223. NHS England. NHS sets up specialist young people's services in $£ 100$ million long COVID care expansion. NHS England; Jun 2021 (www.england.nhs.uk/2021/06/nhs-sets-up-specialist-young-peoples-services-in-100million-long-covid-care-expansion).

224. National Institute for Health and Care Excellence. COVID-19 rapid guideline: managing the long-term effects of COVID-19. NICE guideline [NG188]. NICE; 2020 (www.nice.org.uk/guidance/ng188).

225. UK government. COVID-19 mental health and wellbeing recovery action plan. UK government (www.gov.uk/ government/publications/covid-19-mental-health-and-wellbeing-recovery-action-plan/covid-19-mental-healthand-wellbeing-recovery-action-plan\#implementation-and-next-steps).

226. Murray, R. Lessons from the 2000s: the ambition to reduce waits must be matched with patience and realism. The King's Fund; July 2021 (www.kingsfund.org.uk/publications/nhs-waiting-times).

227. HM government. Build Back Better. Our plan for health and social care. HM government; 2021 (www.gov.uk/ government/publications/build-back-better-our-plan-for-health-and-social-care).

228. BBC News. 4.7 million waiting for operations in England. BBC News; April 2021 (www.bbc.co.uk/news/ health-567525990).

229. Briggs A, Göpfert A, Thorlby R, et al. Integrated health and care systems in England: can they help prevent disease? Integrated Healthcare Journal. 2020; 2: e000013 (doi: 10.1136/ihj-2019-000013).

230. UK government. Advancing our health: prevention in the 2020s. UK government; 2019 (https://assets.publishing. service.gov.uk/government/uploads/system/uploads/attachment_data/file/819766/advancing-our-healthprevention-in-the-2020s-accessible.pdf) (p 4).

231. Smokefree Action Coalition. Roadmap to a Smokefree 2030. 2020 (http://ash.org.uk/wp-content/ uploads/2020/01/Roadmap-to-a-Smokefree-2030-FINAL.pdf) (p 2).

232. McGovern L. The Relative Contribution of Multiple Determinants to Health. Health Affairs Health Policy Brief; 21 August 2014 (doi: 10.1377/hpb20140821.404487).

233. Marmot M, Allen J, Goldblatt P, Herd E, Morrison J. Build Back Fairer: The COVID-19 Marmot Review. The Pandemic, Socioeconomic and Health Inequalities in England. Institute of Health Equity; 2020 (www.health.org. uk/sites/default/files/upload/publications/2020/Build-back-fairer-the-COVID-19-Marmot-review.pdf).

234. The Health Foundation. Has government grasped the full enormity of the country's public health challenges? The Health Foundation; Mar 2021 (www.health.org.uk/news-and-comment/news/has-government-grasped-thefull-enormity-of-public-health-challenges).

235. Department of Health and Social Care/The Rt Hon Matt Hancock MP. The future of healthcare. DHSC; Jul 2020 (www.gov.uk/government/speeches/the-future-of-healthcare).

236. Horton T, Hardie T, Mahadeva S, Warburton W. Securing a positive health care technology legacy from COVID-19. The Health Foundation; 2021 (www.health.org.uk/publications/long-reads/securing-a-positive-health-caretechnology-legacy-from-covid-19).

237. Mind. Trying to connect. The importance of choice in remote mental health services. Mind; 2021 (www.mind.org uk/media/7592/mind-20582-trying-to-connect-report-low-res.pdf).

238. Healthwatch. Locked out: digitally excluded people's experience of remote GP appointments. Healthwatch; 2021 (www.healthwatch.co.uk/report/2021-06-16/locked-out-digitally-excluded-peoples-experiences-remote-gpappointments).

239. Salisbury C, Murphy M, Duncan P. The Impact of Digital-First Consultations on Workload in General Practice: Modeling Study. J Med Internet Res. 2020; 22(6): e18203 (doi: 10.2196/18203).

240. Clarke G, Conti S, Wolters A, Steventon A. Evaluating the impact of healthcare interventions using routine data BMJ 2019; 365: I2239 (doi:10.1136/bmj.I2239). 
241. Majeed A, Maile E, Coronini-Cronberg S. Covid-19 is magnifying the digital divide. BMJ blogs; Sept 2020. (https://blogs.bmj.com/bmj/2020/09/01/covid-19-is-magnifying-the-digital-divide).

242. Smith J, Parkinson S, Harshfield A, Sidhu M. Early evidence of the development of primary care networks in England: a rapid evaluation study. Southampton: NIHR Health Services and Delivery Research Topic Report; 2020 (doi: https://doi.org/10.3310/hsdr-tr-129678).

243. Pettigrew L, Kumpunen S, Rosen R, Posaner R, Mays N. Lessons for 'large-scale' general practice provider organisations in England from other inter-organisational healthcare collaborations. Health Policy. 2019; 123(1) (https://doi.org/10.1016/j.healthpol.2018.10.017).

244. Alderwick, H., Hutchings, A., Briggs, A, et al. The impacts of collaboration between local health care and non-health care organizations and factors shaping how they work: a systematic review of reviews. BMC Public Health. 2021; 21: 753 (https://doi.org/10.1186/s12889-021-10630-1).

245. Alderwick H, Dunn P, Gardner T, Mays N, Dixon J. Will a new NHS structure in England help recovery from the pandemic? BMJ. 2021; 372: n248 (doi:10.1136/bmj.n248).

246. Alderwick H, Dunn P, McKenna H, Walsh N and Ham C. Sustainability and transformation plans in the NHS: How are they being developed in practice? The King's Fund; 2016 (www.kingsfund.org.uk/sites/default/files/field/ field_publication_file/STPs_in_NHS_Kings_Fund_Nov_2016_final.pdf).

247. Alderwick H, Raleigh V. Yet more performance ratings for the NHS. BMJ. 2017; 358: j3836 (doi:10.1136/bmj. j3836).

248. NHS England. NHS Oversight Metrics for 2021/22. NHS England; 2021 (www.england.nhs.uk/wp-content/ uploads/2021/06/B0693-nhs-oversight-metrics-for-2021-22.pdf).

249. Buchan J, Ball J, Shembavnekar N, Charlesworth A. Building the NHS nursing workforce in England; 2020 (https://doi.org/10.37829/HF-2020-RC14).

250. Health Foundation. NHS pay offer is 'treading water'. Response to the $3 \%$ pay rise for NHS Agenda for Change staff. The Health Foundation; July 2021( https://health.org.uk/news-and-comment/news/nhs-pay-offer-istreading-water).

251. Dixon J, Everest G. The government's levelling up agenda. An opportunity to improve health in England. The Health Foundation; 2021 ((https://doi.org/10.37829/HF-2021-C07). 


\section{Annex A}

\section{NHS Long Term Plan Implementation Framework headline metrics}

\section{1 'A new service model for the 21 st century'}

- 'Primary and community services: annual implementation milestones for 5-year GP contract - more detail to be agreed: new community services response times and teams.'

- 'Comprehensive ICS coverage including a partnership board, drawn from and representing commissioners, trusts, primary care networks, and - with the clear expectation that they will wish to participate - local authorities, the voluntary and community sector and other partners.'

- $\quad$ 'Emergency care: on agreed trajectory for Same Day Emergency Care (SDEC) and Integrated Urgent Care Services (IUCS).'

\section{2 'More NHS action on prevention and health inequalities'}

- 'Prevention (1): increase uptake of screening and immunisation.'

- ' Inequalities: inequalities reduction trajectory.'

- 'Prevention (2): alcohol care teams, tobacco treatment services, and diabetes prevention programme.'

\section{3 'Further progress on care quality, access and outcomes'}

- 'Maternal and children's health: on agreed trajectory for 50\% reduction in stillbirth, neonatal and maternal deaths and brain injury by 2025.'

- 'Improve cancer survival: Improve one and five-year cancer survival; on agreed trajectory so that $75 \%$ of cancer patients diagnosed at stage 1 or 2 by 2028 .'

- 'Learning disability and autism: on agreed trajectory for halving inpatient rate by $2023 / 24$ and increasing learning disability physical health checks to $75 \%$ of people aged over 14 .'

- 'Mental health: on track for locally agreed service expansion, and increase in investment for mental health services as a share of the NHS budget over the next five years, worth in real terms at least a further $£ 2.3$ billion a year by $2023 / 24$.' 
- 'Implementation of agreed waiting times/clinical standards for urgent and emergency care, elective care, cancer and mental health, from April 2020, and the maintenance and improvement of performance for cancer treatment and $A \& E$ until that point.'

\section{4 'NHS staff will get the backing they need'}

Workforce metrics will be agreed through development of the NHS People Plan but will include:

- 'Staff retention: retention rate to improve by at least $2 \%$ '

- ' 'Leadership: CQC well led indicator, and staff engagement indicator.'

- 'Diversity/inclusion: BME representation, gender, bullying/harassment.'

1.5 'Digitally-enabled care will go mainstream across the NHS'

- 'Outpatient reform: 30\% reduction trajectory, outpatient digital role out [sic].'

- $\quad$ 'Empowering people: Summary care record roll out.'

- $\quad$ 'Access to online/telephone consultations in primary care.'

1.6 'Taxpayers' investment will be used to maximum effect' (aka the 'five tests')

- 'The NHS will return to financial balance.'

- 'The NHS will achieve cash-releasing productivity growth of at least $1.1 \%$ per year NHS.'

- 'The NHS will reduce growth in demand for care through better integration and prevention.'

- 'The NHS will reduce variation in performance across the health system.'

- 'The NHS will make better use of capital investment and its existing assets to drive transformation.' 
The Health Foundation is an independent charity committed to bringing about better health and health care for people in the UK.

Our aim is a healthier population, supported by high quality health care that can be equitably accessed. We learn what works to make people's lives healthier and improve the health care system. From giving grants to those working at the front line to carrying out research and policy analysis, we shine a light on how to make successful change happen.

We make links between the knowledge we gain from working with those delivering health and health care and our research and analysis. Our aspiration is to create a virtuous circle, using what we know works on the ground to inform effective policymaking and vice versa.

We believe good health and health care are key to a flourishing society. Through sharing what we learn, collaborating with others and building people's skills and knowledge, we aim to make a difference and contribute to a healthier population.

8 Salisbury Square, London EC4Y 8AP

$\mathrm{T}+44(\mathrm{o}) 2072578000$

E info@health.org.uk

y @HealthFdn

www.health.org.uk 